NBER WORKING PAPER SERIES

\title{
INEQUALITY AND AGGREGATE DEMAND
}

\author{
Adrien Auclert \\ Matthew Rognlie \\ Working Paper 24280 \\ http://www.nber.org/papers/w24280
NATIONAL BUREAU OF ECONOMIC RESEARCH
1050 Massachusetts Avenue
Cambridge, MA 02138
February 2018

We thank Mark Aguiar, Romain Baeriswyl, Eduardo Dávila, Gauti Eggertsson, Emmanuel Farhi, Andrea Ferrero, Greg Kaplan, Ralph Luetticke, Alisdair McKay, Neil Mehrotra, Ben Moll, Ezra Oberfield, Stavros Panageas, Pontus Rendahl, David Romer, Kathrin Schlafmann, Paolo Surico and Iván Werning for detailed comments and discussions, and participants at many conferences and seminars for their feedback. Yoko Shibuya and Andrés Yany provided valuable research assistance. Adrien Auclert and Matthew Rognlie thank the Washington Center for Equitable Growth and the Institute for New Economic Thinking, respectively, for financial support. The authors also thank Princeton University for its hospitality during part of this research. The views expressed herein are those of the authors and do not necessarily reflect the views of the National Bureau of Economic Research.

NBER working papers are circulated for discussion and comment purposes. They have not been peer-reviewed or been subject to the review by the NBER Board of Directors that accompanies official NBER publications.

(C) 2018 by Adrien Auclert and Matthew Rognlie. All rights reserved. Short sections of text, not to exceed two paragraphs, may be quoted without explicit permission provided that full credit, including $(\odot$ notice, is given to the source. 
Inequality and Aggregate Demand

Adrien Auclert and Matthew Rognlie

NBER Working Paper No. 24280

February 2018

JEL No. D31,D52,E21,E63

\begin{abstract}
$\underline{\text { ABSTRACT }}$
We explore the transmission mechanism of income inequality to output. In the short run, higher inequality reduces output because marginal propensities to consume are negatively correlated with incomes, but this effect is quantitatively small in the data and in our model. In the long run, the output effects of income inequality are small if inequality is caused by rising dispersion in individual fixed effects, but can be large if it is the manifestation of higher individual income risk. We formalize the connection between partial and general equilibrium effects, and show that the two are closely related under standard assumptions about the behavior of monetary policy. Our economy features a depressed long-run real interest rate, allowing us to quantify the potential contribution of income inequality to secular stagnation.
\end{abstract}

Adrien Auclert

Department of Economics

Stanford University

579 Serra Mall

Stanford, CA 94305-6072

and NBER

aauclert@stanford.edu

Matthew Rognlie

Department of Economics

Northwestern University

2211 Campus Drive, 3rd Floor

Evanston, IL 60208

matthew.rognlie@northwestern.edu 


\section{Introduction}

There is an old idea ${ }^{1}$ that the distribution of income is an important determinant of aggregate economic activity, with higher income inequality reducing aggregate demand and employment. These concerns resurfaced during the Great Recession, at a time where most central banks around the world hit the zero lower bound. For example, the 2012 Economic Report of the President (Council Of Economic Advisers 2012) argued that

some of the recent patterns in aggregate spending and saving behavior-including the sluggish growth in consumer spending-may reflect the sharp rise over the past 30 years in the inequality in the income distribution in the United States. [...] The rise in income inequality may have reduced aggregate demand, because the highest income earners typically spend a lower share of their income-at least over intermediate horizons-than do other income groups.

In this paper, we formally investigate the link between income inequality and output. We use a canonical Bewley (1977) model that provides a good fit to the U.S. income and wealth distributions. The heterogeneity in marginal propensities to consume out of one-time income (MPCs) generated by the model plays a central role in our analysis. To study the connection with monetary policy, we also introduce downward nominal wage rigidities, as in SchmittGrohé and Uribe (2016) and Eggertsson, Mehrotra and Robbins (2017). Examining a range of plausible scenarios under which inequality can rise, we generally find output effects that are negative but small, with one notable exception: if inequality is caused by an increase in individual income risk, and monetary policy does not or cannot lower interest rates enough to offset it, then a large, long-lasting slump can ensue.

For temporary increases in inequality, in line with common intuition, we find that the key is the relationship between MPCs and income. But although the rich have lower MPCs than the poor, the gap is not large enough for realistic changes in the income distribution to have much effect on aggregate consumption. For instance, in our calibrated model, the average MPC of the top $10 \%$ of income earners is about 0.10 less than the average MPC of the bottom $90 \%$ of earners. In household-level data, the average MPCs for these two groups are even closer. Hence, every additional $1 \%$ of overall income shifting from the bottom $90 \%$ to the top $10 \%$ (a larger-thanusual year on year change; see Piketty and Saez 2003) lowers aggregate consumption by no more than $0.1 \%$ of total income.

Such calculations, however, are only directly informative about a partial equilibrium (PE) effect: the impact of inequality on consumption demand, shutting off endogenous responses from interest rates and incomes. In principle, these endogenous responses could move the general equilibrium (GE) output effect in either direction. On the one hand, feedback between

\footnotetext{
${ }^{1}$ Famous proponents include Pigou (1920), Keynes (1936), Kaldor (1955) and, more recently, Blinder (1975).
} 
aggregate consumption and incomes could aggravate the output decline; on the other, an equilibriating fall in real interest rates could offset or even overturn the negative output effect.

To sort through these forces, we develop a novel methodology that connects the GE outcome to its PE underpinnings. We show that, to first order, the percentage change $\frac{d Y}{Y}$ in the level of output resulting on impact from an inequality shock can always be expressed as

$$
\frac{d Y}{Y}=(\text { General equilibrium multiplier }) \cdot(\text { Partial equilibrium sufficient statistic })
$$

Here, both the multiplier and the sufficient statistic are vectors, and the outcome is their dot product. The sufficient statistic measures the partial equilibrium consumption effect of the shock, and can be written explicitly as the sequence of cross sectional covariances $\operatorname{Cov}\left(M P C_{i t}, d y_{i 0}\right)$ between households' income shocks $d y_{i 0}$ and their marginal propensities to consume $M P C_{i t}$ at each horizon $t$ following a shock. ${ }^{2}$ This formalizes the role of MPCs in the response to an inequality shock, clarifying exactly what moments matter for aggregate outcomes. The general equilibrium multiplier, by contrast, reflects a variety of forces in the model, especially the monetary and fiscal policy rules in place. Crucially, however, it does not depend on the particular shock being considered: the same multiplier applies for any shock to income distribution. This allows us to cleanly isolate and test the role of general equilibrium forces.

In our model, if monetary policy allows the real interest rate to adjust to maintain full employment, we find that the multiplier is identically 0: regardless of the inequality shock, output is unchanged on impact. This "neoclassical" policy, however, requires that monetary policy respond to inequality in an aggressive and immediate way, which may not be likely or even feasible in practice. As an alternative, we consider a benchmark scenario where monetary policy is constrained by the zero lower bound (ZLB) - as it was in the U.S. until recently, and continues to be in many other developed economies. Here, we find that the multiplier takes a simple form: its first entry is approximately 1, and its other entries approximately 0 . In other words, the GE and PE effects of an inequality shock on output approximately coincide. Since the PE effect on impact is measurable, this allows us to directly verify our results using household-level data.

As our main quantitative experiment, we consider a temporary increase of 0.04 in the standard deviation of log earnings, roughly the increase in the U.S. since 2000. In the benchmark zero lower bound scenario, we find that output declines by $0.2 \%$. Using (1), this can be traced directly to the first entry of our sufficient statistic-the covariance between current-period MPCs and the distributional shock-which we show is also $0.2 \%$, both in our model and in data from the Italian Survey of Income and Wealth. We obtain similar results under several alternative monetary rules, including a rule that holds real interest rates constant and conventional Taylor rules unconstrained by the ZLB. The key is limited monetary feedback: as long

\footnotetext{
${ }^{2}$ In this notation, the usual notion of MPC is $M P C_{i 0}$, which measures the marginal propensity to consume within the same period out of a one-time income shock.
} 
as monetary policy does not adjust rates too aggressively in response to inequality shocks, the partial equilibrium decline in consumption translates directly into a general equilibrium fall in output of about the same magnitude.

We next consider a case where the same rise in inequality is permanent. Here, we show that the source of rising inequality is crucial: if it comes from fixed effects, which permanently make some households richer than others, long-run effects are minimal. This is a result of standard assumptions about household utility, which make long-run behavior invariant to the scale of income. On the other hand, if rising inequality is associated with higher income risk and volatility, in our benchmark the shock results in a $2 \%$ decline in steady-state output, ten times larger than the impact effect in the short-run case. As before, this decline only occurs when the interest rate response is constrained-in the neoclassical case, there is instead a mild long-term output increase from capital accumulation.

To understand the causes of this $2 \%$ decline, we derive a steady-state version of the decomposition in (1). We show that consumption is no longer a good partial equilibrium measure: in the long run, all agents consume exactly their income. Instead, what matters is the impact on long-run household asset demand. Our sufficient statistic is the elasticity of this asset demand to idiosyncratic income risk, for which we find the model matches standard estimates (e.g., Carroll and Samwick 1997). Interestingly, this elasticity is higher for the persistent component of income risk than the transitory one-so while dispersion in fixed effects doesn't matter for aggregate demand, the inequality created by persistent shocks matters a great deal.

Aside from monetary policy, several key forces shape the general equilibrium multiplier. In our benchmark, capital plays a strong amplification role: in a version of the "paradox of thrift", rising asset demand leads to a decline in output, triggering a fall in investment that pushes down asset supply even further. Fiscal policy, by contrast, is stabilizing. Under our calibrated fiscal rules, the government runs deficits in response to recession, which accumulate to increase the supply of assets and mitigate the output decline. Perhaps the most subtle effect comes from the endogenous change in income distribution, where our mechanism can potentially feed back on itself. Evidence from Guvenen et al. (2017) shows that rich and poor workers have incomes more sensitive to recessions than workers in the middle-leading to a feedback that could in principle have either sign, but turns out quantitatively to be stabilizing.

We show that long-run outcomes are quite sensitive to these forces underlying the multiplier. In fact, in a simple alternate calibration where fiscal policy maintains constant debt and spending, and all earners are equally affected by recession, the long-run output effect is vastly larger, at $-24 \%$. This catastrophic outcome reveals the instability of economies suffering from secular stagnation, and the importance of mitigating forces like fiscal policy. The same holds true for short-run outcomes, albeit to a much lesser degree: for instance, without countercyclical fiscal policy, our short-run multiplier rises above one.

Moving beyond our main quantitative experiment, we use the model to study other ef- 
fects of inequality. First, we investigate the extent to which the observed increase in income inequality might have contributed to the decline in real interest rates observed since the 1980s. Assuming this increase was associated with a rise in idiosyncratic income risk, we find that inequality contributed around 80bps to the real interest rate decline-about a fifth of the four percent decline that Laubach and Williams (2015) estimate for this period.

Second, we use the model to study the impact of long-run shifts in income between labor and capital. An influential conjecture made informally by Krugman (2016) and Summers (2015) is that the decline in the labor share may be detrimental to aggregate demand. We show that this argument is incorrect in our model. Since a long-run rise in the capital share increases the supply of assets relative to desired savings out of labor income, it is ultimately expansionary, regardless of whether it comes from a rise in markups or a change in technology. This reinforces our message that the output effects of inequality may not be as large as commonly assumed, and that the underlying drivers of the rise in income inequality matter a great deal.

In the literature, other papers have studied the macroeconomic effects of increasing inequality over time, including on interest rates (for example Favilukis 2013, Kaymak and Poschke 2016), household debt (Iacoviello 2008), and welfare (Heathcote, Storesletten and Violante 2010). One potential source of rising inequality, household-level fixed effects, has little impact in our model because intertemporal utility is homothetic; relaxing this assumption, Kumhof, Rancière and Winant (2015) argue that a decline in aggregate consumption can result. Straub (2017) provides evidence to support such non-homotheticity and further explores its macroeconomic consequences. We find the homothetic benchmark appealing, but non-homotheticities may provide another route to similar results. ${ }^{3}$

The papers mentioned above, like most of the literature, study equilibria with flexible prices. By contrast, we introduce nominal rigidities and are able to evaluate the output effects of inequality directly. Two other papers have a related approach. Athreya, Owens and Schwartzman (2017) study the aggregate effect of redistribution, as in our short-run experiments, and Bayer et al. (2017) study the effect of shocks to household income risk, as in our long-run experiments. ${ }^{4}$ The first paper emphasises the role of heterogeneity in marginal propensities to work. Motivated by empirical evidence that finds little evidence for this heterogeneity, we shut down this channel and focus instead on heterogeneity in marginal propensities to consume. ${ }^{5}$ The second paper also shuts down this channel, but does so using Greenwood, Hercowitz and Huffman (1988) preferences, which lead to extremely large multipliers as a side effect when

\footnotetext{
${ }^{3}$ It is worth noting, however, that household-level fixed effects are less plausible in our infinite-horizon framework: interpreting infinitely-lived households as dynasties as suggested by Boar (2017), fixed effects effectively rule out mean reversion across generations.

${ }^{4}$ Relatedly, Basu and Bundick (2017) study contractionary aggregate risk in a representative agent model.

${ }^{5} \mathrm{~A}$ central paper in this literature is Cesarini, Lindqvist, Notowidigdo and Östling (2017), which using evidence from lotteries finds negligible marginal propensities to earn, and no evidence of heterogeneity according to income. We discuss this further in appendix D.1.
} 
combined with nominal rigidities. ${ }^{6}$

Our paper unifies the treatment of redistribution and income risk within a single model. For both, our methodology separates the role of general equilibrium multipliers from partial equilibrium impulses, corroborating the latter with micro data.

The emphasis on nominal rigidities places our paper as part of a rapidly growing literature that adds these rigidities to heterogeneous-agent models. ${ }^{7}$ A closely related literature has used sufficient statistics to bring the predictions of these models in line with existing evidence from micro data (Auclert 2017, Berger et al. 2018). By demonstrating how to embed these sufficient statistics into a general equilibrium analysis, we hope to provide further empirical discipline for heterogeneous-agent models. We also employ a novel and efficient Newton-based algorithm to solve for general equilibrium paths, which we believe may be useful for the literature going foward.

Finally, our assumption of downward nominal wage rigidities and the possibility of depressed output in a long-run steady state relates our paper to the literature on secular stagnation, inaugurated by Eggertsson et al. (2017). We complement their results by quantifying the general equilibrium forces that can either amplify or mitigate secular stagnation-including the roles of capital, countercyclical fiscal policy, and endogenous inequality. Our paper is the first to consider secular stagnation in the canonical Bewley (1977) incomplete-markets environment, and also the first to compute the full transition dynamics when the wage rigidity constraint is binding.

The remainder of the paper is organized as follows. Section 2 provides the model and calibration. Sections 3 and 4, which contain our main quantiative experiments, study the effect of shocks to labor income inequality that are temporary and permanent, respectively. Section 5 investigates the role of rising inequality in the falling natural real interest rate since 1980. Section 6 examines the consequences of a change in the labor share. Section 7 concludes.

\section{Model}

\subsection{Environment}

Households. We consider a population of infinitely-lived households who face idiosyncratic, but no aggregate, risk. Each household $i$ has a permanent type $\omega_{i} \in \Omega$, and in each period $t$, it also has an idiosyncratic state $\sigma_{i t} \in \mathcal{S}$. $\sigma_{i t}$ follows a Markov process with transition matrix $\Lambda\left(\omega_{i}\right)$. The mass of households of each type $\omega_{i}$ is $\rho\left(\omega_{i}\right)$, and we assume that within each $\omega$, at all times, the mass of households in each idiosyncratic state $\sigma$ is equal to the probability $\lambda(\sigma)$ of $\sigma$ in the ergodic distribution induced by $\Lambda(\omega)$. Hence there is always a mass $\mu\left(s_{i t}\right)=$

\footnotetext{
${ }^{6}$ See Auclert and Rognlie (2017b).

${ }^{7}$ See Guerrieri and Lorenzoni (2017), McKay and Reis (2016), Gornemann, Kuester and Nakajima (2014), McKay, Nakamura and Steinsson (2016), Kaplan, Moll and Violante (2016), and Werning (2015) among many other.
} 
$\rho\left(\omega_{i}\right) \lambda\left(\sigma_{i t}\right)$ of households in each combined state $s_{i t} \equiv\left(\omega_{i}, \sigma_{i t}\right)$.

Each household maximizes $\mathbb{E}\left[\sum \beta^{t} u\left(c_{i t}\right)\right]$, where $u(c)=\frac{c^{1-v^{-1}}}{1-v^{-1}}$ is a common period utility function with constant elasticity of substitution $v$ and $\beta$ a common discount factor, subject to the sequence of period budget constraints

$$
\begin{aligned}
c_{i t}+b_{i t}+p_{t} v_{i t} & =y_{t}\left(s_{i t}\right)+\left(1+r_{t-1}\right) b_{i t-1}+\left(p_{t}+d_{t}\right) v_{i t-1} \\
b_{i t}+p_{t} v_{i t} & \geq 0
\end{aligned}
$$

Two assets are available for intertemporal trade: one-period risk-free real bonds $b_{i t}$, and shares $v_{i t}$, which are claims to firm dividends. Each share costs $p_{t}$ at time $t$ and delivers a stream of dividends $\left\{d_{s}\right\}$ starting at $s=t+1$. Households have perfect foresight over $p_{t}, d_{t}$, and the real interest rate $r_{t}$. They may invest any amount in bonds and shares provided that they keep their net worth $a_{i t} \equiv b_{i t}+p_{t} v_{i t}$ positive at all times. No arbitrage by unconstrained agents implies that the relation

$$
1+r_{t}=\frac{p_{t+1}+d_{t+1}}{p_{t}}
$$

holds at all times along the perfect-foresight path, and households are indifferent between holding bonds and shares.

Upon an unexpected shock at the end of period $t, p_{t+1}$ and $d_{t+1}$ no longer satisfy (3) and we need to know household porfolios to determine the implied wealth revaluations. At such times, we assume that households have allocated the fraction $\theta(a)$ of their wealth $a$ to shares $p v$, and in our calibration we infer $\theta(a)$ directly from data on household balance sheets.

We specify household income in two steps. First, pre-tax labor income $z_{i t}$ is given by the product of the real wage $\frac{W_{t}}{P_{t}}$ and the amount of endowment that households are able to supply:

$$
z_{t}\left(s_{i t}\right)=\frac{W_{t}}{P_{t}} \cdot L_{t} \cdot \gamma\left(s_{i t}, L_{t}\right) \cdot e_{t}\left(s_{i t}\right)
$$

where the $\gamma$ function satisfies

$$
\gamma(s, 1)=1 \quad \forall s
$$

Households' full idiosyncratic labor endowment is $e_{i t}$, and since there is no disutility from labor, this is the amount that they choose to supply in the case of full employment $\left(L_{t}=1\right)$. As per the standard formulation in the literature, their pre-tax income is then given by $\frac{W_{t}}{P_{t}} e_{i t}$.

Because of downward nominal wage rigidities, the economy may experience a labor demand shortfall, with $L_{t}<1$. In that case, the labor market experiences rationing, and a household in state $s$ is constrained to supply the fraction $L_{t} \gamma\left(s, L_{t}\right)$ of his full endowment, with $L_{t}$ describing the aggregate impact of employment conditions and $\gamma$ the distributional impact of 
these conditions. More specifically, we normalize the $\gamma$ function so that

$$
\mathbb{E}\left[\gamma\left(s_{i t}, L\right) e_{t}\left(s_{i t}\right)\right]=1 \quad \forall L \leq 1, \forall t
$$

and hence that $\mathbb{E}\left[z_{i t}\right]=\frac{W_{t}}{P_{t}} L_{t}$ at all times. When $\gamma\left(s, L_{t}\right)=1$, for all $s$, the labor supply of all households is proportionally rationed. By contrast, when $\gamma\left(s, L_{t}\right) \neq 1$ for some $s$, labor demand shortfalls can be a source of endogenous change in inequality.

Our specification of the $\gamma$ function allows us to flexibly parametrize the incidence of changes in labor demand across the population. In particular, using this formulation, we are able to calibrate our model to directly match Guvenen et al. (2017)'s empirical evidence on 'worker betas' - the exposures of gross worker earnings to GDP conditional on their place in the earnings distribution. ${ }^{8}$ A leading alternative in the literature is to drop (4)-(5) and keep households on their labor supply curves at all times, so that recessions correspond to optimal responses of workers to falls in real wages. In appendix D.1, we explain why this alternative approach is either inconsistent with microeconomic evidence on marginal propensities to earn (when preferences are separable) or with macroeconomic evidence on government spending multipliers (when wealth effects on labor supply are shut down). A more complex alternative is to microfound the $\gamma$ function with a search and matching model of the labor market. ${ }^{9}$ Similar to Werning (2015), our simpler formulation preserves the core insights of these models while maintaining the rich consumption dynamics of an unrestricted Bewley (1977) model.

The income $y_{i t}$ that enters household's budget constraint is post-tax. We assume that the government runs an affine tax system:

$$
y_{t}\left(s_{i t}\right)=T_{t}+\left(1-\tau_{t}\right) z_{t}\left(s_{i t}\right)
$$

where $T_{t}$ is a common tax intercept and $\tau_{t}$ a common marginal tax rate. ${ }^{10}$ As we show in appendix B.3, this provides a good approximation to the U.S. tax and transfer system.

Final goods firm. The final good $Y_{t}$ has price $P_{t}$ and is produced by a competitive final good sector using the Cobb-Douglas technology

$$
Y_{t}=F\left(K_{t-1}, L_{t}\right)
$$

\footnotetext{
${ }^{8}$ Note that adjustment in our model happens along the intensive margin, with the fraction of individuals within each state $s$ remaining constant at $\mu(s)$ while their gross income varies with $L$. We treat all households within a given income state $s$ as if they are equally affected by changes in aggregate conditions; alternative assumptions would imply even greater individual income risk than the already high level implied by our model.

${ }^{9}$ See Ravn and Sterk (2017), Challe, Matheron, Ragot and Rubio-Ramirez (2017), or den Haan, Rendahl and Riegler (2018) for examples of such a formulation.

${ }^{10}$ Because we assume that labor supply is inelastic, the tax rate $\tau_{t}$ in our model is not distortionary. We abstract away from the efficiency costs of taxes to better focus on their effect on the income distribution.
} 
At the beginning of each period $t$, the representative firm owns capital $K_{t-1}$. It pays dividends $d_{t}$ to its shareholders, equal to revenue net of the cost of labor and investment, and chooses its investment $I_{t}$ and employment $L_{t}$ to maximize the net present value of future dividends $\left\{d_{t}\right\} .{ }^{11}$ Capital adjustment is subject to quadratic costs worth $\frac{1}{2 \delta \epsilon_{I}}\left(\frac{K_{t}-K_{t-1}}{K_{t-1}}\right)^{2} K_{t-1}$. In appendix A.1 we show that the firm's problem implies standard equations from $Q$ theory. In particular, investment $I_{t}=K_{t}-(1-\delta) K_{t-1}$ relates to the secondary market price of capital $q_{t}$ following

$$
\frac{I_{t}}{\delta K_{t-1}}-1=\epsilon_{I}\left(q_{t}-1\right)
$$

and employment is determined such that, in each period, the physical marginal product of labor is equal to the real wage $\frac{W_{t}}{P_{t}}$

$$
F_{L}\left(K_{t-1}, L_{t}\right)=\frac{W_{t}}{P_{t}}
$$

In steady state, capital is constant at $K$ with $q=1$, and marginal product $F_{K}(K, L)$ equals user $\operatorname{cost} r+\delta$. Away from steady state, adjustment costs slow down the period-by-period change in capital in response to fluctuations in the cost of capital $r_{t}$ and employment $L_{t}$.

Given the unit mass of shares outstanding overall, the price of shares at time $t$ is given by the value of installed capital, $p_{t}=q_{t} K_{t}$. Hence, all firm earnings are capitalized into the value of assets that household trade. ${ }^{12}$

Wage rigidities. Following Schmitt-Grohé and Uribe (2016) and Eggertsson et al. (2017), we introduce a role for monetary policy and the possibility of equilibrium slumps in our model by assuming that the economy-wide nominal wage can only fall by a limited amount each period:

$$
W_{t} \geq \kappa W_{t-1}
$$

for some $0<\kappa \leq 1 .{ }^{13}$ When labor demand falls short of the aggregate endowment because the constraint $(11)$ is binding, households are rationed $\left(L_{t}<1\right)$ and are each constrained to supply the fraction $L_{t} \gamma\left(s_{i t}, L_{t}\right)$ of their labor endowment.

As discussed in appendix D.1, our choice of wage rigidities resolves several counterfactual implications of the leading models in the literature, which tend to assume price rigities instead. ${ }^{14}$ The wage Phillips curve embodied in (11) is a stylized one: recessions are times

\footnotetext{
${ }^{11}$ Because of perfect foresight and the absence of aggregate risk, future dividends are unambiguously discounted at the sequence of real interest rates $r_{t}$.

${ }^{12}$ This approach avoids the need to set-up an ad-hoc rule for the distribution of dividend income, as is typically done in the literature.

${ }^{13}$ Note that individual wages always rise and fall due to movements in idiosyncratic productivity. Equation (11) only holds at the aggregate level and reflects a constraint on an allocative price, but it cannot directly be mapped to individual data.

${ }^{14}$ Another counterfactual implication of models with price rigidities is that they lead to very countercyclical profit margins. With heterogeneity, these in turn have large distributional consequences that are not directly supported
} 
when the wage deflation rate is equal to $\kappa-1$, irrespective of the size or duration of the slump. This simplification allows us to introduce a role for monetary policy in the canonical model of consumption in the simplest possible way.

Fiscal policy. The fiscal authority chooses the lump sum $T_{t}$, the marginal tax rate on labor income $\tau_{t}$, government spending $G_{t}$ and the level of bonds $B_{t}$ subject to the flow budget constraint

$$
\tau_{t} \frac{W_{t}}{P_{t}} L_{t}+B_{t}=G_{t}+\left(1+r_{t-1}\right) B_{t-1}+T_{t}
$$

The government follows linear fiscal rules for spending and debt:

$$
\begin{aligned}
\frac{G_{t}}{Y_{s S}} & =\frac{G_{s S}}{Y_{s S}}-\epsilon_{G L}\left(L_{t}-L_{s s}\right) \\
\frac{B_{t}-B_{t-1}}{Y_{s S}} & =-\epsilon_{D L}\left(L_{t}-L_{s s}\right)-\epsilon_{D B} \frac{B_{t-1}-B_{s S}}{Y_{s S}}
\end{aligned}
$$

where $Y_{s s}, L_{s s}$, and $B_{s s}$ represent the initial steady-state levels of output, employment and bonds, respectively. These specifications are inspired by the large theoretical and empirical literature on fiscal rules (Leeper 1991, Bohn 1998). Since Ricardian equivalence fails in our model, the deficit rule matters independently of the government spending rule.

The government's tax adjustment rule also matters. We assume that the government earmarks an exogenous fraction $\tau_{t}^{r}$ of aggregate labor income $\frac{W_{t}}{P_{t}} L_{t}$ for the lump-sum $T_{t}$, and then lowers $T_{t}$ by $\tau_{t}^{r}$ dollars for each dollar of revenue it needs to raise in each period:

$$
T_{t}=\tau_{t}^{r} \frac{W_{t}}{P_{t}} L_{t}-\tau_{t}^{r}\left(G_{t}+\left(1+r_{t-1}\right) B_{t-1}-B_{t}\right)
$$

Combining (7) with (12)-(15) and defining $\tau_{t}^{g} \equiv \frac{\tau_{t}-\tau_{t}^{r}}{1-\tau_{t}^{r}}$ as the endogenous fraction of labor income used towards government revenue, it is easy to check that net labor income is equal to

$$
y_{i t}=\left(1-\tau_{t}^{g}\right)\left(\tau_{t}^{r} \mathbb{E}_{I}\left[z_{i t}\right]+\left(1-\tau_{t}^{r}\right) z_{i t}\right)
$$

The rate $\tau_{t}^{r} \in[0,1]$ is therefore a simple measure of the degree of progressivity of the tax system. We hold $\tau^{r}$ fixed in all of our benchmark experiments. Equation (16) then shows that any change in government revenue, through its endogenous effect on $\tau_{t}^{g}$, affects household net-of-tax incomes $y_{i t}$ in proportion.

by micro evidence. 
Monetary policy. The central bank controls the nominal interest rate $i_{t}$ on nominal bonds. ${ }^{15}$ Perfect foresight implies that the real interest rate is

$$
1+r_{t}=\frac{1+i_{t}}{1+\pi_{t+1}}
$$

where $\pi_{t+1}$ is the rate of price inflation, $1+\pi_{t+1} \equiv \frac{P_{t+1}}{P_{t}}$. We consider three specifications of monetary policy. Under neoclassical policy, the central bank sets a path for $i_{t}$ that is consistent with $L_{t}=1$ for all $t$. In doing so, it achieves a path $r_{t}^{*}$ for the real interest rate, and the economy behaves as if the wage rigidity constraint (11) was absent. We follow the literature and call $r_{t}^{*}$ the 'natural interest rate' path. Under constant- $r$ policy, the central bank targets a real rate that is constant at the economy's steady-state natural rate, $r_{t}=r^{*}$, and does not change this target in response to any of our experiments. This policy shuts off all equilibriating real interest rate movements, including those driven by changes in expected inflation. Finally, our benchmark monetary policy is one in which the monetary authority sets the nominal interest rate according to a Taylor rule subject to the zero lower bound,

$$
i_{t}=\max \left(\underline{i}_{,}\left(1+r^{*}\right)\left(1+\pi^{*}\right)\left(\frac{P_{t} / P_{t-1}}{1+\pi^{*}}\right)^{\phi}-1\right)
$$

where $r^{*}$ is the steady state natural rate, $\pi^{*}$ is the inflation target, $\phi>1$ and we set $\underline{i}=0$ throughout, except in section 4.5 when we explore the benefits of negative interest rates. In our calibrated exercises, the zero lower bound in (18) will always be binding.

\subsection{Equilibrium}

We model inequality changes as affecting the way endowments are distributed across individuals in different states $s_{i t}=\left(\omega_{i}, \sigma_{i t}\right)$, through the time-varying function $e_{t}\left(s_{i t}\right)$. We also consider experiments where the redistributive tax rate $\tau_{t}^{r}$ varies exogenously, generating exogenous movements in post-tax income inequality. We define equilibrium as follows.

Definition 1. Given initial capital $K_{-1}$ and nominal wages $W_{-1}$, a sequence of exogenous shocks $\left\{e_{t}(\cdot), \tau_{t}^{r}\right\}$, and an initial joint distribution $\Psi_{-1}(s, b, v)$ over idiosyncratic states, bonds and stocks, an equilibrium is a set of aggregate quantities $\left\{C_{t}, I_{t}, K_{t}, Y_{t}, L_{t}, d_{t}\right\}$, prices $\left\{r_{t}, p_{t}, q_{t}, P_{t}, W_{t}\right\}$, government policy $\left\{i_{t}, G_{t}, T_{t}, \tau_{t}^{g}, B_{t}\right\}$, individual decision rules $\left\{c_{t}(s, b, v), b_{t}(s, b, v), v_{t}(s, b, v)\right\}$ and joint distributions $\Psi_{t}(s, b, v)$, such that households maximize utility subject to their budget constraint, firms maximize profits, the government follows its fiscal rule, the central bank follows its monetary policy rule, the Fisher equation (17) holds, the distribution of households

\footnotetext{
${ }^{15}$ Nominal bonds can formally be introduced as assets in zero net supply that can be traded by households. Condition (17) is then an equation of no arbitrage between nominal and real bonds. Implementation issues are discussed in appendix D.3.
} 


\begin{tabular}{cccc} 
Parameters & Description & Main calibration & Target \\
\hline \hline$v$ & EIS & 0.5 & Standard calibration \\
$\beta$ & Discount factor & 0.962 & $r=0$ \\
\hline$\alpha$ & Labor share & $87.2 \%$ & $\alpha=1-(r+\delta) \frac{K}{Y}$ \\
$\delta$ & Depreciation rate & $4.0 \%$ & NIPA 2013 \\
$\frac{K}{Y}$ & Capital-output ratio & $321 \%$ & FoF hh. net worth 2013 \\
$\frac{I}{Y}$ & Investment rate & $12.8 \%$ & $\delta \frac{K}{Y}$ \\
$\epsilon_{I}$ & Elasticity of $I$ to $q$ & 1 & Macro investment literature \\
\hline$i$ & Nominal interest rate & $0 \%$ & Zero lower bound \\
$r$ & Eqbm real rate & $0 \%$ & TIPS yields 2013 \\
$L_{s S}$ & Employment gap & 0.975 & CBO output gap estimate \\
$\pi^{*}$ & Inflation target & 0 & $\frac{i-r}{1+r}$ \\
$\kappa$ & Gross wage deflation rate & 1 & $\frac{1+i}{1+r}$ \\
\hline$\frac{B_{s S}}{Y}$ & Govtt debt & $55.4 \%$ & Domestic holdings 2013 \\
$\frac{G_{s S}}{Y}$ & Govtt spending & $18.7 \%$ & NIPA 2013 \\
$\tau^{r}$ & Redistributive tax rate & $17.5 \%$ & see appendix B.3 \\
$\epsilon_{G L}$ & Response of spending to $L$ & 0.10 & see appendix B.3 \\
$\epsilon_{D L}$ & Response of deficits to $L$ & 0.75 & see appendix B.3 \\
$\epsilon_{D B}$ & Response of deficits to debt & 0.07 & see appendix B.3 \\
\hline
\end{tabular}

Table 1: Calibration parameters

is consistent with the exogenous law of motion and the decision rules, and all markets clear,

$$
\begin{aligned}
\int v_{t}(s, b, v) d \Psi_{t-1}(s, b, v) & =1 \\
\int b_{t}(s, b, v) d \Psi_{t-1}(s, b, v) & =B_{t} \\
C_{t}+I_{t}+G_{t}+\frac{1}{2 \delta \epsilon_{I}}\left(\frac{K_{t}-K_{t-1}}{K_{t-1}}\right)^{2} K_{t-1} & =Y_{t}
\end{aligned}
$$

except possibly for the labor market $\left(L_{t} \leq 1\right)$ with complementary slackness in the wage rigidity constraint (11).

Equilibrium uniqueness. Our model is a one-asset heterogeneous agent New Keynesian model, for which general results on equilibrium uniqueness do not yet exist. In appendix C.3, we numerically verify uniqueness for both the steady state and transition paths in the neighborhood of the steady state in our baseline calibration. ${ }^{16}$ We also provide some useful sufficient conditions for steady state uniqueness under all three monetary rules. 


\subsection{Calibration}

Table 1 summarizes our calibration parameters. We capture the recent US macroeconomic condition of very low real interest rates. We choose 2013 as our base year, since this is the last year for which household-level balance sheet data is available from the Survey of Consumer Finances (SCF), and income inequality data is available from Song et al. (2016). Average 10year TIPS yields over that year were $0.07 \% .{ }^{17}$ We therefore set $r=0$. Since unemployment in 2013 averaged 7.4\%, while the long-term natural rate of unemployment calculated by the CBO averaged $5.0 \%$, we assume that the economy is at mildly depressed employment, setting $L_{s s}=(1-0.074) /(1-0.050) \approx 0.975$. We also assume that the zero lower bound on nominal interest rates is binding: $i=0$. Together, these assumptions imply zero steady state price inflation $\left(\pi^{*}=0\right)$, and therefore zero steady-state wage inflation $(\kappa=1)$.

Household parameters. We follow the literature practice of setting the elasticity of intertemporal elasticity of substitution in consumption at $v=\frac{1}{2}$ and calibrating $\beta$ to hit our target for the real interest rate.

We choose a process for skills $s_{i t}$ and our incidence function $\gamma$ to be consistent with evidence from US W2s recently documented by Guvenen, Song and coauthors. Specifically, we pick $s_{i t}$ so that the steady-state endowment process is the sum of three orthogonal components:

$$
\log e_{i t}=\omega_{i}+\xi_{i t}+\chi_{i t}
$$

where $\omega_{i}$ represents an individual fixed effect, $\xi_{i t}$ a transitory component, and $\chi_{i t}$ a persistent component of earnings risk.

We take the processes $\xi_{i t}$ and $\chi_{i t}$ from Kaplan et al. (2016), who capture the higher-order moments of the distribution of earnings changes from US W2s documented by Guvenen, Ozkan and Song (2014). This process involves substantially more idiosyncratic risk than typical calibrations based on AR processes with normal innovations.

We then pick a calibration for fixed effects $\omega_{i}$ to hit exactly the cross-sectional standard deviation of earnings levels in 2013, as documented by Song et al. (2016). ${ }^{18}$ It turns out that $\omega_{i}=$ 0 is enough to do this-in other words, the accumulation of income risk captured by our income process is enough to explain the entire cross-sectional dispersion in 2013 U.S. male earnings. This is consistent with a broad interpretation of earnings risk as spanning generations, with existing income inequality reflecting the slow accumulation of luck across dynasties. ${ }^{19}$

To calibrate our incidence function $\gamma$, we use the worker beta evidence from Guvenen et al.

\footnotetext{
${ }^{16}$ Multiplicity is possible under certain parameters, see appendix D.6.

${ }^{17}$ Appendix B.1 provides details of all sources for our calibration.

${ }^{18}$ Their sample is that of workers in establishment with at least 20 employees.

${ }^{19}$ Indeed, the half-life of our $\chi_{i t}$ process is about 15 years, so its innovations can be thought of as those of a new generation.
} 
(2017). The incidence is U-shaped across the income distribution, with the bottom and the top of the income distribution being most exposed to an decline in aggregate employment. We also consider two alternative calibrations: one in which recessions have equal incidence $(\gamma=1)$ and one in which the standard deviation of log gross earnings has a constant negative elasticity with respect to employment, reflecting countercyclical earnings risk as in Storesletten, Telmer and Yaron (2004). Appendix B.2 provides more details on our calibration of $\gamma$.

We pick our aggregates $B$ and $K$ to be consistent with both Survey of Consumer Finances (SCF) and Flow of Funds data. From the 2013 SCF, we back out a smooth distribution $\theta(a)$ representing the average fraction of wealth invested in shares for individuals with wealth $a$, which we use to calculate portfolio revaluations after unexpected shocks.

Production parameters. We calibrate to a Cobb-Douglas production function, $F\left(K_{t-1}, L_{t}\right)=$ $A K_{t-1}^{1-\alpha} L_{t}^{\alpha}$. We calibrate the capital share such that $1-\alpha=(r+\delta) \frac{K}{Y}$. Given our choice for $r$, the 2013 NIPA data for $\delta$ and $\frac{K}{Y}$ imply a high labor share of $\alpha=87.2 \%$, which is natural for a model without an equity premium. Similarly, we understate the investment ratio in the data, which is natural for a model without growth.

We set the elasticity of investment to $q$ to $\epsilon_{I}=1$, consistent with Gilchrist and Himmelberg (1995)'s estimates of the relationship with between aggregate investment and Tobin's $Q{ }^{20}$

Fiscal and monetary policy rules. We calibrate our redistributive tax rate $\tau^{r}$ using data from the Congressional Budget Office (2013), and the parameters $\epsilon_{G L}, \epsilon_{D L}$, and $\epsilon_{D B}$ of the fiscal rules (13)-(14) to be consistent with the empirical fiscal rules literature and our own estimated rules. We then derive $\tau^{g}$ residually from the government budget constraint. Appendix B.3 provides details.

Steady-state distributions of consumption, income and wealth. As appendix B.4 illustrates, our benchmark steady state achieves an excellent fit to the distributions of consumption, income, and wealth reported in the 2013 SCF. In particular, our calibration matches all three Gini coefficients exactly, and only misses the very top of the income and wealth distributions. This is a large improvement over standard calibrations of Aiyagari models (see for example Quadrini and Rios-Rull 1997), owing mainly to the richer earnings dynamics of our model.

\subsection{Experiments: inequality changes}

As figure 1 illustrates, income inequality-measured here as the standard deviation of male log earnings_-has been rising in the United States since at least the beginning of the 1980s. This rise in inequality has been the subject of a very extensive literature, which has identified

\footnotetext{
${ }^{20}$ Their table 1 report a range of 0.027 to 0.063 for $\delta \epsilon_{I}$, depending on the sample. Our calibration falls in the middle of this range and is consistent with typical business cycle models such as Bernanke, Gertler and Gilchrist (1999).
} 


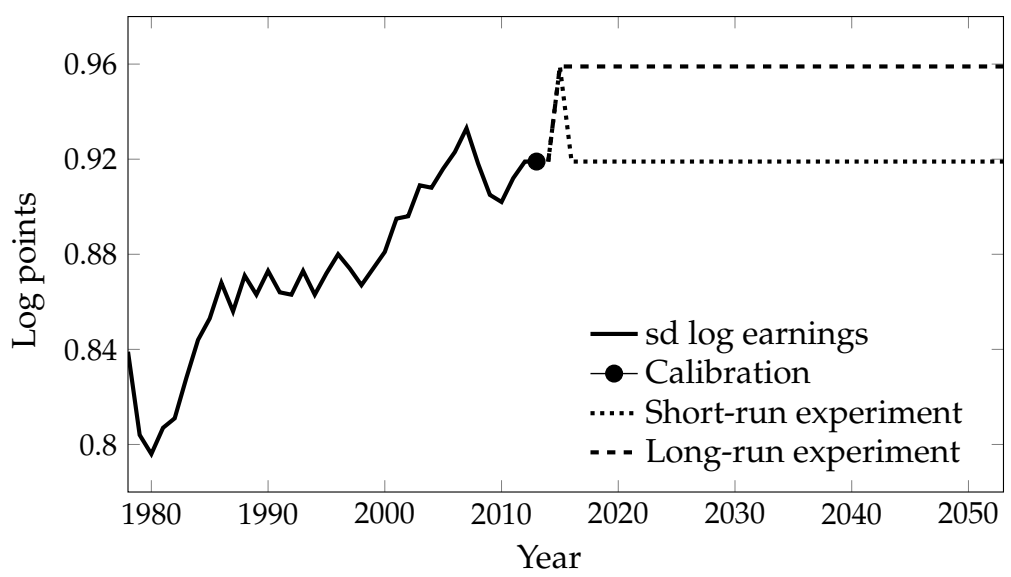

Figure 1: Retrospective and prospective income inequality paths.

multiple fundamental causes, all of which can be argued to have changed the innate earnings ability $e_{t}\left(s_{i t}\right)$ of individuals in different groups $s_{i t} .{ }^{21}$ Since our framework is concerned with the change in aggregate consumption and savings patterns induced by this increase in inequality, we do not need to explicitly model the root cause of this change, and can instead focus directly on how $e_{t}$ changed over time for different groups-consistent with the approach taken by the large literature on earnings dynamics.

Specifically, we modify the steady-state income process (19), for $t \geq 0$, to read

$$
\log e_{i t}=\widetilde{\omega}_{i}+A_{t} \xi_{i t}+B_{t} \chi_{i t}-C_{t}
$$

for a new distribution $\widetilde{\omega_{i}}$ and deterministic trends $A_{t}, B_{t}$. These trends are calibrated to achieve a given target path for the standard deviation of the $\log$ endowment distribution, $\operatorname{sd}\left(\log e_{i t}\right)$, while the constant $C_{t}$ enforces a constant mean endowment $\mathbb{E}\left[e_{i t}\right]=1$. Figure 1 plots two of our target paths, which each achieve an increase of 4 points in the standard deviation of log endowments, but one is immediately reversed while the second is permanent. ${ }^{22}$

As initially argued by Gottschalk and Moffitt (1994) and since confirmed by Kopczuk, Saez and Song (2010) and many others, statistical decompositions of changes in inequality tend to attribute a role for both the the persistent and the transitory component of earnings risk. Consistent with this evidence, our baseline experiment sets $A_{t}=B_{t}$ and maintains $\widetilde{\omega}_{i}=0$. However, the view that fixed effects have played no role is not universal (see for example Straub 2017). This distinction turns out to be especially important when analyzing the long run. In

\footnotetext{
${ }^{21}$ Example include: a rising skill premium from skill-biased technological change (Katz and Murphy 1992), increasing prevalence of superstar pay (Rosen 1981), improved information technology (Garicano and RossiHansberg 2004), trade and globalization (Feenstra and Hanson 1999, Autor, Dorn and Hanson 2013), financial deregulation (Philippon 2015), rising assortativeness between workers and firms (Card, Heining and Kline 2013), as well as fundamental changes in labor market institutions.

${ }^{22}$ In section 3.5 we also consider intermediate cases with mean reversion in $\mathrm{sd}\left(\log e_{i t}\right)$.
} 
section 4 , we therefore consider the following alternative views: one in all inequality is due to transitory component of risk $\left(B_{t}=1\right)$, one in which it is all the persistent component of risk $\left(A_{t}=1\right)$, and one in which inequality comes entirely from the distribution of fixed effects $\widetilde{\omega}_{i}$.

Appendix A provides a summary of the model equations. Appendix B provides details on our calibration and experiments, and our online appendix explains our computational methods. All of our proofs are in Appendix C.

\section{Inequality in the short run}

We start by investigating increases in inequality in the short run. In our setup, a purely transitory increase in inequality is the same as a one-time redistribution of income. Hence, this section provides a general characterization of the effects of exogenous income redistribution, both in partial and in general equilibrium.

\subsection{Partial equilibrium effect}

We consider first the effect of redistributive labor income shocks, defined as follows.

Definition 2. A redistributive labor income shock is an unexpected change in $e_{t}(\cdot)$ or in $\tau_{t}^{r}$. We say the shock is one-time if only $e_{0}(\cdot)$ or $\tau_{0}^{r}$ is affected, and that it is transitory if $e_{t}(\cdot)$ and $\tau_{t}^{r}$ limit to their initial steady state values.

Both types of redistributive labor income shock operate by changing the distribution of net incomes $y_{i t}$. For example, in partial equilibrium starting from a full employment steady state, a small one-time endowment shock affects the date- 0 net income of individuals in state $s_{i 0}$ by $d y_{i 0}\left(s_{i 0}\right) \equiv(1-\tau) \frac{W}{P} d e_{0}\left(s_{i 0}\right)$. Similarly, a small one-time contractionary redistributive tax change $d \tau_{0}^{r}<0$ affects the net income of an individual with current income $y_{i 0}$ by $d y_{i 0}=$ $\left(\mathbb{E}\left[y_{i 0}\right]-y_{i 0}\right) \frac{d \tau_{0}^{r}}{1-\tau^{r}}$, expanding the distribution linearly away from its mean.

We now characterize the effect of these shocks on the partial equilibrium consumption path chosen by households. A formal definition of these paths is given in appendix A.2: it is the solution to the household problem, taking into account the exogenous shocks $\left\{e_{t}(\cdot), \tau_{t}^{r}\right\}$ but holding all other inputs into the household problem constant at their steady state values. These paths are useful for two reasons: first, they can be interpreted as the small open economy outcome of redistributive shocks. Second, they are a direct determinant of the closed economy general equilibrium outcome, as we will show in theorem 4.

For any vector $\mathbf{X}$, define $N P V(\mathbf{X})=\sum \frac{1}{(1+r)^{t}} X_{t}$ as the net present value of that vector discounted using the steady-state interest rate. 

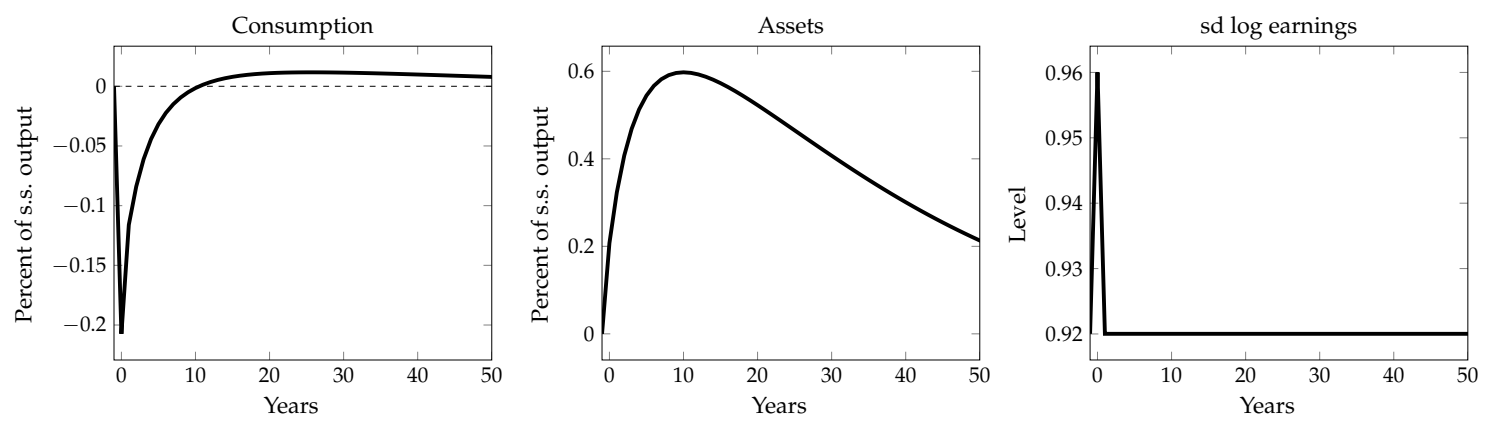

Figure 2: Partial equilibrium effect of increasing inequality

Proposition 3. In response to a one-time redistributive labor income shock, the partial equilibrium change in the path for $C_{t}$ is given, to first order, by

$$
\partial C_{t}=\operatorname{Cov}_{I}\left(M P C_{i t}, d y_{i 0}\right)
$$

where $M P C_{i t}$ is $i$ 's spending at date tof date 0 income. In particular, $N P V(\partial \mathbf{C})=0$.

Proposition 3 shows the precise sense in which the distribution of marginal propensities to consume is important to determine the effect of a rise in inequality. Its final statement follows from the fact that

$$
N P V\left(\mathbf{M P C}_{i}\right)=1 \quad \forall i
$$

In other words, all agents have an equal MPC of 1 once expressed in present value terms. The aggregate effects of income redistribution arise because agents are heterogeneous in the way they wish to time their spending of additional income, but an intertemporal budget constraint implies that they all spend this income at some point in time.

According to proposition 3, different types of inequality shocks affect aggregate consumption in different ways. For example, as discussed above, changes in the redistributive tax rate $\tau_{0}^{r}$ expand the distribution of net incomes linearly around its mean level. Applying proposition 3 for this particular distribution of $d y_{i 0}$, we obtain

$$
\partial C_{t}=\operatorname{Cov}_{I}\left(M P C_{i t}, y_{i 0}\right) \frac{d \tau_{0}^{r}}{1-\tau^{r}}
$$

The covariance between MPCs and net incomes is directly relevant to understand the equilibrium impact of such a shock. For more general shocks, such as for our baseline experiment, we need to know how the income changes induced by the shock correlate with marginal propensities to consume. ${ }^{23}$

Figure 2 illustrates proposition 3 in the context of our main short-run experiment. That

\footnotetext{
${ }^{23}$ As another example, consider the one discussed in the introduction. Suppose that the top $10 \%$ of income earners get a positive transfer proportional to their income, financed by an equivalent transfer from the bottom $90 \%$, such
} 

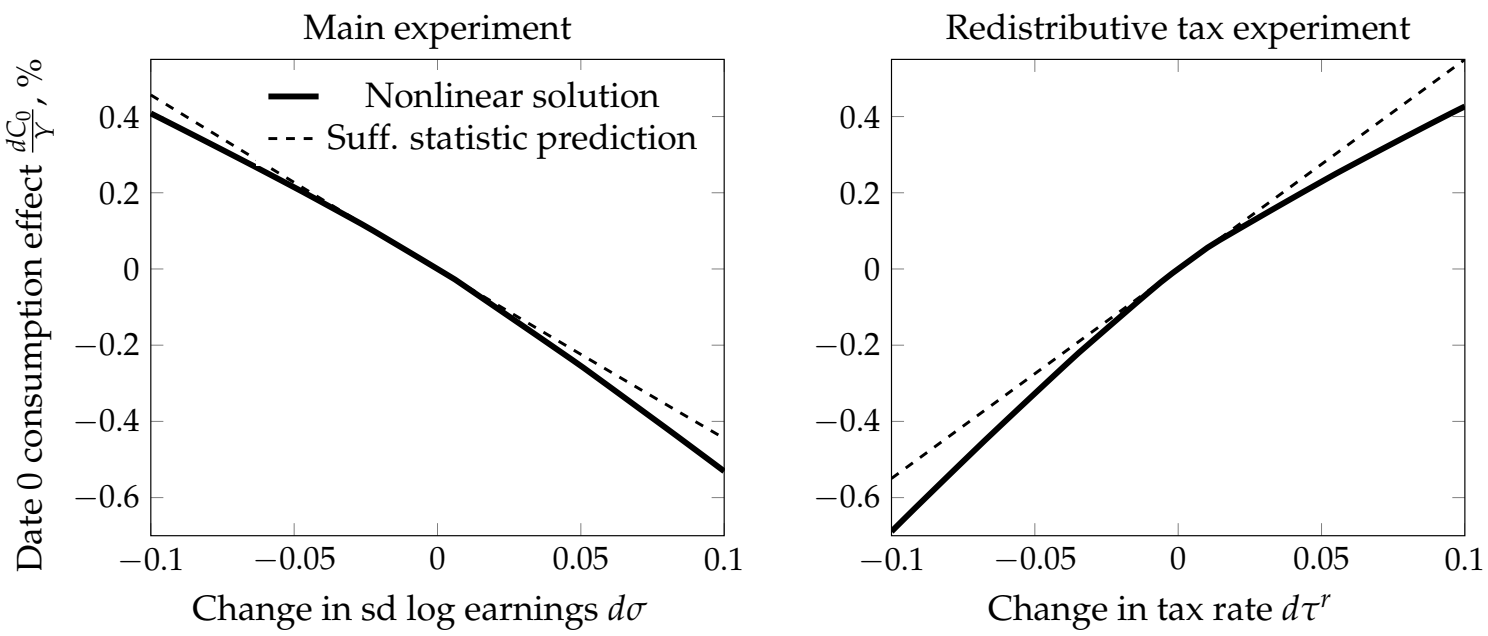

Figure 3: Sufficient statistic prediction vs. nonlinear model solution

experiment redistributes income from agents with high current MPCs to agents with low current MPCs, implying a fall in consumption for a number of periods. As a result, the economy accumulates assets, and aggregate consumption actually increases after around 10 years.

Quality of approximation. The key benefit of proposition 3 is that it gives us a potentially powerful way of connecting a model object to an object in the data. But how important are nonlinearities? Figure 3 shows the quality of our first-order approximation for both our main inequality shock and a redistributive tax change, by looking at the first component of the response $\partial C_{0}$ when we vary the size of the shocks. We focus on the first entry of the sufficient statistic, $\partial C_{0}$, since it is the dominant effect-which, as section 3.3 will explain, carries over to general equilibrium. The current marginal propensity to consume, $M P C_{i 0}$, is also the MPC most readily available in data.

The left panel shows the effect of changing the year-0 standard deviation of log earnings labelled $d \sigma$, and the right panel does the same for a redistributive tax change of a given size $d \tau^{r}$. As is clear from the figure, the approximation is excellent, including for very large shocks. The aggregate nonlinearities generated by the concavity of the consumption function are small enough that the first order approximation provides a useful map between model and data.

Sufficient statistic evaluation. We are ready to use proposition 3 to compare our results to those in the data. Our data comes from the Italian Survey of Income and Wealth. We use this survey because it is, to our knowledge, the highest quality survey that contains individuallevel information on both MPCs and income, therefore enabling us to compute the covariance that the total transfer is $d T$. Then the aggregate effect is $\partial C_{t}=\left({\overline{M P C_{t}}}^{\mathrm{T} 10}-{\overline{M P C_{t}}}^{\mathrm{B} 90}\right) d T$, where ${\overline{M P C_{t}}}^{\mathrm{X}}$ is the average income-weighted MPC of agents in group X (top 10\%, bottom 90\%). See Auclert and Rognlie (2017a). 


\begin{tabular}{ccc|ccc}
\hline Sufficient statistic & Value, Data & Value, Model & Experiment & Predicted $\frac{d C_{0}}{Y}$ & Actual $\frac{d C_{0}}{Y}$ \\
\hline $\operatorname{Cov}\left(M P C_{i}, \frac{d y_{i}}{Y}\right) \frac{1}{d \sigma}$ & -0.049 & -0.045 & $d \sigma=0.04$ & $-0.180 \%$ & $-0.202 \%$ \\
$\operatorname{Cov}\left(M P C_{i}, \frac{y_{i}}{Y}\right)$ & -0.038 & -0.045 & $d \tau^{r}=-2.5 \%$ & $-0.137 \%$ & $-0.156 \%$ \\
$\overline{M P C}^{T 10}-\overline{M P C}^{B 90}$ & -0.061 & -0.104 & $\frac{d T}{Y}=1 \%$ & $-0.104 \%$ & $-0.113 \%$ \\
\hline
\end{tabular}

Table 2: Sufficient statistics, data vs. model; linear vs. nonlinear

directly. Appendix B.1 contains details on our treatment of the data. ${ }^{24}$

Table 2 shows how the magnitudes compare for the three types of redistributive income shocks mentioned thus far. We see that our model does very well at capturing the relevant joint moments of MPCs and incomes in the data. This makes us confident that the partial equilibrium effect we obtain in the model accurately captures the consumption effect of income redistribution in practice, both in terms of general time path (down, then up) and in terms of magnitude on impact (since it matches the date-0 sufficient statistic.) Our main conclusion is that these magnitudes are small for plausible changes in income inequality. Note, however, that this result is conditional on the types of income-based redistribution we consider here: each redistributive shock has its own sufficient statistic, and both model and data feature significant MPC heterogeneity along other dimensions.

\subsection{General equilibrium}

The previous section confirmed common intuitions about the partial equilibrium effects of increases in income inequality. It showed the precise sense in which the covariance between MPCs and income matters, and showed that our baseline calibration is in line with available information in the data.

However, it is clear that the relationship between income inequality and output is ultimately a general equilibrium question. Figure 4 plots the effect under our three monetary policy rules.

In the ZLB and constant- $r$ cases, the results resemble partial equilibrium: output falls on impact by a magnitude similar to consumption, as investment and government spending are little changed. In the neoclassical case, by contrast, outcomes are reversed in general equilibrium: there is a small positive effect on the path of output. A decline in real interest rates mitigates the decline in consumption and elicits a rise in investment, creating enough demand to maintain full employment. Higher investment accumulates to a larger capital stock, leading to a slight rise in output after the first period.

Figure 4 therefore illustrates that the response of real interest rates is crucial in determining

\footnotetext{
${ }^{24}$ The SHIW MPCs are self-reported measures of marginal propensities to consume. Parker and Souleles (2017) has recently shown that these measures tend to correlate highly with estimates from actual behavior in surveys. Similar magnitudes for the covariance between MPCs and income using alternative sources of identification for MPCs can be found in US data (Auclert 2017) and in Norwegian data (Fagereng, Holm and Natvik 2016).
} 

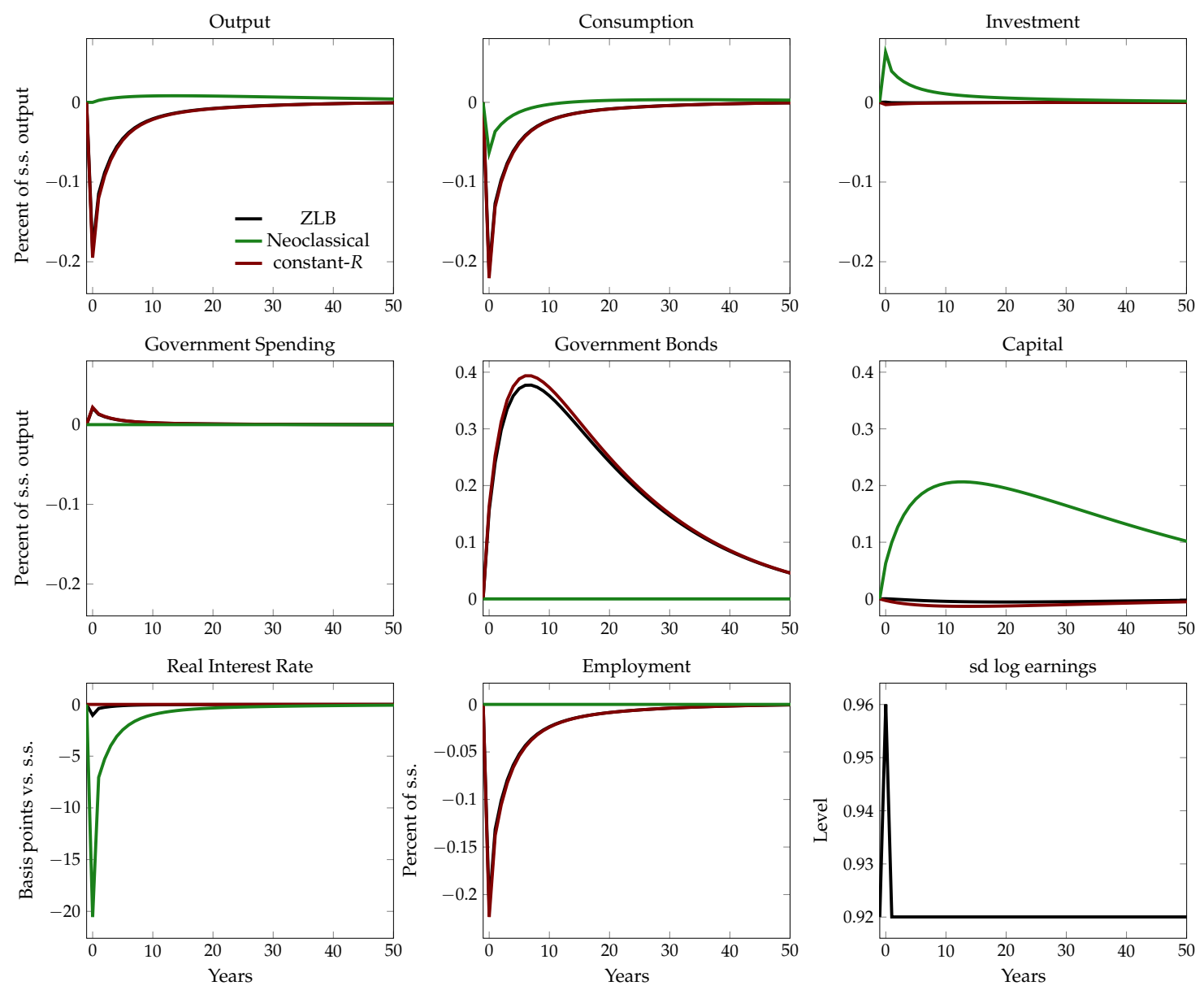

Figure 4: General equilibrium

whether partial equilibrium effects carry over to general equilibrium. The decline in aggregate consumption demand from an inequality shock will cause a decline in output unless real interest rates fall by enough-in this case, an immediate decline of 20 basis points. In our benchmark case, the zero lower bound prevents this decline, but many alternative monetary policy rules would deliver a similar output decline. For instance, we show that is the case for typical calibrations of Taylor rules in appendix D.4.

Investment and the paradox of thrift. One striking difference across experiments in figure 4 is the behavior of aggregate investment. Appendix A.1 shows that, given new path for $\left\{r_{t}, L_{t}\right\}$, $I_{t}^{n e t}=I_{t}-\delta K_{t-1}$ always responds by

$$
d I_{t}^{n e t}=\epsilon_{I} I \sum_{s=0}^{\infty}\left(\frac{1}{1+r}\right)^{s+1}\left\{d M P K_{t+s+1}-d r_{t+s}\right\}
$$



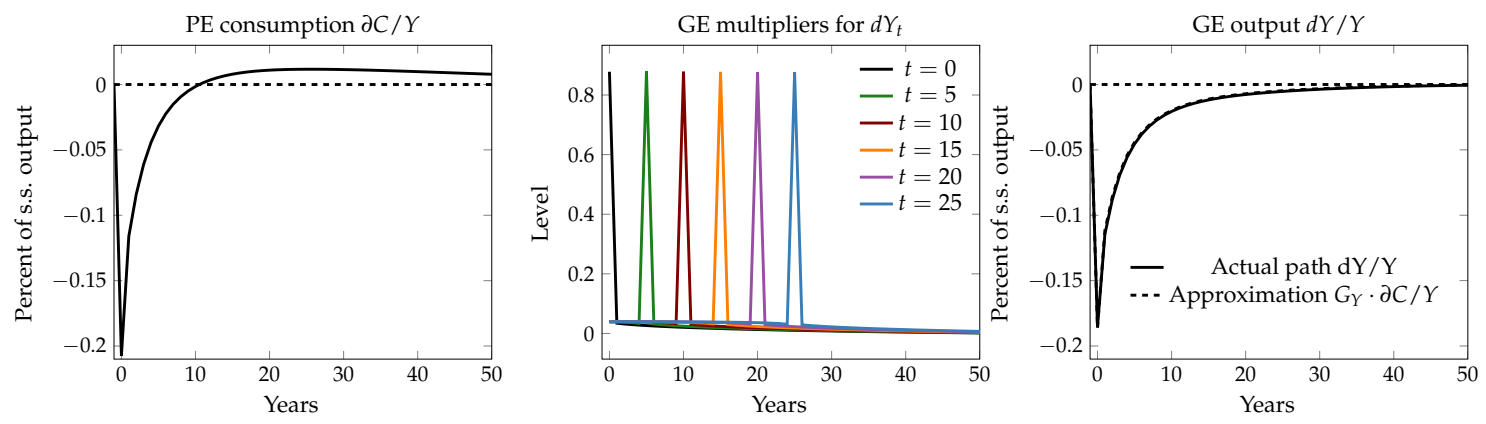

Figure 5: Increase in income inequality: from partial to general equilibrium

where $M P K_{t} \equiv F_{K}\left(K_{t-1}, L_{t}\right)$. Hence, the effect on net investment reflects the combination of a cost of capital effect $\left(d r_{t}\right)$ and an effect on the marginal product of capital $\left(d M P K_{t}\right)$.

In the neoclassical case, the decline in $r$ dominates, leading to a rise in investment. In both the ZLB and the constant- $r$ cases, by contrast, the real interest rate is roughly unchanged, so the investment response is driven by the marginal product of capital, which declines endogenously due to the fall in employment. Since net saving in the economy equals net investment, this implies that net saving must decline in equilibrium. This is the paradox of thrift described by Keynes (1936): while the shock to inequality raises saving in partial equilibrium, it lowers saving in general equilibrium. ${ }^{25}$

\subsection{From partial to general equilibrium: the multiplier methodology}

A striking feature of constant- $r$ and ZLB experiments is that the general equilibrium output effect looks similar to the partial equilibrium consumption effect, with a similar time path and magnitude. In the following theorem, we generalize this observation by establishing that there exists a precise mapping between partial and general equilibrium outcomes, and that this mapping is close to the identity for constant- $r$ and ZLB policy.

Theorem 4. There exists an output multiplier matrix $G_{Y}$ such that, for any transitory redistributive labor income shock, the impulse response of output to that shock is given, to first order, by

$$
d \mathbf{Y}=G_{Y} \cdot \partial \mathbf{C}
$$

where $\partial \mathbf{C}$ is the partial equilibrium consumption effect of the shock, which satisfies $N P V(\partial \mathbf{C})=0$.

The theorem says that redistributive labor income shocks affect output only through their partial equilibrium effect $\partial \mathbf{C}$, and that this effect works through a matrix $G_{Y}$ that is inde-

\footnotetext{
${ }^{25}$ Although private saving rises, this is more than offset by public deficits due to countercyclical fiscal policy. As we will see in section 3.4, this fiscal policy actually mitigates the decline in output, and therefore also mitigates the paradox of thrift.
} 
pendent of the shock. ${ }^{26}$ Theorem 4 therefore conceptually separates the partial equilibrium question of how inequality shocks affect consumption from the general equilibrium question of how changes in desired consumption affect aggregate outcomes. To obtain the transitory effect of one-time shocks, we can combine proposition 3 and theorem 4 to obtain $d \mathbf{Y}=$ $G_{Y} \operatorname{Cov}_{I}\left(\mathbf{M P C}_{i}, d y_{i 0}\right)$.

Figure 5 illustrates the theorem by plotting multipliers $G_{Y}$ under our benchmark monetary policy (ZLB) rule. The left panel reproduces the partial equilibrium shock path from figure 2. The middle panel plots selected rows of the matrix $G_{Y}$. The row for a given time $t$ shows the weights on the partial equilibrium path $\partial \mathbf{C}$ from the left panel that aggregate to produce $d Y_{t}$. As is clear, $G_{Y}$ is fairly close to the identity matrix for this benchmark monetary policy, with diagonal entries close to 1 and all other entries close to 0 . With sufficiently short-lived partial equilibrium responses, as with the shock we currently consider, these off-diagonal entries can approximately be disregarded. This explains why the partial and general equilibrium responses look so similar.

There are, however, subtle differences between the two. Most notably, while the partial equilibrium path has net present value zero-offsetting low consumption in the years following the shock with slightly higher consumption in later years-the general equilibrium path is strictly negative in every year.

\subsection{Determinants of multipliers}

We now study how various model parameters and policy affect the general equilibrium response to inequality shocks. To do this, we use the lens of theorem 4: we study aspects of the model that affect the multiplier matrix $G_{Y}$ without altering the partial equilibrium path $\partial \mathbf{C}$, which remains the same as in figure 5 . We focus on the multipliers because they are more sensitive to model uncertainty, in contrast to the partial equilibrium path, which is disciplined by a sufficient statistic.

Figure 6 displays the effect of changing the monetary rule, the fiscal rule, and the degree of endogenous inequality as summarized by the $\gamma$ function. The top panels show the output multipliers for $d Y_{0}$, i.e. the first row of $G_{Y}$. The bottom panels show the general equilibrium output paths.

On the left, we display the effect of changing monetary rules, just as in figure 4 . Unsurprisingly, the ZLB and constant- $r$ multipliers are very close to each other, and load on the immediate partial equilibrium impact with a value near one. By contrast, the neoclassical multipliers are exactly zero, reflecting the fact that, with predetermined capital and full employment, output cannot vary at $t=0$.

\footnotetext{
${ }^{26}$ This is the generalized matrix form of equation (1) discussed in the introduction, which refers to only the first row of (23). In the proof of theorem 4 , we show that an analogue exists for all macroeconomic aggregates, not just output.
} 

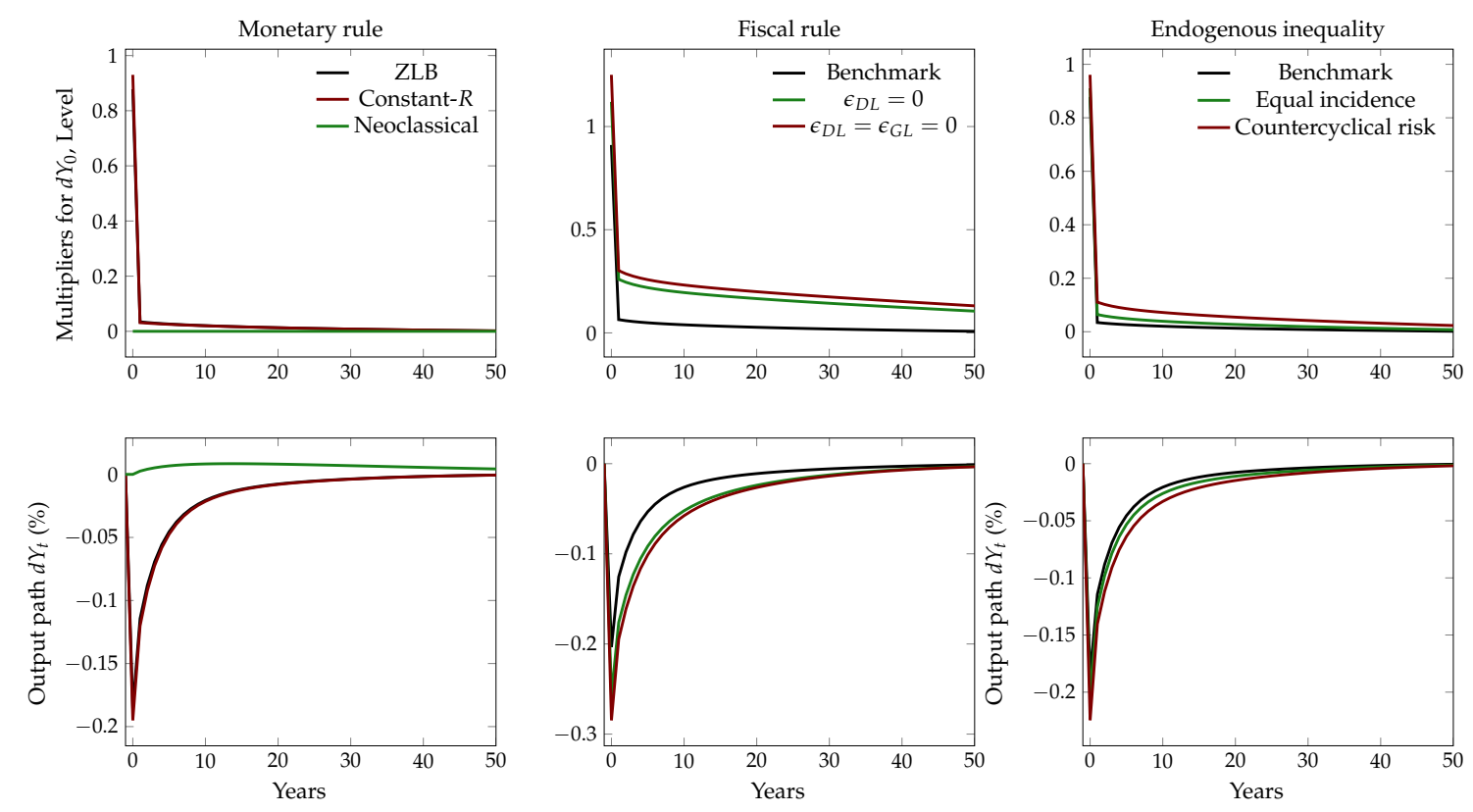

Figure 6: Determinants of multipliers: monetary, fiscal, inequality

In the middle column, we show the effect of progressively less countercyclical fiscal rules. When the government does not run deficits in response to low employment $\left(\epsilon_{D L}=0\right)$, the effects of inequality shocks are amplified, with a contemporaneous multiplier above one. There are also significant general equilibrium spillover effects from later dates: the multipliers for $d Y_{0}$ remain well above zero for $\partial C_{t}$ with $t>0$. Both contribute to a larger general equilibrium response, as seen in the lower panel. This pattern becomes slightly more pronounced when we also shut down the response of government spending to employment $\left(\epsilon_{G L}=0\right)$.

On the right, we display the effect of alternative income incidence rules $\gamma$. First, we compare our benchmark to a case with equal incidence $(\gamma=1)$. In our benchmark calibration to Guvenen et al. (2017) worker betas, both low and high income individuals are relatively sensitive to aggregate income. Since the former have high and the latter have low MPCs, the effect of counterfactually assuming equal incidence is in principle ambiguous, but quantitatively the sensitivity of the rich is more important, and hence the equal incidence case has slightly more amplification. We next consider a rule in which low income states are disproportionately affected by low aggregate employment, leading to countercyclical income risk. This features still more amplification, an effect that we might call the inequality multiplier: the endogenous inequality generated by a slump makes the slump even larger.

In conclusion, although procyclical fiscal policy and countercyclical income risk affect the extent of amplification, the most important driver of general equilibrium outcomes is the monetary rule. In figure 6, neoclassical monetary policy eliminates the output response altogether, while all other variations in the model alter the output response by no more than $50 \%$. 

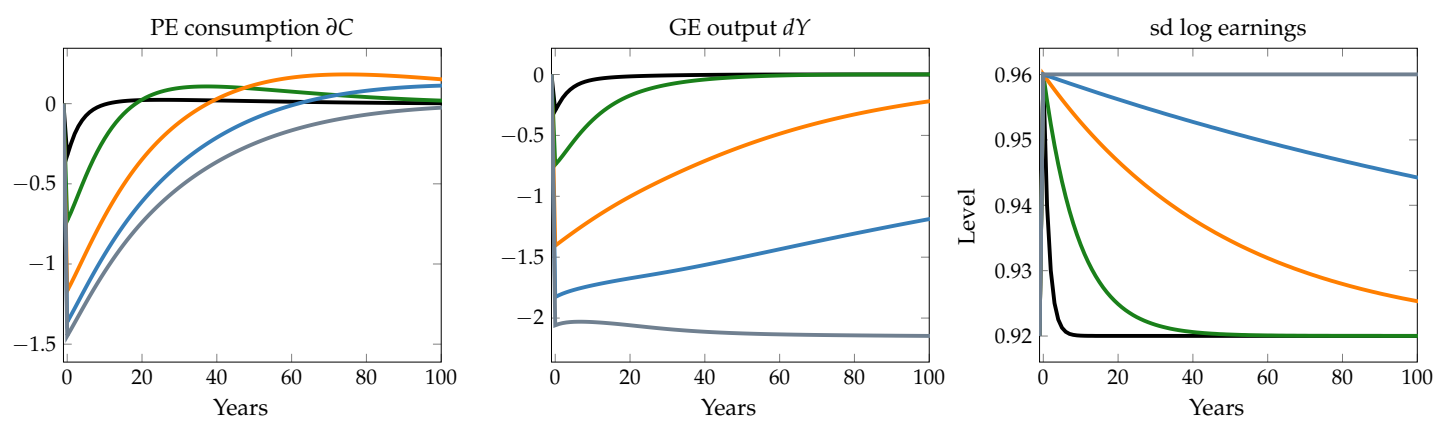

$-\rho=0.5-\rho=0.9-\rho=0.98-\rho=0.995-\rho=1$

Figure 7: Effect of increasing shock persistence

\subsection{Persistence}

So far we have explored the effect of purely transitory shocks, relating them to a simple sufficient statistic. This sheds considerable light on the effect of income redistribution on output, and the role played by marginal propensities to consume in this process. However, figure 1 illustrates that the rise in income inequality is not just a transitory phenomenon. It displays a clear trend, requiring us to consider the effect of persistence.

To do so, we must take a stance on how household income processes are changing. We address this issue in more detail in the next section. Here, we consider only our main experiment, one that spreads out the persistent and transitory components of earnings equally so as to achieve a target path for the standard deviation of log incomes. As before, we assume that this standard deviation increases at $t=0$ by 0.04 , but this change now persists at a rate $\rho>0$ :

$$
\mathrm{sd}\left(\log e_{t+1}\right)-\mathrm{sd}\left(\log e_{s s}\right)=\rho\left(\operatorname{sd}\left(\log e_{t}\right)-\mathrm{sd}\left(\log e_{s s}\right)\right)+\epsilon_{t}
$$

Figure 7 plots partial and general equilibrium outcomes as we vary $\rho$. In partial equilibrium, increasing persistence implies a more negative immediate consumption effect and a slower bounce back. As before, this reflects redistribution taking place over a longer time period, as the incomes of the poor are lower for longer. It also, however, reflects a new channel: the desire to accumulate precautionary savings in response to the higher income risk associated with persistent inequality.

In general equilibrium, the effect is larger on impact and much more persistent, especially as $\rho$ approaches 1 . For instance, in the $\rho=0.98$ case, the partial equilibrium effect is positive starting at $t=40$, but the general equilibrium effect remains significantly negative even at $t=100$. In terms of the output multiplier matrix $G_{Y}$, this reflects the accumulation of many off-diagonal entries, which are together nontrivial due to the persistence of the shock.

The most extreme case is that of a permanent increase in inequality $\rho=1$, for which general equilibrium output never recovers, even though partial equilibrium consumption eventually 

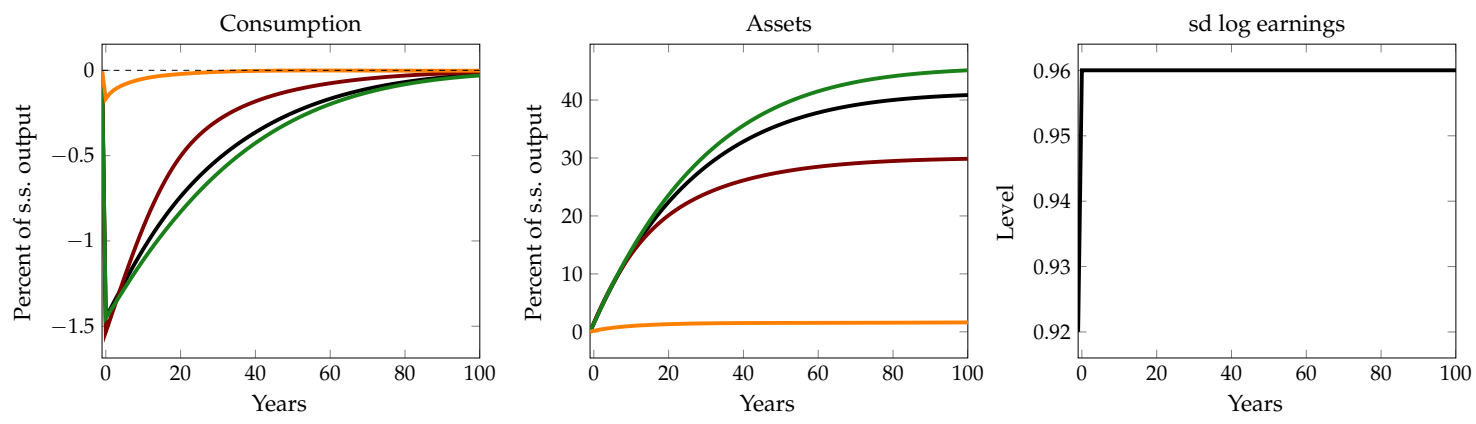

— Benchmark — Only transitory — Only persistent — Only fixed effects

Figure 8: Partial equilibrium effect of increasing inequality: permanent shock case

does. Here, partial equilibrium consumption effects are no longer useful in determining longrun output responses. Studying this relationship necessitates a new set of tools, which we develop in the next section.

\section{Inequality in the long run}

We now consider the effect of long-run increases in inequality. Our main experiment is now that of the dashed line in figure 1 , and a continuation of the $\rho=1$ case of the previous section. We first consider the partial equilibrium effect, but emphasize the role of asset accumulation rather than consumption, since our experiments do not affect the latter in the long run. We then turn to the general equilibrium output effect.

\subsection{Partial equilibrium effect}

Figure 8 shows the partial equilibrium effect of increasing inequality under our benchmark scenario and three alternative assumptions about the drivers of the increase in inequality: fixed effects, the transitory component, or the persistent component of earnings risk.

In each of these scenarios, consumption falls in the short run as agents accumulate assets, before recovering in the long run. By contrast, aggregate assets accumulate toward a new, higher steady state. When inequality is caused by increased volatility, the magnitudes are substantial: assets increase by somewhere between 30 and 45 percent of steady state output (respectively 8 and 12 percent of steady state assets). By contrast, when inequality is the result of more dispersed fixed effects, the steady state effects are near zero. The following proposition sheds light on this result.

Proposition 5. When the tax and transfer system has no lump-sum component $\left(\tau^{r}=0\right)$, changes in the distribution of fixed effects $\widetilde{w_{i}}$ in equation (20) have no effect on the steady-state levels of assets and consumption. 
Proposition 5 arises from the homotheticity of intertemporal consumption embodied in our choice of utility $u(c)=\frac{c^{1-v^{-1}}}{1-v^{-1}}$. This homotheticity is the prevalent assumption in models of consumption and savings behavior, both at the individual and at the aggregate level. ${ }^{27}$ It is therefore a useful benchmark to study the consequences of long-run increases in income inequality. Under this assumption, the savings rate is neutral with respect to shocks that scale up or down the entire after-tax income process. Thanks to our redistributive fiscal rule with $\tau^{r}>0$, this neutrality does not quite hold for changes in fixed effects, but figure 8 indicates that the departure from neutrality is insignificant in practice.

This result shows that the consequences of the observed long run increase in inequality depend on its underlying drivers, and particularly on the distinction between rising fixed effects and a rising persistent component of earnings risk, which induces the largest asset response in figure 8. Empirically, this distinction is difficult because existing studies of earnings dynamics tend to focus on individual earnings trajectories rather than tracking generations over time. If individual fixed effects are mean-reverting, they may correspond more closely to persistent shocks in our infinite-horizon setting. ${ }^{28}$ Distinguishing between these two sources of long-run increases in inequality is an important question for empirical work going forward.

Empirical assessment. We now connect to the existing empirical evidence on the effect of risk on savings to judge whether the magnitudes implied by figure 8 are reasonable. There exists a long empirical literature on the topic (see Browning and Lusardi (1996) for a survey). A typical regression in this literature is

$$
\log a_{i}=\alpha_{\eta} s_{i \eta}^{2}+\alpha_{\epsilon} s_{i \epsilon}^{2}+\beta Z_{i}+u_{i}
$$

where $a_{i}$ is individual wealth and $Z_{i}$ are individual-level controls. In (24), $\alpha_{\eta}$ provides a weighted average of individual semielasticities of wealth to a change in the variance of innovations to the permanent component of earnings, $s_{i \eta}^{2}$, while $\alpha_{\epsilon}$ provides the equivalent for innovations to the transitory component $s_{i \epsilon}^{2}$. These cross-sectional elasticities correspond to the partial equilibrium outcomes in our model in which aggregates are held constant. ${ }^{29}$ Hence the direct counterpart of $\alpha_{\eta}$ and $\alpha_{\epsilon}$ in the model is the partial derivative of log aggregate asset demand with respect to the innovations to each component $x \in\{\eta, \epsilon\}$ holding income and interest rates fixed, $\frac{\partial \log A^{d}}{\partial s_{x}^{2}}$.

Table 3 compares the figures given by the model and those from the data as computed by Carroll and Samwick (1997), a reference in the literature. The first two columns directly com-

\footnotetext{
${ }^{27}$ A number of important entries in the literature, such as De Nardi and Fella (2017), have questioned this homotheticity assumption on the grounds that it cannot account for the savings behavior of the rich. Recently, Straub (2017) has shown that consumption appears not to scale linearly with permanent income, a sign of aggregate nonhomotheticities. In these models, permanent income inequality can have large effects on aggregate savings in the long run.

${ }^{28}$ Boar (2017) provides empirical support for the view that parents save to insure against children's earnings risk, and suggests that infinite-horizon incomplete markets models can be interpreted as dynastic models with this
} 


\begin{tabular}{cccc}
\hline & Data & \multicolumn{2}{c}{ Model } \\
& $\partial \log a_{i} / \partial s_{i x}^{2}$ & $\partial \log A^{d} / \partial s_{x}^{2}$ & $\partial \log A^{d} / \partial \sigma_{x}^{2}$ \\
\hline \hline Persistent $(\eta)$ & 12.09 & 12.87 & 1.59 \\
Transitory $(\epsilon)$ & 7.11 & 0.50 & 0.97 \\
Fixed effects & - & - & 0.06 \\
\hline Benchmark persistent + transitory & - & - & 1.44
\end{tabular}

Table 3: Response of savings to income process changes

pare the relevant estimates, and show that model and data implications for the semielasticity of asset demand to persistent income risk are extremely close. By contrast, the model's implied elasticity of asset demand to transitory income risk is below the data by a factor of 14, suggesting that, if anything, our large estimates of the effect of inequality on savings are an understatement of potential empirical magnitudes.

The last column translates this evidence into semielasticities of asset demand with respect to cross-sectional variance, $\frac{\partial \log A^{d}}{\partial \sigma_{x}^{2}} .{ }^{30}$ To translate these numbers into magnitudes that we will use in the next section, consider an experiment that increases the cross-sectional standard deviation of log earnings by $d \sigma$, and therefore its variance by $d \sigma^{2}=1.84 d \sigma$. Suppose that the persistent, the transitory, and the fixed effect components of earnings risk respectively account for SharePersistent, ShareTransitory, and ShareFixedEffects of this variance increase. Then, multiplying by 1.84, table 3 implies that the semielasticity of savings to $\sigma$ is

$$
\frac{\partial \log A^{d}}{\partial \sigma}=2.93 \times \text { SharePersistent }+1.78 \times \text { ShareTransitory }+0.11 \times \text { ShareFixedEffects }
$$

For example, our benchmark experiment has SharePersistent $=0.76$ and ShareFixedEffects $=$ 0 , and therefore $\frac{\partial \log A^{d}}{\partial \sigma}=2.66$ : every 1-point increase in $\sigma$ translates into a $2.66 \%$ increase in assets. We will next show why this number is a sufficient statistic for the long-run outcome.

\subsection{Steady state in a special case}

It is useful to first focus on a special tractable case of the model. While this case may not be quantitatively realistic, it clearly illustrates the forces that shape long-run employment outcomes, including the roles played by monetary and fiscal policy. This special case modifies our benchmark calibration to feature:

a) Equal incidence: $\gamma(s, L)=1 \forall s, L$

\footnotetext{
intergenerational saving motive.

${ }^{29}$ By contrast, time series changes in income risk can only be mapped to general equilibrium model outcomes, a much more difficult task.

${ }^{30}$ In all our experiments, cross-sectional variance $\sigma_{x}^{2}$ scales linearly in innovation variance $s_{x}^{2}$. The ratio $\sigma_{x}^{2} / s_{x}^{2}$ reflects the persistence of income innovations.
} 
b) No responsiveness of deficits or spending: $\epsilon_{G L}=\epsilon_{D L}=0$ (hence $B_{t}=B$ and $G_{t}=G, \forall t$ )

As appendix C.2 explains, long-run equilibrium in the model is characterized a single market clearing equation for the stocks of assets, ${ }^{31}$

$$
A=B+K
$$

Under our assumptions, asset demand $A$ and asset supply $B+K$ are, in steady state, both linear functions of $L$.

Proposition 6. Assume that a) and b) hold. Then the steady-state real interest rate $r$ and employment level L jointly solve the equation

$$
(w(r) L-(G+r B)) \widehat{a}^{d}(r, \sigma)=B+\kappa(r) L
$$

where $\widehat{a}^{d}(r, \sigma)=\frac{A}{\left(1-\tau^{g}\right) \frac{W}{P} L}$ is steady-state asset demand given the income process parametrized by $\sigma$ and the real interest rate $r$ (a function independent of $\tau^{g}, \frac{W}{P}$ or $L$ ) and $w(r), \kappa(r)$ are the steady state real wage and capital-labor ratio given $r$.

The key to the proof is again the homotheticity property of consumption-savings decisions in our model. Homotheticity implies that steady-state asset accumulation is proportional to aggregate pre-tax labor income $\left(1-\tau^{g}\right) \frac{\mathrm{W}}{P} L$, which is the ultimate source of savings for households. The rest of the proof follows from the steady state government budget constraint and long-run neoclassical factor demand conditions.

Figure 9 contrasts the determination of long-run equilibrium under neoclassical monetary policy (where employment is constant at $L=1$ and the real interest rate $r$ adjusts to clear markets), and under ZLB monetary policy (where instead $r$ is fixed and $L$ adjusts to clear markets). As discussed in the previous section, a rise in inequality raises asset demand at a given level of $r$ and $L$. Under neoclassical monetary policy, the real interest rate falls and the capital stock increases, boosting long-run output. The equilibrating forces at the ZLB are quite different: an increase in asset demand leads to a decline in employment, which further reduces asset supply as firms readjust their capital stock to bring its marginal product back in line with its cost $r+\delta$-another manifestation of the paradox of thrift. The equilibrium outcome can be a large fall in $L$.

We now examine the quantitative implications of Proposition 6, tying them back to the magnitude of the asset demand effect of inequality $\frac{\partial \log A^{d}}{\partial \sigma}$ characterized in the previous section.

Corollary 7. To first order, the equilibrating changes in the natural interest rate $r^{*}$ (under neoclassical monetary policy) or in output and employment (under ZLB or constant-r policy) that result from a

\footnotetext{
${ }^{31}$ Studying equilibrium in the goods market does not suffice: see appendix D.2.
} 

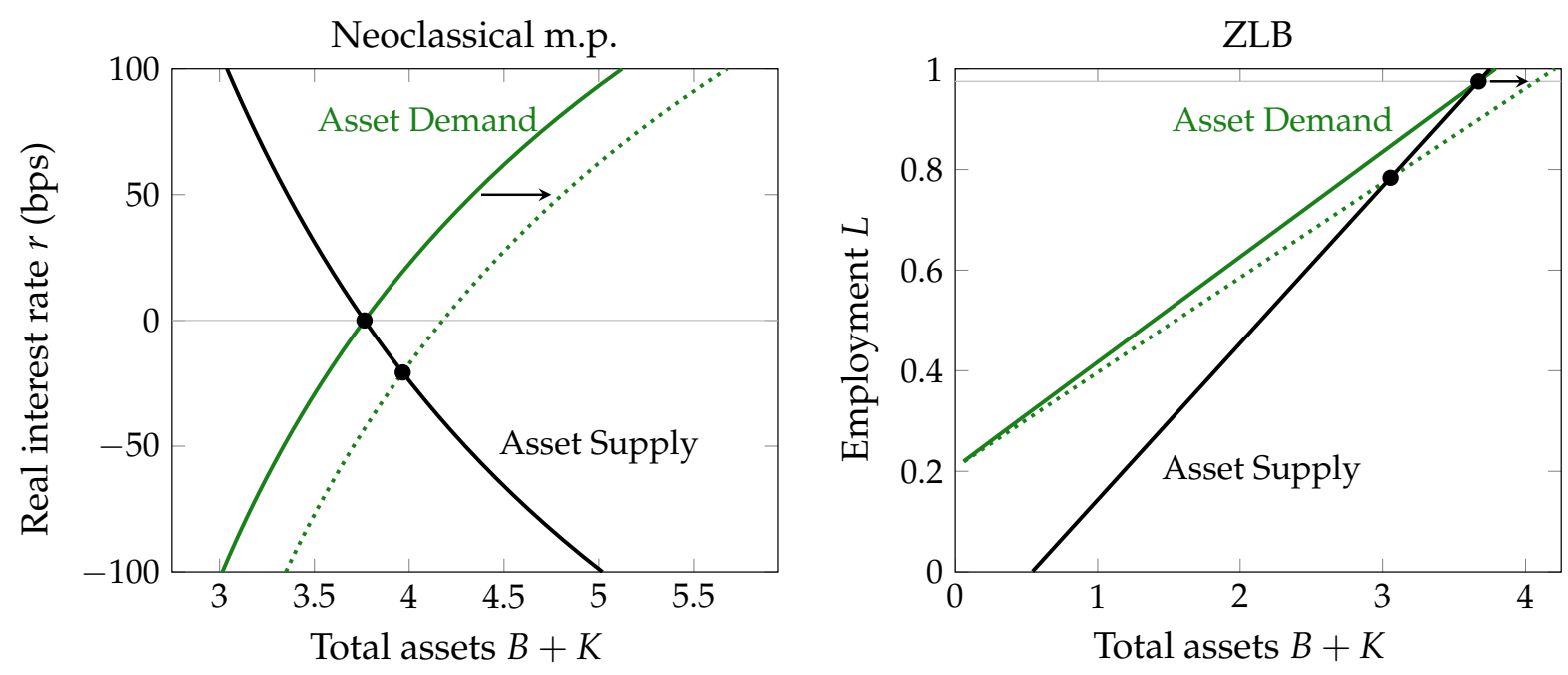

Figure 9: Monetary policy rule and equilibrium determination (special case)

change in $\sigma$ are given by

$$
\begin{aligned}
d r^{*} & =\frac{-1}{\epsilon_{D}-\epsilon_{S}} \frac{\partial \log A^{d}}{\partial \sigma} d \sigma \\
\frac{d Y}{Y}=\frac{d L}{L} & =\frac{-1}{\frac{B}{A}+\frac{\tau^{g}}{1-\tau^{g}}} \frac{\partial \log A^{d}}{\partial \sigma} d \sigma
\end{aligned}
$$

where $\epsilon_{D}, \epsilon_{S}$ are the semielasticities of asset demand and supply with respect to $r$.

Corollary 7 provides a simple steady state version of theorem 4 . The equilibrium change in price or quantity depends on the extent to which the asset demand curve shifts (our sufficient statistic) and on the difference in the semielasticities of asset demand and supply. When it is employment that adjusts, these semielasticities take a particularly simple form, so that the multiplier is a function of observables: the sum of the bond to asset ratio $\left(\frac{B}{A}=15 \%\right.$ in our calibration) and a simple function of the tax rate $\left(\frac{\tau^{g}}{1-\tau^{g}}=27 \%\right)$. This leads to an output-onasset multiplier of $\frac{1}{15 \%+27 \%}=2.4$. Given that our benchmark increase in income inequality of $d \sigma=0.04$ pushes up asset demand by $2.66 \times 0.04 \simeq 10 \%$, inequality therefore implies an output fall of $24 \% !^{32}$ This stark outcome reveals the instability of economies that suffer from secular stagnation. In the next section, we show how proactive fiscal policy can dramatically mitigate the output decline.

\footnotetext{
${ }^{32}$ We can contrast this $24 \%$ output fall with the modest decline in the long-run real interest rate of 21 basis points under neoclassical monetary policy. Interest rate declines are effective at restoring equilibrium because the long-run elasticities $\epsilon_{D}$ and $\epsilon_{S}$ of asset supply and demand are large-a common feature of general equilibrium models that we discuss further in section 5. This contrast will become less extreme in the next section, as declines in $L$ become much more effective at restoring equilibrium with our richer fiscal policy and income incidence rules.
} 


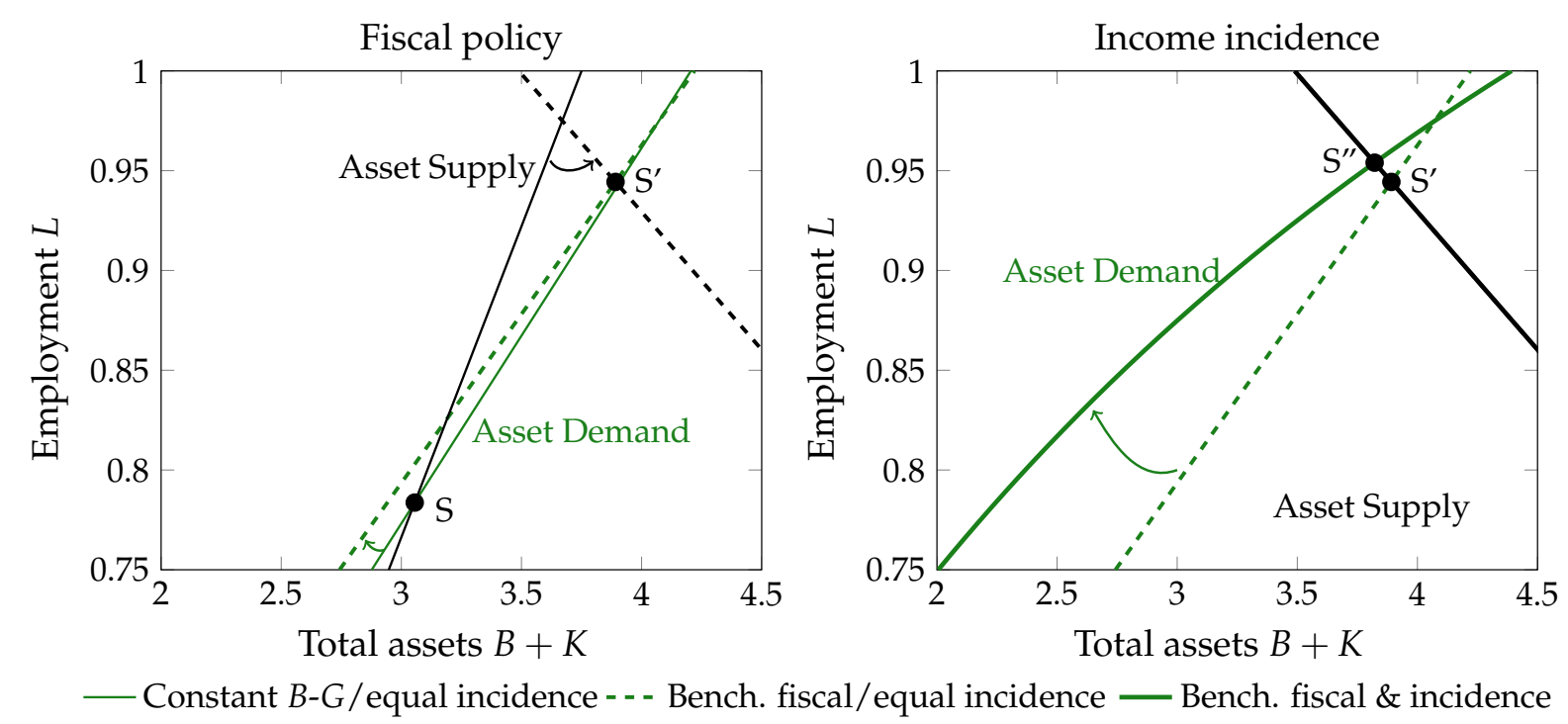

Figure 10: Role of fiscal policy and income incidence

\subsection{Steady state in the general case}

Our general model differs from the special case discussed in the preceding section because our calibrated fiscal rules imply that both government debt and government spending are responsive to falls in employment, and because our calibrated income incidence function $\gamma$ departs from the equal incidence benchmark.

Consider first the effect of the fiscal rule, holding income incidence at $\gamma=1$. In a steady state with employment $L$ below its initial steady state level of $L_{s s}$, we see from (14) that steadystate bonds $B$ are

$$
B=B_{s s}+\frac{\epsilon_{D L}}{\epsilon_{D B}}\left(L_{s s}-L\right) .
$$

Fiscal policy therefore endogenously raises asset supply $A=K+B$ as employment falls. In our baseline calibration, this effect is powerful enough that the slope of the asset supply curve changes sign, as illustrated in the left panel of figure 10. This shows the power of expansionary fiscal policy in sustaining demand in the long run by acting as a source of assets for the economy, $^{33}$ thereby substituting for the lack of appropriate monetary policy. Quantitatively, this is a very powerful effect: with our calibrated fiscal rule, equilibrium moves from point $S$ to point $S^{\prime}$, propping up employment by over 15 points.

Consider next the effect of income incidence. Departing from the $\gamma=1$ benchmark implies that the asset demand curve is no longer linear in employment, since changes in aggregate

\footnotetext{
${ }^{33}$ The left panel of figure 10 also shows that fiscal policy affects the asset demand curve, rotating it to the left. The reason is that steady-state taxes must rise to be consistent with the higher level of government spending. Lower employment in steady state therefore lowers individuals' post-tax labor incomes and induces them to save less, explaining the direction of rotation of the asset demand curve.
} 
income now affect the structure of risk that individuals face. Relative to this benchmark, there are two effects at play when employment falls. If the incomes of low-skill individuals are affected by more, this could raise aggregate precautionary savings. If the incomes of highskill individuals are affected by more, on the other hand, aggregate savings could fall due to a wealth effect. As was the case in the short-run, in our calibration to the Guvenen et al. (2017) worker betas, the effect at the top dominates and is overall mitigating, ${ }^{34}$ with equilibrium employment propped up by an extra point.

Just as with equation (29), it is possible to put all of these effects together and obtain a formula for the aggregate multiplier that translates a given change in asset demand into an effect on long-run output.

Proposition 8. To first order, the long-run output response is given by

$$
\frac{d Y}{Y}=\frac{-1}{\frac{B}{A}+\frac{\tau^{g}}{1-\tau^{g}}+\eta_{F}+\eta_{I}} \frac{\partial \log A^{d}}{\partial \sigma} d \sigma
$$

where $\eta_{F} \equiv Y \frac{\epsilon_{D B}}{\epsilon_{D L}}\left(\frac{L}{A}+\frac{r}{\left(1-\tau^{g}\right) w}\right)+Y \frac{\epsilon_{G L}}{\left(1-\tau^{g}\right) w^{\prime}}$, and $\eta_{I}=\frac{\partial \log A /\left(\left(1-\tau^{g}\right) \frac{W}{P} L\right)}{\partial L}$ are the contributions of fiscal policy and income incidence to the steady-state multiplier. The change in $r^{*}$ is still given by equation (28).

Proposition 8 shows the importance of fiscal policy in mitigating the recession, as well as the possibly ambiguous effect of income incidence. Quantitatively, $\eta_{F}=3$ and $\eta_{I}=1.5$. Together, these forces bring down the output multiplier in (30) from 2.4 in the special case of the previous section to only 0.21 in our benchmark, shrinking the fall in output to a milder $2.1 \%$.

\subsection{Transition dynamics}

Figure 11 shows the impulse response to the benchmark long-run income inequality shock under our three monetary policy rules. Once again, the transitions for the constant- $r$ and the ZLB case are very close, and we have already established that they converge to identical steady states, with the level of output reduced by $2.1 \%$. The adjustment toward steady state outcomes for output, consumption, and investment is almost immediate. This is true even though fiscal policy takes several decades to converge to the new steady state for bonds, and capital disinvestment also takes several decades to run its course.

Under neoclassical policy, by contrast, the transition dynamics of all aggregate variables are slower. Here, the dominant force is capital accumulation, which absorbs the rise in saving and leads to higher output in the long run. Since capital is a stock, this accumulation takes place over many decades, and the real interest rate declines at a similarly slow pace.

\footnotetext{
${ }^{34}$ If, on the contrary, the precautionary savings effect dominates, it is possible for the asset demand curve to become backward bending and for multiple equilibria to appear. See appendix D.6 for such an example.
} 

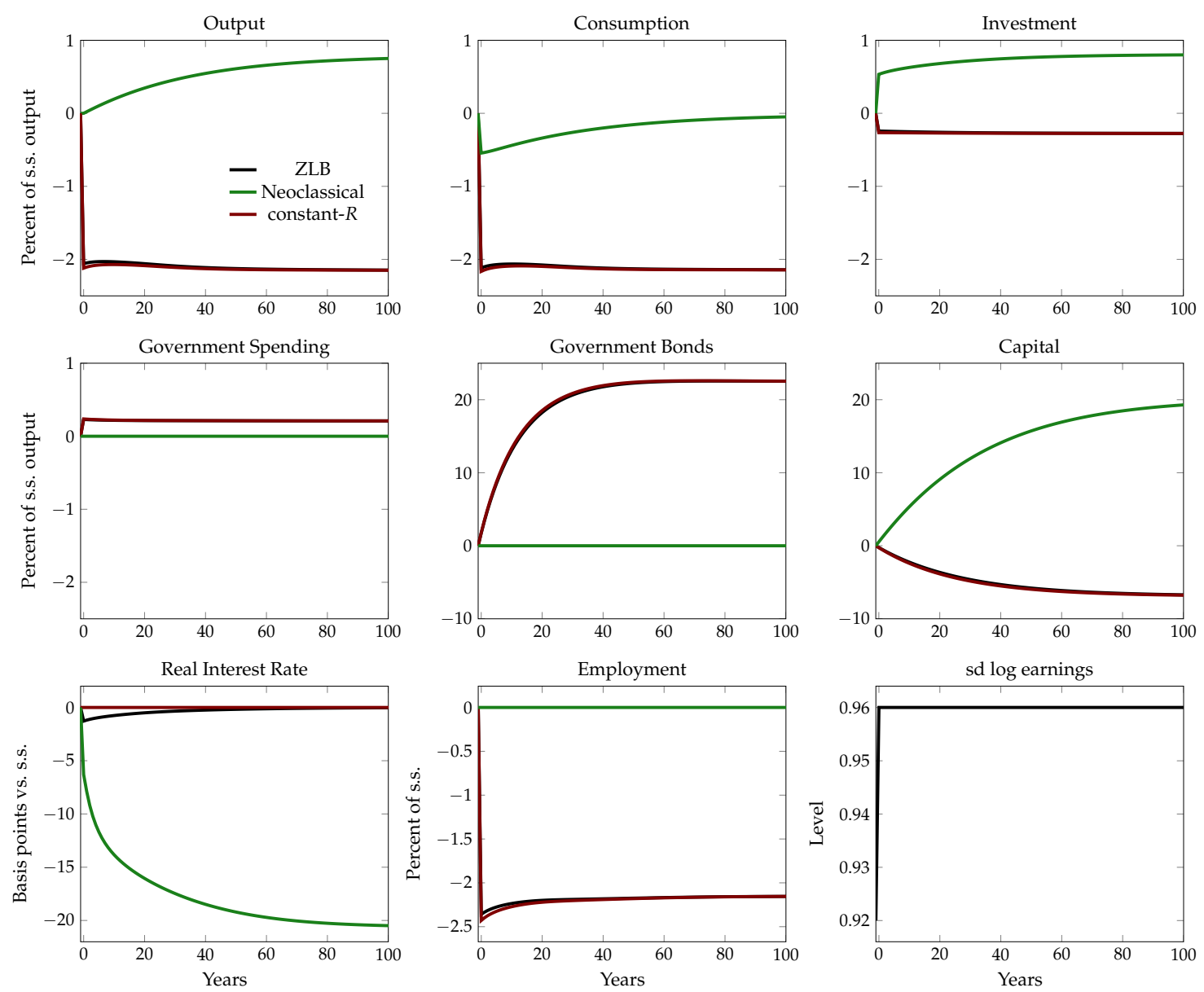

Figure 11: General equilibrium

\subsection{Policy solutions at the zero lower bound}

We conclude this section by discussing how various features of the environment affect equilibrium under our benchmark monetary policy constrained by the zero lower bound.

We first ask whether wage adjustment can help improve long-run outcomes. One intuition is that, since the downward rigidity of wages (11) is the root cause of the long-run slump, it may help to let wages fall faster. As the left panel of figure 12 shows, however, this intuition is incorrect. The more $\kappa$ falls, the more depressed long-run employment is-and moreover, this force is quantitatively very potent: when $\kappa=0.97$ and long-run wages fall at a rate of $3 \%$, long-run disemployment falls from our benchmark of $4.6 \%$ to a dire $33 \%$. The reason is that, in steady-state, long-run wage deflation implies long-run price deflation, pushing up the steadystate real interest rate and causing a decline in employment. This mechanism is often called the paradox of flexibility (e.g., Eggertsson 2011 or Werning 2012).

Next, we ask whether introducing an less-than-zero effective lower bound on nominal in- 

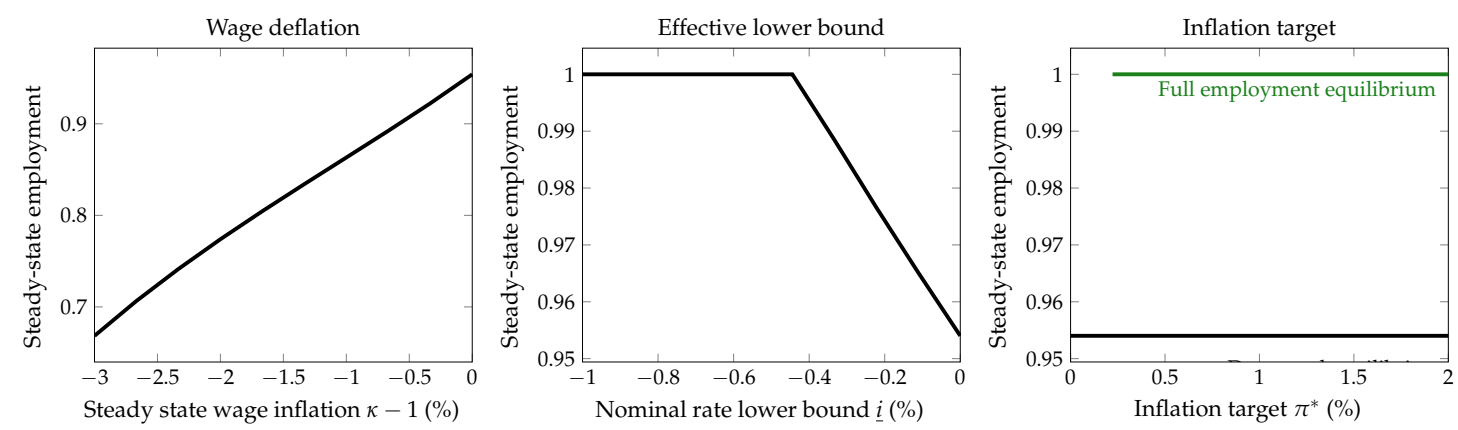

Figure 12: Alternative general equilibrium adjustments

terest rates can improve outcomes. Many central banks have started implementing negative nominal rates (see for example Rognlie 2015b). We therefore consider varying $\underline{i}$ in equation (18) from its benchmark value of zero to more negative values. The middle panel of figure 12 shows that, in our model, the benefits of breaking through the zero lower bound are quantitatively large. The mechanism here is exactly the reverse of the effect of wage deflation.

Another policy tool that has been proposed to fight the zero lower bound is raising the inflation target (e.g. Coibion, Gorodnichenko and Wieland 2012). The right panel of figure 12 shows that, indeed, another full employment equilibrium exists in our model provided that the increase in inflation target is large enough. The logic is that the increase in the inflation target might achieve a lower equilibrium real interest rate despite the zero lower bound. However, there is always an equilibrium in which the downward wage rigidity (11) remains binding and inflation is below the target: the central bank wants inflation but cannot achieve it. ${ }^{35}$

\section{Inequality and the decline in $r^{*}$}

According to Laubach and Williams (2015), there has been a 4 percentage point decline in the natural interest rate $r^{*}$ since 1980. How much of this can we attribute to rising labor income inequality? We answer this question by computing the decline in $r^{*}$ implied by our model, given the observed path of inequality since 1980 .

More specifically, we first recalibrate the model to a 1980 steady state, as described in more detail in appendix B.5. We then feed in the historical path for the standard deviation of $\log$ earnings in the right panel of figure 13 and compute model outcomes, assuming neoclassical monetary policy so that employment is kept at potential throughout the transition. In this thought experiment, households become fully informed in 1980 about the new path for inequality, and they assume it will remain at its 2013 level forever. The left panel of figure 13 shows the resulting path for the real interest rate: an eventual fall in $r^{*}$ of 82 basis points, with

\footnotetext{
${ }^{35}$ See section C.3 for a formal analysis of steady-state equilibrium multiplicity.
} 

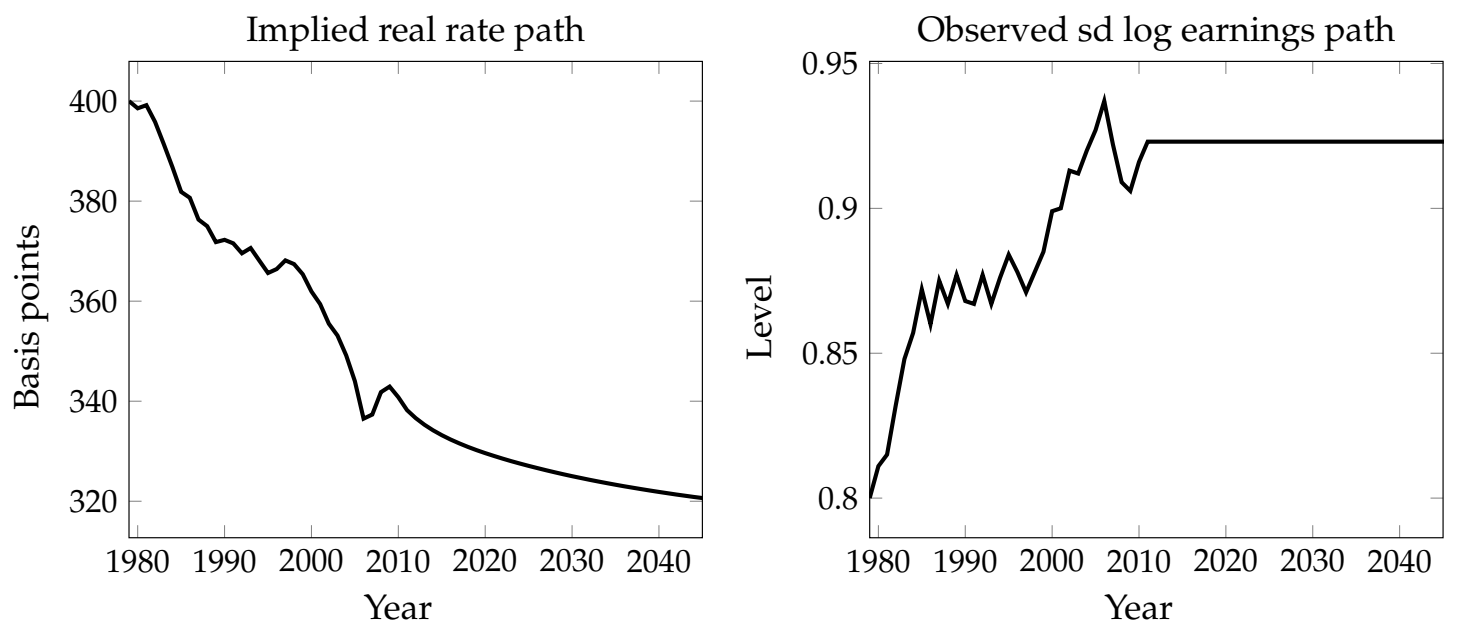

Figure 13: Inequality and the $r^{*}$ decline

a very slow transition. This is roughly one-fifth of the observed decline.

Equation (28) helps us decompose the sources of this fall in $r^{*}$. We can first ask how much the rise in inequality would increase aggregate asset demand, holding everything constant. In this new calibration, this is $\frac{\partial \log A^{d}}{\partial \sigma}=3.11$. Next, we can ask how elastic asset demand and asset supply are to the real interest rate. Our model implies a semielasticity of asset demand $\epsilon_{D} \simeq 27$ and a semielasticity of asset supply $\epsilon_{S} \simeq-16$. Putting those numbers together, (28) predicts a steady-state decline in $r^{*}$ from the observed increase of 12 points in the standard deviation of log earnings of

$$
-d r^{*}=\frac{\frac{\partial \log A^{d}}{\partial \sigma} \times d \sigma}{\epsilon_{D}-\epsilon_{S}}=\frac{3.11 \times 0.12}{27+16}=87
$$

basis points, only slightly above what we compute in the model on account of nonlinearities from the large shock.

This exercise is another application of our sufficient statistic methodology, separating the general equilibrium outcome into two parts. First, there is the impulse $\frac{\partial \log A^{d}}{\partial \sigma} \times d \sigma$ to the asset demand curve, a partial equilibrium sufficient statistic for the inequality shock that we validated empirically in section 4.1 (assuming that inequality reflects a rise in income risk). Second, there is the general equilibrium multiplier $\frac{1}{\epsilon_{D}-\epsilon_{S}}$, which tells us how far we need to move along the asset demand and supply curves to restore equilibrium. Since this multiplier is small, it converts the fairly substantial impulse to asset demand in (31), a rise of $3.11 \times 0.12 \approx 37 \%$, into a moderate decline in $r^{*}$ of 82 basis points.

The small multiplier arises from the large interest semielasticities of asset supply and demand in the model. The asset supply semielasticity, $\epsilon_{S} \simeq-16$, follows directly from the capital demand implied by our Cobb-Douglas production function. ${ }^{36}$ The asset demand semielastic-

\footnotetext{
${ }^{36}$ Explicitly, it can be written as $\epsilon_{S}=-\frac{K}{A} \frac{1}{\alpha} \frac{\varepsilon}{r+\delta}$, where $\varepsilon$ is the elasticity of substitution between capital and labor.
} 
ity, $\epsilon_{D} \simeq 27$, captures the usual long-run interest sensitivity of household savings in Aiyagari models-which, although there is no longer an infinite elasticity as in a representative agent model, is still quite high. There is a plausible case for smaller elasticities: for instance, some of the empirical literature on the production function points to an elasticity of substitution less than one (implying smaller $\epsilon_{S}$ ), and OLG models can feature strong income effects that dampen or overturn the savings response to interest rates (implying smaller $\epsilon_{D}$ ). Either change would lead to a larger multiplier, and therefore an even larger role for inequality in the long-run $r^{*}$ decline.

We argue that this analysis illustrates the value of our methodology: decomposing via (31) allows us to identify which features of the model matter most to the general equilibrium outcome. Going forward, the role of asset supply and demand elasticities will be an important question for the literature on secular stagnation and the natural rate.

\section{Inequality and the labor share}

The paper has thus far considered the impact of changes in labor income inequality. Another key dimension of the income distribution is the split between labor and capital income. The recent global decline in the labor share is a widely-studied macroeconomic trend, and although its contribution to overall inequality to date has been much smaller than that from labor income inequality (see Francese and Mulas-Granados 2015), it may rise in importance going forward.

The model in section 2 features a Cobb-Douglas production function with a fixed labor share parameter $\alpha$. It also assumes a perfectly competitive production sector, eliminating the possibility of rising markups - which recent work has suggested to be a major cause of the declining labor share. ${ }^{37}$ To study the impact of changes in the labor share, therefore, it is necessary to enrich the model. We do so along three dimensions: allowing for a general production function, allowing the price of investment to vary, and replacing competitive with monopolistic production.

Modified production model. The final good is produced by a competitive retail sector that packages a continuum of intermediate goods $x_{j t}$ :

$$
Y_{t}=\left(\int_{0}^{1}\left(x_{j t}\right)^{\mu}\right)^{\frac{1}{\mu}}
$$

One unit of the final good can be transformed costlessly into one unit of the consumption good and $1 / X_{t}$ units of the investment good. The price of investment is therefore $P_{t}^{I}=X_{t} P_{t}$, where $P_{t}=\left(\int_{0}^{1}\left(P_{j t}\right)^{\frac{1}{\mu_{t}-1}}\right)^{\mu_{t}-1}$ is the price of consumption, which we continue to use as the

In our 1980 calibration, $\frac{K}{A}=0.91, \alpha=0.81, \varepsilon=1$, and $r+\delta=0.069$.

${ }^{37}$ See Rognlie (2015a), Barkai (2016), de Loecker and Eeckhout (2017). 
numeraire. A decline in $X_{t}$ represents an exogenous improvement in the production technology for investment goods relative to the technology for consumption goods.

Each intermediate good $j$ is produced by a monopolistically competitive firm $j$, which has the production function

$$
x_{j t}=F\left(K_{j t-1}, L_{j t}\right)
$$

where $K_{j t-1}$ is the capital owned by the firm at the beginning of period $t$. Capital adjustment costs remain the same, but must be paid in investment goods. We maintain our assumption that firm profits are capitalized into the value of assets that households trade. As before, each firm maximizes the present value of the path of dividends $\left\{d_{t}\right\}$, with the price $P_{j t}$ now being an additional choice variable. Given the demands implied by (32), firms optimally set $P_{j t}$ equal to $\mu$ times marginal cost, allowing us to interpret $\mu$ as a markup.

Assuming all firms are identical initially, they remain identical at all times and their shares will trade at the same real price $p_{t}$. For simplicity, we will assume that the only equity asset traded by households is a composite share of all firms, which also trades at $p_{t}$. Appendix A.1 shows that $p_{t}=q_{t} X_{t} K_{t}+\Pi_{t}$, where $q_{t} X_{t} K_{t}$ is the value of installed capital and $\Pi_{t}$ is the present discounted value of monopoly profits. In steady state, this reduces to

$$
p=q X K+\Pi=X K+\frac{\left(1-\frac{1}{\mu}\right) Y}{r}
$$

where $\left(1-\frac{1}{\mu}\right) Y$ is the steady-state flow monopolists' profit, capitalized into $\Pi$ at rate $r{ }^{38}$

Finally, we assume that the fiscal rules (13) and (14) are normalized by the $Y$ that occurs in steady state after the shock, rather than by the initial $Y_{s s}$. This keeps the effective stance of fiscal policy constant as we change the production side of the economy, which is important for isolating the impact of the labor share.

Steady-state result. With the newly-enriched model, we can study the effects of three distinct shocks that influence the labor share: shocks to the production function, investment prices, and markups.

Proposition 9. Consider an exogenous change in the production function or investment prices, or a rise in markups, that leads to a decrease in the labor share holding $r$ constant. Under zero lower bound or constant-r policy, this causes an increase in aggregate employment starting from a depressed steady state. Under neoclassical policy, it causes a rise in $r^{*}$.

\footnotetext{
${ }^{38}$ Note that this formula requires $r>0$, which is inconsistent with our original calibration to $r=0$. Given the assumptions in this section, $r>0$ will always hold in steady-state equilibrium: asset supply (34) approaches infinity as as $r \downarrow 0$, and equilibrium with asset demand will hold for some strictly positive $r$. We therefore consider $r>0$ in this section. An earlier version of this paper added an "equity premium" such that asset supply can be finite even for negative risk-free $r$.
} 
This simple but surprising result provides a unified analysis of the labor share and aggregate demand. The contrast with section 4 is striking: there, a rise in labor income inequality was contractionary in the long run, while here, a fall in the labor share is expansionary, even though it also increases overall income inequality. ${ }^{39}$ The intuition behind proposition 9 is that a decline in the labor share, by increasing the capital or profit shares, pushes up the total value of assets supplied by the private sector-and in our framework, an increase in asset supply relative to demand is expansionary in the long run. ${ }^{40}$

When thinking about income distribution, therefore, it is important to consider which income streams will be capitalized into tradable assets. This is one instance of a more general theme in this paper: the effects of inequality on aggregate demand may not be as large as commonly assumed, and very much depend on the source of that inequality.

\section{Conclusion}

In this paper, we proposed a framework to analyze the effects of changes in the income distribution on consumption and output. We found that transitory income redistribution can lead to declines in both consumption and output, but that this effect is likely small. By contrast, we found that the long-run effect of income inequality, if it involves an increase in idiosyncratic income risk, can potentially be quite large.

There are several important directions for future research. On the theory side, the most important next step is to better understand the dynamic general equilibrium multipliers in theorem 4, which here we are only able to compute numerically. We pursue this agenda in Auclert, Rognlie and Straub (2017), relating these multipliers to individual marginal propensities to consume. On the empirical side, our research calls for better empirical evidence on the relationship between marginal propensities to consume and income, for revived attention on the empirical magnitude of precautionary savings, and for disentangling the role of fixed effects relative to persistent income risk in explaining the recent rise in income inequality.

\section{References}

Achdou, Yves, Jiequn Han, Jean-Michel Lasry, Pierre-Louis Lions, and Benjamin Moll, "Income and Wealth Distribution in Macroeconomics: A Continuous-Time Approach," Manuscript, November 2017.

\footnotetext{
${ }^{39}$ For evidence that a fall in the labor share increases income inequality, see IMF (2017).

${ }^{40}$ In principle, if the elasticity of substitution is extremely high, a markup increase can lead to a decline in capital demand so large that it overwhelms the rise in capitalized profits, resulting in an asset supply decline. Whenever this happens, however, there will also be a rise in the labor share. Hence, the conditional statement in proposition 9 holds: as long as rising markups cause a decline in the labor share, they will be expansionary.
} 
Athreya, Kartik, Andrew Owens, and Felipe Schwartzman, "Does Redistribution Increase Output? The Centrality of Labor Supply," Quantitative Economics, October 2017, 8 (3), 761808.

Auclert, Adrien, "Monetary Policy and the Redistribution Channel," Manuscript, May 2017.

- and Matthew Rognlie, "Aggregate Demand and the Top 1 Percent," American Economic Review Papers and Proceedings, May 2017, 107 (5), 588-592.

_ and _ , "A Note on Multipliers in NK Models with GHH Preferences," Manuscript, August 2017.

_ , - , and Ludwig Straub, “The Intertemporal Keynesian Cross," Manuscript, December 2017.

Autor, David H., David Dorn, and Gordon H. Hanson, "The China Syndrome: Local Labor Market Effects of Import Competition in the United States," American Economic Review, 2013, 103 (6), 2121-68.

Barkai, Simcha, "Declining Labor and Capital Shares," Manuscript, 2016.

Basu, Susanto and Brent Bundick, "Uncertainty Shocks in a Model of Effective Demand," Econometrica, May 2017, 85 (3), 937-958.

Bayer, Christian, Ralph Lütticke, Lien Pham-Dao, and Volker von Tjaden, "Precautionary Savings, Illiquid Assets, and the Aggregate Consequences of Shocks to Household Income Risk," Manuscript, May 2017.

Berger, David, Veronica Guerrieri, Guido Lorenzoni, and Joseph Vavra, "House Prices and Consumer Spending," Review of Economic Studies, 2018, Forthcoming.

Bernanke, Ben S., Mark Gertler, and Simon Gilchrist, “Chapter 21 - The Financial Accelerator in a Quantitative Business Cycle Framework," in John B. Taylor and Michael Woodford, eds., Handbook of Macroeconomics, Vol. 1, Part C, Elsevier, 1999, pp. 1341-1393.

Bewley, Truman, “The Permanent Income Hypothesis: A Theoretical Formulation," Journal of Economic Theory, December 1977, 16 (2), 252-292.

Blanchard, Olivier Jean and Charles M. Kahn, "The Solution of Linear Difference Models under Rational Expectations," Econometrica, July 1980, 48 (5), 1305-1311.

Blinder, Alan S., "Distribution Effects and the Aggregate Consumption Function," Journal of Political Economy, June 1975, 83 (3), 447-475.

Boar, Corina, “Dynastic Precautionary Savings," Manuscript, February 2017.

Bohn, Henning, "The Behavior of U.S. Public Debt and Deficits," Quarterly Journal of Economics, 1998, 113 (3), 949-963.

Browning, Martin and Annamaria Lusardi, "Household Saving: Micro Theories and Micro Facts," Journal of Economic Literature, December 1996, 34 (4), 1797-1855.

Card, David, Jörg Heining, and Patrick Kline, "Workplace Heterogeneity and the Rise of West German Wage Inequality," Quarterly Journal of Economics, August 2013, 128 (3), 967-1015.

Carroll, Christopher D. and Andrew A. Samwick, "The Nature of Precautionary Wealth," Journal of Monetary Economics, September 1997, 40 (1), 41-71. 
Cesarini, David, Erik Lindqvist, Matthew J. Notowidigdo, and Robert Östling, "The Effect of Wealth on Individual and Household Labor Supply: Evidence from Swedish Lotteries," American Economic Review, December 2017, 107 (12), 3917-3946.

Challe, Edouard, Julien Matheron, Xavier Ragot, and Juan F. Rubio-Ramirez, "Precautionary Saving and Aggregate Demand," Quantitative Economics, July 2017, 8 (2), 435-478.

Chetty, Raj, Adam Guren, Day Manoli, and Andrea Weber, "Are Micro and Macro Labor Supply Elasticities Consistent? A Review of Evidence on the Intensive and Extensive Margins," American Economic Review Papers and Proceedings, 2011, 101 (3), 471-75.

Coibion, Olivier, Yuriy Gorodnichenko, and Johannes Wieland, "The Optimal Inflation Rate in New Keynesian Models: Should Central Banks Raise Their Inflation Targets in Light of the Zero Lower Bound?," Review of Economic Studies, October 2012, 79 (4), 1371-1406.

_ , - , Lorenz Kueng, and John Silvia, "Innocent Bystanders? Monetary Policy and Inequality," Journal of Monetary Economics, June 2017, 88, 70-89.

Congressional Budget Office, The Distribution of Household Income and Federal Taxes in 2006 November 2013.

Council Of Economic Advisers, Economic Report of the President, Washington, D.C.: U.S. Government Printing Office, 2012.

de Loecker, Jan and Jan Eeckhout, "The Rise of Market Power and the Macroeconomic Implications," Working Paper 23687, National Bureau of Economic Research, August 2017.

den Haan, Wouter J., Pontus Rendahl, and Markus Riegler, "Unemployment (Fears) and Deflationary Spirals," Journal of the European Economic Association, 2018, Forthcoming.

Eggertsson, Gauti B., “What Fiscal Policy Is Effective at Zero Interest Rates?," NBER Macroeconomics Annual, January 2011, 25 (1), 59-112.

_, Neil R. Mehrotra, and Jacob A. Robbins, "A Model of Secular Stagnation: Theory and Quantitative Evaluation," Working Paper 23093, National Bureau of Economic Research January 2017.

Fagereng, Andreas, Martib B. Holm, and Gisle J. Natvik, "MPC Heterogeneity and Household Balance Sheets," Working Paper 2861053, SSRN, October 2016.

Favilukis, Jack, "Inequality, Stock Market Participation, and the Equity Premium," Journal of Financial Economics, March 2013, 107 (3), 740-759.

Feenstra, Robert C. and Gordon H. Hanson, "The Impact of Outsourcing and HighTechnology Capital on Wages: Estimates for the United States, 1979-1990," Quarterly Journal of Economics, 1999, 114 (3), 907-940.

Francese, Maura and Carlos Mulas-Granados, "Functional Income Distribution and Its Role in Explaining Inequality," IMF Working Paper no 15/244, November 2015.

Galí, Jordi and Roberto Perotti, "Fiscal Policy and Monetary Integration in Europe," Economic Policy, October 2003, 18 (37), 533-572. 
Garicano, Luis and Esteban Rossi-Hansberg, "Inequality and the Organization of Knowledge," American Economic Review, 2004, 94 (2), 197-202.

Gilchrist, Simon and Charles P. Himmelberg, "Evidence on the Role of Cash Flow for Investment," Journal of Monetary Economics, December 1995, 36 (3), 541-572.

Gornemann, Nils, Keith Kuester, and Makoto Nakajima, "Doves for the Rich, Hawks for the Poor? Distributional Consequences of Monetary Policy," Manuscript, Federal Reserve Board, University of Bonn, and Philadelphia Fed, March 2014.

Gottschalk, Peter and Robert Moffitt, "The Growth of Earnings Instability in the U.S. Labor Market," Brookings Papers on Economic Activity, January 1994, 1994 (2), 217-272.

Greenwood, Jeremy, Zvi Hercowitz, and Gregory W. Huffman, "Investment, Capacity Utilization, and the Real Business Cycle," American Economic Review, June 1988, 78 (3), 402-417.

Guerrieri, Veronica and Guido Lorenzoni, "Credit Crises, Precautionary Savings, and the Liquidity Trap," Quarterly Journal of Economics, August 2017, 132 (3), 1427-1467.

Guvenen, Fatih, Sam Schulhofer-Wohl, Jae Song, and Motohiro Yogo, "Worker Betas: Five Facts about Systematic Earnings Risk," American Economic Review Papers and Proceedings, May 2017, 107 (5), 398-403.

_ , Serdar Ozkan, and Jae Song, “The Nature of Countercyclical Income Risk," Journal of Political Economy, June 2014, 122 (3), 621-660.

Heathcote, Jonathan and Fabrizio Perri, "Wealth and Volatility," Review of Economic Studies, 2018, Forthcoming.

_ , Kjetil Storesletten, and Giovanni L. Violante, "The Macroeconomic Implications of Rising Wage Inequality in the United States," Journal of Political Economy, August 2010, 118 (4), 681722.

Iacoviello, Matteo, "Household Debt and Income Inequality, 1963-2003," Journal of Money, Credit and Banking, August 2008, 40 (5), 929-965.

IMF, "Chapter 3: Understanding the Downward Trend in Labor Income Shares," in "World Economic Outlook," Washington, D.C.: International Monetary Fund, April 2017.

Jappelli, Tullio and Luigi Pistaferri, "Fiscal Policy and MPC Heterogeneity," American Economic Journal: Macroeconomics, October 2014, 6 (4), 107-136.

Kaldor, Nicholas, "Alternative Theories of Distribution," Review of Economic Studies, January 1955, 23 (2), 83-100.

Kaplan, Greg, Benjamin Moll, and Gianluca Violante, "Monetary Policy According to HANK," Manuscript, January 2016.

Katz, Lawrence F. and Kevin M. Murphy, “Changes in Relative Wages, 1963-1987: Supply and Demand Factors," Quarterly Journal of Economics, February 1992, 107 (1), 35-78.

Kaymak, Barış and Markus Poschke, "The Evolution of Wealth Inequality Over Half a Century: The Role of Taxes, Transfers and Technology," Journal of Monetary Economics, February 2016, 77, 1-25. 
Keynes, John Maynard, The General Theory of Employment, Interest, and Money, London: Macmillan, 1936.

Kopczuk, Wojciech, Emmanuel Saez, and Jae Song, "Earnings Inequality and Mobility in the United States: Evidence from Social Security Data Since 1937," Quarterly Journal of Economics, February 2010, 125 (1), 91-128.

Kreamer, Jonathan, "Household Debt, Unemployment, and Slow Recoveries," Manuscript, January 2016.

Krugman, Paul, “Robber Baron Recessions," The New York Times, April 2016.

Kumhof, Michael, Romain Rancière, and Pablo Winant, "Inequality, Leverage, and Crises," American Economic Review, March 2015, 105 (3), 1217-1245.

Laubach, Thomas and John C. Williams, "Measuring the Natural Rate of Interest Redux," Federal Reserve Bank of San Francisco Working Paper Series, October 2015, 16.

Leeper, Eric M., “Equilibria Under 'Active' and 'Passive' Monetary and Fiscal Policies," Journal of Monetary Economics, February 1991, 27 (1), 129-147.

McKay, Alisdair and Ricardo Reis, "The Role of Automatic Stabilizers in the U.S. Business Cycle," Econometrica, January 2016, 84 (1), 141-194.

_ , Emi Nakamura, and Jón Steinsson, "The Power of Forward Guidance Revisited," American Economic Review, October 2016, 106 (10), 3133-3158.

Nardi, Mariacristina De and Giulio Fella, "Saving and Wealth Inequality," CEPR Discussion Paper No 11746, January 2017.

Parker, Jonathan A. and Nicholas S. Souleles, "Reported Preference vs. Revealed Preference: Evidence from the Propensity to Spend Tax Rebates," Working Paper 23920, National Bureau of Economic Research, October 2017.

Philippon, Thomas, "Has the US Finance Industry Become Less Efficient? On the Theory and Measurement of Financial Intermediation," American Economic Review, April 2015, 105 (4), 1408-1438.

Pigou, Arthur C., The Economics of Welfare, Palgrave Macmillan, 1920.

Piketty, Thomas and Emmanuel Saez, "Income Inequality in the United States, 1913-1998," Quarterly Journal of Economics, February 2003, 118 (1), 1-41.

Quadrini, Vincenzo and José-Victor Rios-Rull, "Understanding the US Distribution of Wealth," Federal Reserve Bank of Minneapolis Quarterly Review, 1997, 21 (2), 22-36.

Ravn, Morten O. and Vincent Sterk, "Job Uncertainty and Deep Recessions," Journal of Monetary Economics, October 2017, 90 (Supplement C), 125-141.

Reiter, Michael, "Solving Heterogeneous-Agent Models by Projection and Perturbation," Journal of Economic Dynamics and Control, March 2009, 33 (3), 649-665.

Rognlie, Matthew, "Deciphering the Fall and Rise in the Net Capital Share," Brookings Papers on Economic Activity, 2015, 2015 (2), forthcoming. 
_, "What Lower Bound? Monetary Policy with Negative Interest Rates," Manuscript, MIT, 2015.

Rosen, Sherwin, "The Economics of Superstars," American Economic Review, December 1981, $71(5), 845-858$.

Schmitt-Grohé, Stephanie and Martín Uribe, “Downward Nominal Wage Rigidity, Currency Pegs, and Involuntary Unemployment," Journal of Political Economy, August 2016, 124 (5), 1466-1514.

Song, Jae, David J. Price, Fatih Guvenen, Nicholas Bloom, and Till von Wachter, "Firming Up Inequality," Manuscript, June 2016.

Storesletten, Kjetil, Chris I. Telmer, and Amir Yaron, "Cyclical Dynamics in Idiosyncratic Labor Market Risk," Journal of Political Economy, June 2004, 112 (3), 695-717.

Straub, Ludwig, "Consumption, Savings, and the Distribution of Permanent Income," Manuscript, November 2017.

Summers, Lawrence H., "Demand Side Secular Stagnation," American Economic Review, May 2015, 105 (5), 60-65.

Teschl, Gerald, Topics in Real and Functional Analysis Graduate Studies in Mathematics, Providence, Rhode Island: American Mathematical Society, 2018.

Werning, Iván, "Managing a Liquidity Trap: Monetary and Fiscal Policy," Manuscript, April 2012.

_ , "Incomplete Markets and Aggregate Demand," Working Paper 21448, National Bureau of Economic Research, August 2015. 


\section{Appendix for Inequality and Aggregate Demand}

\section{A Model details and summary of equations}

\section{A.1 The firm problem}

Extended model. We start by considering the extended model in section 6, and will obtain results for the baseline model of the production sector for sections $2-5$ as a special case.

Let $J_{t-1}\left(K_{t-1}^{j}\right)$ be the value of firm $j$ with capital $K_{t-1}^{j}$ at the end of period $t-1$. The firm problem is defined recursively as follows:

$$
\begin{aligned}
\left(1+r_{t-1}\right) J_{t-1}\left(K_{t-1}^{j}\right)= & \max _{K_{t}^{j}, L_{t}^{j}, P_{t}^{j}} \frac{P_{t}^{j}}{P_{t}} F\left(K_{t-1}^{j}, L_{t}^{j}\right)-\frac{W_{t}}{P_{t}} L_{t}^{j} \\
& \quad-X_{t}\left(K_{t}^{j}-(1-\delta) K_{t-1}^{j}+\frac{1}{2 \delta \epsilon_{I}}\left(\frac{K_{t}^{j}-K_{t-1}^{j}}{K_{t-1}^{j}}\right)^{2} K_{t-1}^{j}\right)+J_{t}\left(K_{t}^{j}\right) \\
& \text { s.t. } \frac{P_{t}^{j}}{P_{t}}=\left(\frac{F\left(K_{t-1}^{j}, L_{t}^{j}\right)}{Y_{t}}\right)^{\frac{1}{\mu_{t}}-1}
\end{aligned}
$$

where $P_{t}^{j}$ is the firm's sales price and the constraint gives the demand induced by the CES final goods aggregator.

Taking the first-order condition with respect to $K_{t}^{j}$ in (35), we obtain

$$
\frac{1}{\delta \epsilon_{I}}\left(\frac{K_{t}^{j}-K_{t-1}^{j}}{K_{t-1}^{j}}\right)=\frac{1}{X_{t}} J_{t}^{\prime}\left(K_{t}^{j}\right)-1 \equiv q_{t}^{j}-1
$$

where we define $q_{t}^{j} \equiv \frac{1}{X_{t}} J_{t}^{\prime}\left(K_{t}^{j}\right)$ as the marginal value of capital normalized by price. Using the fact that firms are symmetric, and that therefore they will make identical choices (and have identical trajectories) if they start identical, we can replace $K_{t}^{j}$ and $K_{t-1}^{j}$ with $K_{t}$ and $K_{t-1}$, and conclude that $q_{t}^{j}$ has a common value of $q_{t}$ for all firms $j$ :

$$
\frac{1}{\delta \epsilon_{I}}\left(\frac{K_{t}-K_{t-1}}{K_{t-1}}\right)=q_{t}-1
$$

Now, going back to (35), rewrite the choice variable $K_{t}^{j}$ as capital growth $k_{t} \equiv K_{t}^{j} / K_{t-1}^{j}$ and substitute in the demand constraint to obtain

$$
\begin{aligned}
\left(1+r_{t-1}\right) J_{t-1}\left(K_{t-1}^{j}\right)=\max _{k_{t}, L_{t}^{j}, P_{t}^{j}} F\left(K_{t-1}^{j}, L_{t}^{j}\right)^{\frac{1}{\mu_{t}}} Y_{t}^{1-\frac{1}{\mu_{t}}}-\frac{W_{t}}{P_{t}} L_{t}^{j} \\
\quad-X_{t} K_{t-1}^{j}\left(\left(k_{t}-(1-\delta)\right)+\frac{1}{2 \delta \epsilon_{I}}\left(k_{t}-1\right)^{2}\right)+J_{t}\left(k_{t} K_{t-1}^{j}\right)
\end{aligned}
$$


Taking the envelope condition with respect to $K_{t-1}^{j}$, we obtain

$$
\begin{aligned}
\left(1+r_{t-1}\right) J_{t-1}^{\prime}\left(K_{t-1}^{j}\right)=\frac{1}{\mu_{t}} F_{K}\left(K_{t-1}^{j}, L_{t}^{j}\right)\left(\frac{Y_{t}}{F\left(K_{t-1}^{j}, L_{t}^{j}\right)}\right)^{1-\frac{1}{\mu_{t}}} & \\
& \quad-X_{t}\left(\left(k_{t}-(1-\delta)\right)+\frac{1}{2 \delta \epsilon_{I}}\left(k_{t}-1\right)^{2}\right)+k_{t} J_{t}^{\prime}\left(k_{t} K_{t-1}^{j}\right)
\end{aligned}
$$

Again using symmetry and the definition of $q_{t}$, we can rewrite this in terms of aggregates as

$$
\begin{aligned}
\left(1+r_{t-1}\right) X_{t-1} q_{t-1}=\frac{1}{\mu_{t}} F_{K}\left(K_{t-1}, L_{t}\right) & \\
& -X_{t}\left(\frac{K_{t}}{K_{t-1}}-(1-\delta)+\frac{1}{2 \delta \epsilon_{I}}\left(\frac{K_{t}-K_{t-1}}{K_{t-1}}\right)^{2}\right)+X_{t} \frac{K_{t}}{K_{t-1}} q_{t}
\end{aligned}
$$

Finally, taking the first-order condition for $L_{t}^{j}$ in (38) and using symmetry to write in terms of aggregates, we have simply

$$
\frac{1}{\mu_{t}} F_{L}\left(K_{t-1}, L_{t}\right)=\frac{W_{t}}{P_{t}}
$$

Together, equations (37), (39), and (40) characterize the solution to the firm's problem.

Total firm value. Defining $p_{t}=J_{t}\left(K_{t}\right)$ to be the aggregate value of firm shares, and rewriting (38) in aggregates, we get

$$
\left(1+r_{t-1}\right) p_{t-1}=F\left(K_{t-1}, L_{t}\right)-\frac{W_{t}}{P_{t}} L_{t}-X_{t}\left(K_{t}-(1-\delta) K_{t-1}+\frac{1}{2 \delta \epsilon_{I}}\left(\frac{K_{t}-K_{t-1}}{K_{t-1}}\right)^{2} K_{t-1}\right)+p_{t}
$$

Multiplying (39) by $K_{t-1}$ and subtracting from (41), we get

$$
\left(1+r_{t-1}\right)\left(p_{t-1}-X_{t-1} q_{t-1} K_{t-1}\right)=F\left(K_{t-1}, L_{t}\right)-\frac{1}{\mu} F_{K}\left(K_{t-1}, L_{t}\right) K_{t-1}-\frac{W_{t}}{P_{t}} L_{t}+p_{t}-X_{t} q_{t} K_{t}
$$

Using (40) and the first-order homogeneity of $F$, we have $\frac{1}{\mu_{t}} F_{K}\left(K_{t-1}, L_{t}\right) K_{t-1}+\frac{W_{t}}{P_{t}} L_{t}=\frac{1}{\mu_{t}} F\left(K_{t-1}, L_{t}\right)$, and (42) becomes simply

$$
\left(1+r_{t-1}\right)\left(p_{t-1}-X_{t-1} q_{t-1} K_{t-1}\right)=\left(1-\frac{1}{\mu_{t}}\right) F\left(K_{t-1}, L_{t}\right)+\left(p_{t}-X_{t} q_{t} K_{t}\right)
$$

Defining $\Pi_{t} \equiv p_{t}-X_{t} q_{t} K_{t}$, this is a recursion in $\Pi_{t}$

$$
\left(1+r_{t-1}\right) \Pi_{t-1}=\left(1-\frac{1}{\mu_{t}}\right) Y_{t}+\Pi_{t}
$$

and $\Pi_{t}$ is clearly just the present discounted value of flow monopolistic profits $\left(1-\frac{1}{\mu_{t}}\right) Y_{t}$. 
Putting it all together, we can express the price $p_{t}$ of firm shares as

$$
p_{t}=\Pi_{t}+X_{t} q_{t} K_{t}
$$

where $\Pi_{t}$ is the capitalized value of profits given by (43), and $q_{t}$ is the price in investment goods of installed capital given by (39).

Steady-state share value. In steady state, contant $K$ implies from (37) that $q=1$. Further, solving (43), we get $\Pi=\frac{\left(1-\frac{1}{\mu}\right) Y}{r}$. Hence the value of shares is

$$
p=\frac{\left(1-\frac{1}{\mu}\right) Y}{r}+X K
$$

Baseline model. In the baseline model prior to section 6, we have $X_{t}=1$, and production is competitive rather than monopolistic. The representative firm's problem in the competitive case, however, is exactly the same as the monopolist's problem (35) if we substitute in $\mu_{t}=1$, because then the firm can sell an unlimited quantity at the market price $P_{t}$.

We can therefore apply all results above to the baseline model, simply by substituting $X_{t}=1$ and $\mu_{t}=1$ everywhere. With $q_{t}=J_{t-1}^{\prime}\left(K_{t-1}\right)$, (37) is unchanged

$$
\frac{1}{\delta \epsilon_{I}}\left(\frac{K_{t}-K_{t-1}}{K_{t-1}}\right)=q_{t}-1
$$

(39) becomes

$$
\left(1+r_{t-1}\right) q_{t-1}=F_{K}\left(K_{t-1}, L_{t}\right)-\left(\frac{K_{t}}{K_{t-1}}-(1-\delta)+\frac{1}{2 \delta \epsilon_{I}}\left(\frac{K_{t}-K_{t-1}}{K_{t-1}}\right)^{2}\right)+\frac{K_{t}}{K_{t-1}} q_{t}
$$

and (40) becomes

$$
F_{L}\left(K_{t-1}, L_{t}\right)=\frac{W_{t}}{P_{t}}
$$

Capitalized profits are $\Pi_{t}=0$, and the value of firm shares is just

$$
p_{t}=q_{t} K_{t}
$$

which reduces to simply

$$
p=K
$$

in steady state.

Drivers of investment in the baseline model. Linearizing $\left(39^{\prime}\right)$ around the steady state, we have

$$
(1+r) d q_{t-1}+d r_{t-1}=d M P K_{t}+d q_{t}
$$

where $d M P K_{t} \equiv d F_{K}\left(K_{t-1}, L_{t}\right)$. 
Rewriting $d q_{t}$ as a forward-looking average given (46), we obtain

$$
d q_{t}=\sum_{s=0}^{\infty}\left(\frac{1}{1+r}\right)^{s+1}\left\{d M P K_{t+s+1}-d r_{t+s}\right\}
$$

Finally, using (37) combined with the observation that, in steady state, $I=\delta K$, this becomes

$$
d I_{t}^{n e t}=\epsilon_{I} I \sum_{s=0}^{\infty}\left(\frac{1}{1+r}\right)^{s+1}\left\{d M P K_{t+s+1}-d r_{t+s}\right\}
$$

which is the expression (22) used in the analysis of section 3.2.

\section{A.2 The household problem}

Households maximize $\mathbb{E}\left[\sum \beta^{t} u\left(c_{i t}\right)\right]$, where $u$ is a common period utility function and $\beta$ a common discount factor, subject to the sequence of period budget constraints

$$
\begin{aligned}
c_{i t}+b_{i t}+p_{t} v_{i t} & =y_{t}\left(s_{i t}\right)+\left(1+r_{t-1}\right) b_{i t-1}+\left(p_{t}+d_{t}\right) v_{i t-1} \\
b_{i t}+p_{t} v_{i t} & \geq 0
\end{aligned}
$$

where the combined state $s_{i t} \equiv\left(\omega_{i}, \sigma_{i t}\right)$ consists of a fixed effect $\omega_{i}$, distributed with masses $\rho\left(\omega_{i}\right)$, and an idiosyncratic state $\sigma_{i t}$ that follows an independent Markov process for each household $i$, with the Markov transition matrix $\Lambda\left(\omega_{i}\right)$ possibly depending on the household fixed effect.

Simplification. As discussed briefly in section 2, perfect foresight implies that unless there is an unanticipated shock at $t+1$, the return on bonds and shares is equal:

$$
1+r_{t}=\frac{p_{t+1}+d_{t+1}}{p_{t}}
$$

Wherever perfect foresight holds, therefore, we may define the consolidated asset position

$$
a_{i t} \equiv b_{i t}+p_{t} v_{i t}
$$

and simplify the household budget constraint (2) using (47) to be

$$
\begin{aligned}
c_{i t}+a_{i t} & =y_{t}\left(s_{i t}\right)+\left(1+r_{t-1}\right) a_{i t-1} \\
a_{i t} & \geq 0
\end{aligned}
$$

The household's problem otherwise remains identical: it merely faces the budget constraint (49) rather than (2).

Partial equilibrium. We first consider the partial equilibrium determination of aggregate consumption and savings, building from the individual decision problem. 
Definition 10 (Household's simplified partial equilibrium decision problem). The household maximizes utility $\mathbb{E}\left[\sum \beta^{t} u\left(c_{i t}\right)\right]$ subject to the budget constraints

$$
\begin{aligned}
c_{i t}+a_{i t} & =y_{t}\left(s_{i t}\right)+\left(1+r_{t-1}\right) a_{i t-1} \\
a_{i t} & \geq 0
\end{aligned}
$$

given initial state $\left(s_{i 0}, a_{i,-1}\right)$, and taking paths $\left\{y_{t}(s)\right\}$ and $\left\{r_{t}\right\}$ for the mapping of $s$ to income and the real interest rate as exogenous.

The solution to the simplified decision problem consists of recursive policy functions $c_{t}(s, a)$ and $a_{t}^{\prime}(s, a)$ for consumption $c_{t}$ and assets $a_{t}$ as a function of $\left(s_{t}, a_{t-1}\right)$. By construction, these policy functions only depend on $\left\{y_{u}(s)\right\}_{u \geq t}$ and $\left\{r_{u}\right\}_{u \geq t-1}$.

Consider now aggregation. Starting with an initial distribution ${ }^{41} \Psi_{-1}$ over households $\left(s_{0}, a_{-1}\right)$, applying the policy functions $a_{t}^{\prime}(s, a)$ at each $t$ leads to a series of distributions $\left\{\Psi_{t}\right\}$, recursively given by

$$
\Psi_{t}\left(s^{\prime}, a^{\prime}\right)=\sum_{s} \pi\left(s^{\prime} \mid s\right) \Psi_{t-1}\left(s, a_{t}^{\prime-1}\left(s, a^{\prime}\right)\right)
$$

Each $\Psi_{t}$, by construction, depends on $\Psi_{-1}$ and the full sequences $\left\{y_{t}(s)\right\}$ and $\left\{r_{t}\right\}$ of the after-tax income process and real interest rate, through their impact on agents' policy choices $a_{t}^{\prime}(s, a)$.

With these distributions, we can find aggregate consumption $C_{t}$ and assets $A_{t}$

$$
\begin{aligned}
C_{t} & \equiv \int c_{t}(s, a) \cdot d \Psi_{t-1}(s, a) \\
A_{t} & \equiv \int a_{t}(s, a) \cdot d \Psi_{t-1}(s, a)
\end{aligned}
$$

which also depend on $\Psi_{-1},\left\{y_{t}(s)\right\}$ and $\left\{r_{t}\right\}$.

Definition 11 (Aggregate partial equilibrium). We refer to the functions $C_{t}^{P E}\left(\left\{y_{t}(s)\right\},\left\{r_{t}\right\}, \Psi_{-1}\right)$ and $A_{t}^{P E}\left(\left\{y_{t}\{s\}\right\},\left\{r_{t}\right\}, \Psi_{-1}\right)$ as aggregate partial equilibrium consumption and assets given initial distribution $\Psi_{-1}$.

At a steady state with constant $r$ and income process $\{y(s)\}$, the simplified partial equilibrium decision problem yields stationary decision rules $c_{S s}(s, a)$ and $a_{s s}^{\prime}(s, a)$. Using the latter in (50) delivers a distribution $\Psi_{s S}$ as a fixed point.

Definition 12 (Steady state partial equilibrium). We refer to the functions $C_{s s}^{P E}(\{y(s)\}, r)$ and $A_{s s}^{P E}(\{y\{s\}\}, r)$, obtained by aggregating $c_{S S}(a, s)$ and $a_{s S}^{\prime}(a, s)$ using the stationary distribution $\Psi_{s s}$, as steady state partial equilibrium consumption and assets.

Next, we examine the general equilibrium determinants of aggregate consumption and assets. There are two steps in building from the partial equilibrium: first, revaluation effects determine the initial asset positions, and second, equilibrium effects affect the household income process.

General equilibrium 1: determination of asset positions. In general equilibrium, initial assets $a_{i,-1}$ are given by bonds and shares according to

$$
a_{i,-1}=b_{i,-1}+p_{-1} v_{i,-1}
$$

\footnotetext{
${ }^{41}$ We write $\Psi_{t}(s, a)=\operatorname{Pr}\left(\left(a_{i t}, s_{i t}\right): a_{i t} \leq a\right.$ and $\left.s_{i t}=s\right)$.
} 
We are given the initial joint distribution $\widetilde{\Psi}$ over $\left(s_{0}, \tilde{a}_{i,-1}\right)$, where $\tilde{a}_{i,-1} \equiv b_{i,-1}+\tilde{p} v_{i,-1}$ is the value of assets prior to the unanticipated shock being realized. We are also given the initial amount of government bonds $B_{-1}$, which is assumed to be fixed in any of our general equilibrium experiments. To to obtain the joint distribution over $\left(s_{0}, b_{i,-1}, v_{i,-1}\right)$, we proceed in two steps. First, we back out the share price $\widetilde{p}$ that ensures market clearing before the shock, that is, $\widetilde{p}=\mathbb{E}_{\widetilde{\Psi}}[a]-B_{-1}$. Next, we assume that initially, each household $i$ holds a fraction proportional to $\theta\left(\tilde{a}_{i}\right)$ of its consolidated asset position $\tilde{a}_{i}$ in shares $\tilde{p} v_{i}$. We calibrate the function $\theta(\cdot)$ to match empirical features of household balance sheets as explained in appendix B.1. We ensure that the market for shares clears at $t=-1$ by finding the constant $\tilde{\Theta}$ that ensures ${ }^{42}$

$$
\tilde{\Theta} \int \tilde{p}^{-1} \theta\left(\tilde{a}_{i,-1}\right) \tilde{a}_{i,-1} d \widetilde{\Psi}\left(s_{0}, \tilde{a}_{i,-1}\right)=1
$$

Given $p_{-1}, B_{-1}$, and (53), this procedure delivers an updated distribution $\widehat{\Psi_{-1}}\left(p_{-1} ; B_{-1}, \widetilde{\Psi}\right)$ over $\left(s_{0}, a_{i,-1}\right)$, with

$$
a_{i,-1}=\left(1-\tilde{\Theta} \theta\left(\tilde{a}_{i,-1}\right)\right) \tilde{a}_{i,-1}+\frac{p_{-1}}{\tilde{p}} \tilde{\Theta} \theta\left(\tilde{a}_{i,-1}\right) \tilde{a}_{i,-1}
$$

General equilibrium 2: determination of post-tax income. We further develop the consumption and asset functions $C_{t}$ and $A_{t}$ by bringing in the general equilibrium determinants of the after-tax income process $\left\{y_{t}(s)\right\}$.

Pretax income is given by

$$
z_{t}\left(s_{i t}\right)=\frac{W_{t}}{P_{t}} \cdot\left(e_{t}\left(s_{i t}\right) \cdot L_{t} \cdot \gamma\left(s_{i t}, L_{t}\right)\right)
$$

where the mapping of $e_{t}(\cdot)$ of states to endowments is given by the calibration, and after-tax income is given by

$$
y_{t}\left(s_{i t}\right)=\left(1-\tau_{t}^{g}\right)\left(\tau_{t}^{r} \frac{W_{t}}{P_{t}} L_{t}+\left(1-\tau_{t}^{r}\right) z_{t}\left(s_{i t}\right)\right)
$$

Combining (4) and (16), we see that $\left\{y_{t}(s)\right\}$ is determined entirely by the exogenous initial distribution $\widetilde{\Psi}$, the exogenous paths $\left\{e_{t}(s), \tau_{t}^{r}\right\}$, the endogenous share value $p_{-1}$, and the endogenous paths $\left\{\frac{W_{t}}{P_{t}}, L_{t}, \tau_{t}^{g}\right\}$. We therefore rewrite the aggregate consumption and asset functions as

$$
\begin{aligned}
& C_{t}\left(p_{-1}, B_{-1},\left\{\frac{W_{t}}{P_{t}}, L_{t}, \tau_{t}^{g}, r_{t}\right\} ;\left\{e_{t}(s), \tau_{t}^{r}\right\}, \widetilde{\Psi}\right)=C_{t}^{P E}\left(\left\{y_{t}(s)\right\},\left\{r_{t}\right\}, \widehat{\Psi_{-1}}\left(p_{-1} ; B_{-1}, \widetilde{\Psi}\right)\right) \\
& A_{t}\left(p_{-1}, B_{-1},\left\{\frac{W_{t}}{P_{t}}, L_{t}, \tau_{t}^{g}, r_{t}\right\} ;\left\{e_{t}(s), \tau_{t}^{r}\right\}, \widetilde{\Psi}\right)=A_{t}^{P E}\left(\left\{y_{t}(s)\right\},\left\{r_{t}\right\}, \widehat{\Psi_{-1}}\left(p_{-1} ; B_{-1}, \widetilde{\Psi}\right)\right)
\end{aligned}
$$

where

$$
y_{t}(s)=\left(1-\tau_{t}^{g}\right) \frac{W_{t}}{P_{t}} L_{t}\left(\tau_{t}^{r}+\left(1-\tau_{t}^{r}\right) e_{t}(s) \gamma\left(s, L_{t}\right)\right)
$$

Let $\mathbf{x} \equiv\left(p_{-1},\left\{\frac{W_{t}}{P_{t}}, L_{t}, \tau_{t}^{g}, r_{t}\right\}_{t}\right)$ be the vector containing all the endogenous series that enter in the determination of $C_{t}$ and $A_{t}$, and let $\varphi \equiv\left(\left\{e_{t}(s)\right\}_{t},\left\{\tau_{t}^{r}\right\}_{t}\right)$ be the vector of exogenous series, which we refer to in Definition 2 as redistributive labor income shocks. Given (54) and (55), we have

\footnotetext{
${ }^{42}$ Since all our shocks start from steady state $\left(\widetilde{\Psi}=\Psi_{s s}\right)$, in practice we only need to perform this normalization once. See appendix B.1.
} 
Lemma 13. The change in the consumption and assets paths in response to any redistributive labor income shock $\varphi$ is given by

$$
\begin{aligned}
& C_{\varphi}(\mathbf{x}, \varphi, \Psi) d \varphi=C_{\mathbf{y}}^{P E}\left(\left\{y_{t}(s)\right\},\left\{r_{t}\right\}, \varphi, \Psi\right) \cdot \mathbf{y}_{\varphi} d \varphi \equiv \partial \mathbf{C} \\
& A_{\varphi}(\mathbf{x}, \varphi, \Psi) d \varphi=A_{\mathbf{y}}^{P E}\left(\left\{y_{t}(s)\right\},\left\{r_{t}\right\}, \varphi, \Psi\right) \cdot \mathbf{y}_{\varphi} d \varphi \equiv \partial \mathbf{A}
\end{aligned}
$$

where the components of $\mathbf{y}_{\varphi}$ are given by

$$
\begin{aligned}
\frac{\partial y_{t}(s)}{\partial e_{u}\left(s^{\prime}\right)} & =\left(1-\tau_{t}\right) \frac{W_{t}}{P_{t}} L_{t} \gamma\left(s, L_{t}\right) \mathbf{1}_{\left\{u=t, s=s^{\prime}\right\}} \\
\frac{\partial y_{t}(s)}{\partial \tau_{u}^{r}} & =\frac{1}{1-\tau_{t}^{r}}\left(\mathbb{E}_{s}\left[y_{t}(s)\right]-y_{t}(s)\right) \mathbf{1}_{\{u=t\}}
\end{aligned}
$$

From (6) these satisfy $\mathbb{E}_{s}\left[\partial y_{t}(s)\right]=0, \forall t, \varphi$.

Lemma 13 will prove useful in establishing the formal connection, on the one hand, between partial equilibrium $\partial C_{t}$ and the data in proposition 3 , and on the other, between partial and general equilibrium outcomes in theorem 4 .

\section{A.3 Summary of model equations}

Subject to initial capital $K_{-1}$, initial government bonds $B_{-1}$, initial nominal wages $W_{-1}$, and the initial joint household distribution $\widetilde{\Psi}(s, a)$, general equilibrium can be characterized by the following set of aggregate equations.

\section{Firms and production.}

- Aggregate production

$$
Y_{t}=F\left(K_{t-1}, L_{t}\right)
$$

- Net investment

$$
\frac{1}{\delta \epsilon_{I}}\left(\frac{K_{t}-K_{t-1}}{K_{t-1}}\right)=q_{t}-1
$$

- Value of installed capital

$$
\left(1+r_{t-1}\right) q_{t-1}=F_{K}\left(K_{t-1}, L_{t}\right)-\left(\frac{K_{t}}{K_{t-1}}-(1-\delta)+\frac{1}{2 \delta \epsilon_{I}}\left(\frac{K_{t}-K_{t-1}}{K_{t-1}}\right)^{2}\right)+\frac{K_{t}}{K_{t-1}} q_{t}
$$

- Optimal labor choice

$$
F_{L}\left(K_{t-1}, L_{t}\right)=\frac{W_{t}}{P_{t}}
$$

- Value of firm shares

$$
p_{t}=q_{t} K_{t}
$$


- Dividends

$$
d_{t}=F_{K}\left(K_{t-1}, L_{t}\right) K_{t-1}-\left(K_{t}-(1-\delta) K_{t-1}+\frac{1}{2 \delta \epsilon_{I}}\left(\frac{K_{t}-K_{t-1}}{K_{t-1}}\right)^{2} K_{t-1}\right)
$$

\section{Fiscal policy.}

- Fiscal balance: combining (12) and (15) and using $\tau_{t}^{g} \equiv \frac{\tau_{t}-\tau_{t}^{r}}{1-\tau_{t}^{r}}$, we obtain

$$
\tau_{t}^{g} \frac{W_{t}}{P_{t}} L_{t}+\bar{B}_{t}=G_{t}+\left(1+r_{t-1}\right) \bar{B}_{t-1}
$$

- Spending and deficit rules

$$
\begin{aligned}
\frac{G_{t}}{Y_{s S}} & =\frac{G_{s S}}{Y_{s S}}-\epsilon_{G L}\left(L_{t}-L_{s s}\right) \\
\frac{\bar{B}_{t}-\bar{B}_{t-1}}{Y_{S S}} & =-\epsilon_{D L}\left(L_{t}-L_{s s}\right)-\epsilon_{D B}\left(\frac{\bar{B}_{t-1}-\bar{B}_{s S}}{Y_{s S}}\right)
\end{aligned}
$$

\section{Inflation and the Fisher equation.}

- Definition of inflation

$$
1+\pi_{t+1}=\frac{P_{t+1}}{P_{t}}
$$

- Fisher equation

$$
1+r_{t}=\frac{1+i_{t}}{1+\pi_{t+1}}
$$

Monetary policy. Monetary policy can be characterized by several different policy rules: our benchmark Taylor rule constrained by the ZLB ("ZLB"), policy that ensures full employment $L_{t}=1$ always ("neoclassical"), and policy that fixes $r_{t}$ at a constant level whenever possible ("constant- $r$ ").

- ZLB policy

$$
i_{t}=\max \left(0,\left(1+r^{*}\right)\left(1+\pi^{*}\right)\left(\frac{P_{t} / P_{t-1}}{1+\pi^{*}}\right)^{\phi}-1\right)
$$

- Neoclassical policy

$$
L_{t}=1
$$

- Constant-r policy

$$
r_{t}=r^{*}
$$

\section{Downward nominal rigidity and labor market clearing.}

- Nominal wage rigidity

$$
W_{t} \geq \kappa W_{t-1}
$$


- Labor market clearing with possible slack

$$
L_{t} \leq 1
$$

- Complementary slackness

$$
\left(W_{t}-\kappa W_{t-1}\right)\left(L_{t}-1\right)=0
$$

Household behavior. As described in the previous section, household behavior implies

- Consumption demand

$$
C_{t}=C_{t}\left(p_{-1}, B_{-1},\left\{\frac{W_{t}}{P_{t}}, L_{t}, \tau_{t}^{g}\right\} ;\left\{e_{t}(s), \tau_{t}^{r}\right\}, \widetilde{\Psi}\right)
$$

- Asset demand

$$
A_{t}=A_{t}\left(p_{-1}, B_{-1},\left\{\frac{W_{t}}{P_{t}}, L_{t}, \tau_{t}^{g}\right\} ;\left\{e_{t}(s), \tau_{t}^{r}\right\}, \widetilde{\Psi}\right)
$$

Market clearing. It suffices to enforce either one of

- Goods market clearing

$$
C_{t}+K_{t}-(1-\delta) K_{t-1}+\frac{1}{2 \delta \epsilon_{I}}\left(\frac{K_{t}-K_{t-1}}{K_{t-1}}\right)^{2} K_{t-1}+G_{t}=Y_{t}
$$

- Asset market clearing

$$
A_{t}=B_{t}+p_{t}
$$

either of which implies the other.

\section{B Calibration details}

\section{B.1 Main calibration sources}

Our 10 year TIPS yield data comes from FRED (series code DFII10). A simple average of daily values over all days in 2013 delivers $0.07 \%$, leading us to our choice of $r=0 \%$.

Our unemployment data is also from FRED (series code UNRATE). An average over monthly values in 2013 delivers $7.4 \%$. The long-term natural rate of unemployment as given by the $\mathrm{CBO}$ has series code UNRO in FRED. Its 2013 average was 5\%. This leads us to steady-state employment gap estimate of $L_{s S}=\frac{1-0.074}{1-0.05}=0.975$.

We obtain the overall depreciation rate $\delta$ by dividing the total consumption of fixed capital from the Integrated Macoeconomic Accounts by the total capital stock. From the June 2016 release of the Flow of Funds accounts, ${ }^{43}$ we obtain the consumption of fixed capital by adding up lines 2 from tables S.3.a (households), S.4.a (nonfinancial noncorporate business), S.5.a (nonfinancial corportate businesss) and S.6.a (financial business). This delivers $\delta K=\$ 2.1 \mathrm{trn}$. The corresponding capital stock $K$ is made of the

${ }^{43}$ Source: https://www.federalreserve.gov/releases/z1/20160609/z1.pdf 
value of household real estate (line 98), and nonfinancial assets from the other three sectors (lines 79, 98, and 100 of their respective tables). This yields $K=\$ 53$ trn, delivering an implied $\delta=4 \%$.

We obtain our steady-state value for $\frac{G}{Y}$ by dividing government consumption expenditures and gross investment in the NIPA (table 1.1.5, line 22) by the headline gross domestic product measure (table 1.1.5, line 1). This delivers $\frac{G}{Y}=\frac{\$ 3.11 \text { trn }}{\$ 16.7 \operatorname{trn}}=18.7 \%$.

We obtain our steady-state value for $\frac{B}{Y}$ by adding up the flow of funds value of marketable Treasury and state and local government securities (table L.210, line 2 and table L.212, line 1) and subtracting the value of treasury securities held by state and local governments and by the rest of the world (table 210, lines 20 and 53). This delivers $\frac{B}{Y}=\frac{\$ 9.25 \mathrm{trn}}{\$ 16.6 \mathrm{trn}}=55.4 \%$.

To obtain the value of the wealth-to-GDP ratio, we use household wealth data from the Flow of Funds (table B.101). We sum the value of real estate (line 4), consumer durables (line 8), deposits (line 10), debt securities (line 15), corporate equities (line 25), mutual fund shares (line 26), and proprietors equity in noncorporate business (line 29). For pension plans, we only include private and public defined contribution plans (table L.117, line 26), since defined benefit pension plans are completely illiquid. ${ }^{44}$ We then subtract the value of household mortgage debt (line 34) and consumer credit (line 35). This delivers $\frac{A}{Y}=\frac{\$ 60.5 \operatorname{trn}}{\$ 16.7 \operatorname{trn}}=363 \%$. We finally compute residually a capital-to-GDP ratio of $\frac{K}{Y}=\frac{A}{Y}-\frac{B}{Y}=$ $3.63-0.554=307 \%$. Note that this is close to the value of $321 \%$ implied by the summing sectoral capital stocks directly, illustrating the consistency of these two approaches to measuring the capitaloutput ratio.

Individual bond and equity holdings. We calibrate our portfolio shares $\theta(a)$ by using data from the the 2013 Survey of Consumer Finances (SCF). ${ }^{45}$ Aggregating up total household net worth $a_{i}$ (financial and nonfinancial assets net of total debt, fin+nf in-debt) using the sample weights delivers aggregate net worth of $\$ 64.7 \mathrm{trn}$, or a net-worth-to GDP ratio of $382 \%$, which is again close to our calibration of $\frac{A}{Y}$ from the flow of funds data.

There are multiple ways to divide individual household net worth $a_{i}$ into the notions of individual share holdings $p_{i} v_{i}$ and bond holdings $b_{i}$ in our model, which depend on our interpretation of the data. We consider three alternatives. A first alternative does not use the SCF data at all and assumes that all households have the same fraction of shares in total net worth. We label this the uniform portfolio allocation, $\theta^{u}(a)=\frac{K}{A}$. A second alternative takes a broad interpretation of shares as including any wealth that is not in the form of deposits or bonds directly held. For each household $i$, we sum all assets held in transactions accounts (liq), savings bonds (savbnd), bonds held directly (bond), and IRA accounts (irakh) and label these as liquid assets $b_{i}$. The remainer of net worth, $a_{i}-b_{i}$, then consistutes household $i$ 's share holdings $p_{i} v_{i}$. Our third definition takes a narrow definition of equity, in which we include only the total value of directly-held equity and equity held through mutual funds (deq), as well as closely held businesses (bus).

More precisely, we consider the set of households with at least $\$ 100$ in net worth and group them by centiles $i=1 \ldots 100$ of net worth. We then compute total capital holdings $p_{i} v_{i}$ and total net worth $a_{i}$ in each bin $i$ under both definitions of $p_{i} v_{i}$, and fit a smooth curve $f$ through the relationship between $\frac{p_{i} v_{i}}{a_{i}}$ and $\log a_{i}$. This allows us to back out $\hat{\theta}^{b}(a)=f^{b}\left(e^{a}\right)$ and $\hat{\theta}^{n}(a)=f^{n}\left(e^{a}\right)$. These two distributions, together with the underlying centile values, are plotted in figure B.1. These curves are passed on to our model, which rescales them by a factor common to all households, $\theta^{b}(a)=\Theta^{b} \hat{\theta}^{b}(a)$ and $\theta^{n}(a)=$

\footnotetext{
${ }^{44}$ Defined benefit pensions are also not recorded in the Survey of Consumer Finances, which we use to back out household portfolios.

${ }^{45}$ Source: https ://www.federalreserve.gov/econres/scf_2013.htm.
} 


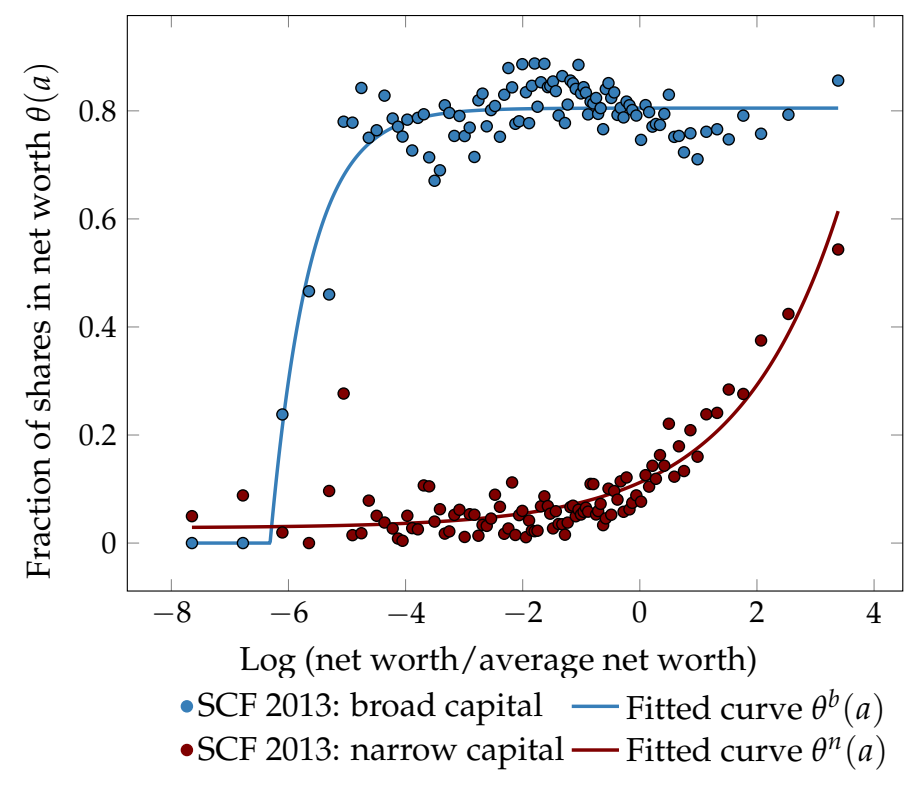

Figure B.1: Individual holdings of equity in the SCF

$\Theta^{n} \hat{\theta}^{n}(a)$ so that the average portfolio share, evaluated at the stationary distribution of household assets, is equal to our calibrated value of $\frac{K}{A} .46$ The implied values are $\Theta^{b}=0.94$ and $\Theta^{n}=3.35$.

Our narrow capital measure reveals a well-known pattern: the share of wealth invested in stocks rises quickly with wealth. Once those positions are scaled up by $\Theta^{n}$, the richest individuals in the economy own levered equity claims. We verify that $b_{i t}+p_{t} v_{i t} \geq 0$ in all our simulations, so that we do not have to deal with cases of bankruptcy.

Inequality data. Our inequality data comes from Song et al. (2016). ${ }^{47}$ Our main inequality measure is the standard deviation of log earnings, which is the square root of their variance series for the earnings of individuals in firms with more than 20 employees (their figure 2(a), top line).

Income process. Our income process is from Kaplan et al. (2016), whose replication material is available online. ${ }^{48}$ We import their 33 grid points for log skills (ymarkov_grid.txt) and their $33 \times 33$ continuous time transition matrix $A$ (ymarkov_combined.txt), and decompose it into its underlying components: a 3 point Markov chain for the transitory component and an 11 point Markov chain for the persistent component of earnings risk. Since their continuous-time matrix is sampled at quarterly frequency, we convert it to a discrete, yearly frequency transition matrix by taking $\Pi=e^{4 A}$. The moments generated by this discrete-time earnings process are nearly identical to the moments from Guvenen et al. (2014) that they target in their income process estimation, as summarized in their table 3.

\footnotetext{
${ }^{46}$ Note that, since households are indifferent between bonds and shares, $\hat{\theta}$ has no effect on the stationary distribution of assets $\Psi(a)$. Once we have obtained the stationary distribution of assets such that $\int a d \Psi(a)=A$, we can therefore back out $\Theta^{b}$ as the solution to $\Theta^{b} \int a \hat{\theta}^{b}(a) d \Psi(a)=K$, and similarly for $\Theta^{n}$.

${ }^{47}$ Source: https://people.stanford.edu/nbloom/sites/default/files/fui_graphdata_20160928.xls.

${ }^{48}$ Source: http://www.princeton.edu/ moll/HANK_replication.zip
} 
Experiments. As described in section 2.4, our experiments scale the cross-sectional distribution of $\log$ endowments to achieve a target path for sd $\left(\log e_{i t}\right)$. All of our grids (for the transitory component, the persistent component, and the fixed effect component of earnings) are symmetric around 0 in logs. In all of our experiments, we hold the transition matrix $\Pi$ fixed, spread out points on the grids for $\log e_{i t}$ around their common mean of 0 so as to achieve our target for the standard deviation of $\operatorname{logs}$, and then rescale endowments by a level factor to ensure $\mathbb{E}\left[e_{i t}\right]=1$. Our experiments differ in the grids that we scale. In our benchmark experiment, we scale the grid for the transitory and the persistent component by a common factor, while the transitory and the persistent experiment only scale the grids of these respective components of earnings risk. Finally, in our fixed effect experiment, we discretize the distribution of $\log$ fixed effects by assuming a normal distribution with mean 0 and 20 equally spaced points, truncated at 4 standard deviations on either side. This final experiment requires us to recompute the household problem 20 times (one for each discretized level of the fixed effect) and then aggregating up.

MPC data. Since detailed data on marginal propensities to consume by income is not available for the United States, we turn to the Italian Survey of Household Income and Wealth (SHIW) used by Jappelli and Pistaferri (2014). ${ }^{49}$ Auclert (2017) shows that the correlations between marginal propensities to consume and income in that survey are consistent with correlations that come out of two U.S. data sources, but the SHIW has the benefit of providing detailed individual-level MPC information, which allows to calculate our key sufficient statistic $\operatorname{Cov}\left(M P C_{i}, d y_{i}\right)$ for the same distribution of changes in income $d y_{i}$ as that featured by our main experiment.

We merge household income information (in the rfam10 dataset) with the MPC information available in the q10e dataset. We take overall income $(y)$ as our income variable $y_{i}$. The standard deviation of $\log y$ in this dataset is $\sigma=0.688$. We pick a desired increase in this standard deviation $d \sigma=0.01$, and for each household $i$, we compute a virtual post-redistribution income measure $y_{i}^{*}$

$$
y_{i}^{*}=\mathbb{E}\left[y_{i}\right] \frac{e^{\left(1+\frac{d \sigma}{\sigma}\right) \log y_{i}}}{\mathbb{E}\left[e^{\left(1+\frac{d \sigma}{\sigma}\right) \log y_{i}}\right]}
$$

This transormation of income corresponds exactly to our main experiment in the model: note in particular that $y_{i}^{*}$ has the same mean as $y_{i}$ and the standard deviation of its $\log$ is $\sigma+d \sigma$. We finally compute $d y_{i}=y_{i}^{*}-y_{i}$ and compute $\operatorname{Cov}\left(M P C_{i}, \frac{d y_{i}}{\mathbb{E}\left[y_{i}\right]}\right) \frac{1}{d \sigma}$ which we report in table 2; we verify that this covariance is quite insentitive to our initial choice of $d \sigma$. We also similarly compute the covariance between MPCs and income, as well as the difference in income-weighted MPC between the top $10 \%$ of income earners and the bottom $90 \%$ of income earners.

\section{B.2 Incidence function}

We use three methodologies to calibrate our incidence function $\gamma$. Our benchmark parametrization uses data from Guvenen et al. (2017), henceforth GSSY.50 These authors estimate worker GDP betas by regressing the log earnings growth $\Delta y_{i, t}$ of individual $i$ in year $t$ on the interaction of log real GDP growth $\Delta y_{t}$ and twelve earnings percentile bins (10 to 90, 99, and 99.9). We use their worker betas for

\footnotetext{
${ }^{49}$ Source: http://www.bancaditalia.it/statistiche/tematiche/indagini-famiglie-imprese/ bilanci-famiglie/distribuzione-microdati/index.html

${ }^{50}$ Source: https : //fguvenendotcom.files.wordpress.com/2014/04/data_nberw231631.xlsx
} 

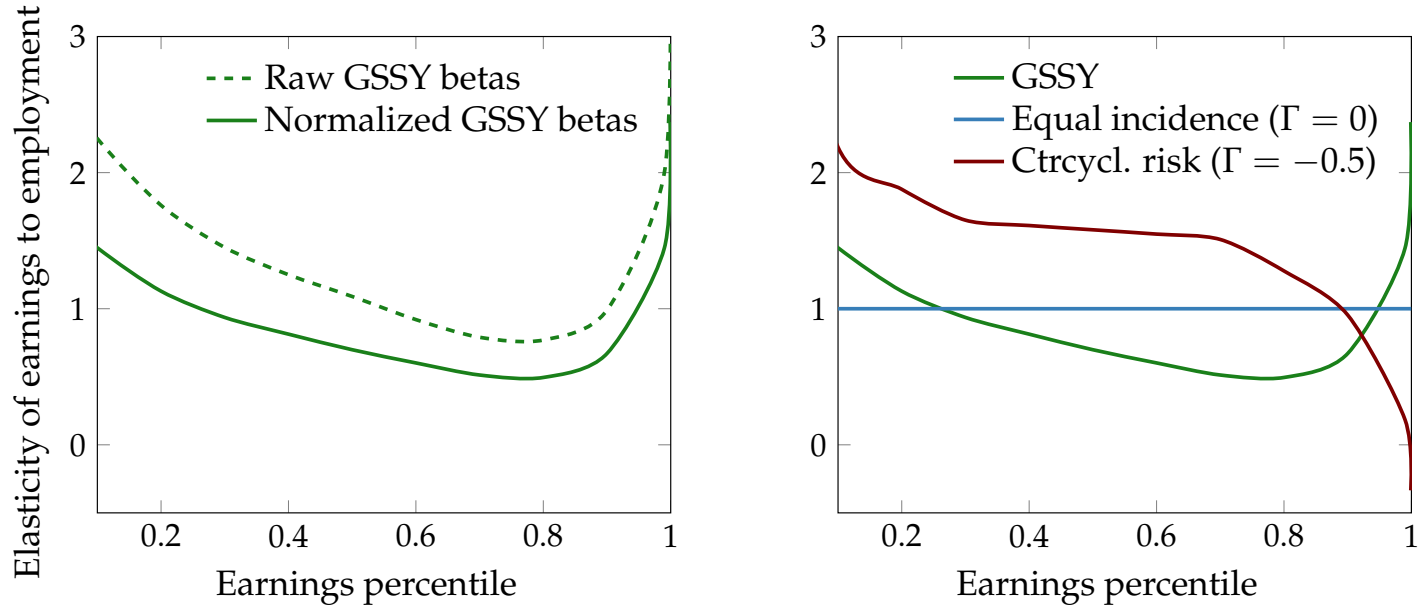

Figure B.2: $\gamma$ function calibration

males aged 36-45 (their figure 1, panel a), which is representative of the evidence for other age groups and for females. These raw betas are reproduced in the dashed line of the left panel of figure B.2. They are U-shaped in a worker's earnings level, implying that the earnings of both the poorest and the richest segments of the population vary more than proportionately with GDP, while the earnings of the middle percentiles are relatively more insulated.

We map these coefficients to our model as follows. Conceptually, the same regression ran in our model recovers $\vartheta\left(1+\frac{\gamma_{L}(s, L) L}{\gamma(s, L)}\right)$ for every $s$, the product of an Okun law coefficient $\vartheta$ by the elasticity of gross earnings $L \gamma$ with respect to $L$. We first interpolate the GSSY betas to recover the data betas for every income state $s$. We then renormalize those betas by a common fraction such that the incomeweighted beta is one, taking care of the Okun law constant $\vartheta$. This delivers the solid line in the left panel of figure B.2. We finally obtain our function $\gamma(s, L)$ by assuming that the elasticity $\frac{\gamma_{L}(s, L) L}{\gamma(s, L)}$ remains constant as $L$ increases for given $s$.

As an alternative and to examine the robustness of our results with respect to this aspect of our calibration, we consider a simple parametrization of the $\gamma$ function given by

$$
\gamma(s, L)=\frac{e(s)^{\Gamma \log L}}{\mathbb{E}\left[e^{1+\Gamma \log L}\right]}
$$

In this simple one-parameter family of functions, $\Gamma$ represents the elasticity of the standard deviation of log gross earnings (a standard measure of inequality) to employment, in other words,

$$
\operatorname{sd}\left(\log z_{i}(L)\right)=\operatorname{sd}\left(\log z_{i}(1)\right)+\Gamma \log L
$$

The case where $\Gamma=0$ corresponds to a simple constant-incidence benchmark in the gross earnings of all individuals are equally affected by changes in $L$. When $\Gamma$ is negative, recessions are times when the income distribution widens endogenously, capturing countercyclical income risk. There is some evidence that such a widening of the income distribution tends to happen in response to contractionary monetary policy shocks (e.g. Coibion, Gorodnichenko, Kueng and Silvia 2017), suggesting $\Gamma<0$ as a relevant empirical case. We pick $\Gamma=-0.5$ for illustrative purposes, and consider the consequences of 
using alternative values in section D.6.

The right panel of figure B.2 reproduces the implied elasticities of gross earnings $L \gamma(s, L)$ under these three benchmark parametrizations of the $\gamma$ function. Equal incidence corresponds to the case where this elasticity is a constant of one. Relative to the U-shaped pattern of GSSY, our $\Gamma<0$ parameterization has elasticities that monotonically decline in a worker's gross earnings percentile, so that richer individuals' earnings are systematically more insulated from employment fluctuations than poorer individuals' earnings are.

\section{B.3 Fiscal rules}

Redistributive transfer $T_{t}$. We use Congressional Budget Office (2013) to calibrate the redistributive tax rate $\tau_{t}^{r}$. Equation (16) shows that

$$
y_{i t}=\left(1-\tau_{t}^{g}\right)\left(\tau_{t}^{r} \mathbb{E}_{I}\left[z_{i t}\right]+\left(1-\tau_{t}^{r}\right) z_{i t}\right)
$$

The $\mathrm{CBO}$ report shows average market income $\mathbb{E}_{J}\left[z_{i}\right]$ and average market income plus federal transfers net of taxes $\mathbb{E}_{J}\left[y_{i}\right]$ at each quintile $J$ of the income distribution of nonelderly households in 2006, the latest year in which the data is available. Running a linear regression, we recover

$$
\frac{\mathbb{E}_{J}\left[y_{i}\right]}{\mathbb{E}\left[z_{i}\right]}=0.143+0.666 \frac{\mathbb{E}_{J}\left[z_{i}\right]}{\mathbb{E}\left[z_{i}\right]}
$$

with an $R^{2}$ of 0.99 . This delivers an implied steady-state redistributive tax rate of $\tau^{r}=\frac{0.143}{0.143+0.666}=$ $17.7 \%$.

We can also recover an estimate of $\tau^{g}=1-(0.143+0.666)=19.1 \%$. This is a little below the value of $\tau^{g}=21.4 \%$ that we derive residually from the government budget constraint. This discrepancy might in part be due to the fact that we model the income tax as the only source of government revenue.

Government spending and debt rules. We start from a slight generalization of our fiscal rules (13)-(14) that allows for responsiveness of government spending to past debt directly,

$$
\begin{aligned}
\frac{G_{t}}{Y_{s s}} & =\frac{G_{s s}}{Y_{s s}}-\epsilon_{G L}\left(L_{t}-L_{s s}\right)-\epsilon_{G B} \frac{B_{t-1}-B_{s s}}{Y_{s s}} \\
\frac{\bar{B}_{t}-B_{t-1}}{Y_{s s}} & =-\epsilon_{D L}\left(L_{t}-L_{s s}\right)-\epsilon_{D B} \frac{B_{t-1}-B_{s s}}{Y_{s s}}
\end{aligned}
$$

In the data, estimates of potential output $Y_{t}^{\text {pot }}$ are more readily available than estimates of potential employment. Noticing that our model implies that the conversion ratio between the employment gap and the output gap (the inverse of the Okun law coefficient) is around 1 at all times, ${ }^{51}$ we therefore first replace $L_{t}-L_{s s}$ by $\frac{Y_{t}-Y_{s s}}{Y_{s s}}$ in (68)-(69). Next, to deal with nominal growth, we replace $Y_{s s}$ by the trending variable $Y_{t}^{\text {pot }}$. This delivers the following estimable equations for a panel of countries $i$ observed over

\footnotetext{
${ }^{51}$ In the short-run, capital $K_{s r}$ is fixed so $\frac{d Y_{s r}}{Y_{s s}}=\alpha \times \frac{d L_{s r}}{L_{s s}}$, where $\alpha=0.872$ is our calibrated labor share. In the longrun, capital adjusts to ensure $\frac{K_{s r}}{L_{s r}}$ is in line with the value consistent with the cost of capital $r+\delta$, so $\frac{d Y_{l r}}{Y_{s s}}=1 \times \frac{d L_{l r}}{L_{s s}}$. Hence the inverse Okun law coefficient is between 1 and 1.15 .
} 


\begin{tabular}{ccccc} 
Dependent variable & \multicolumn{2}{c}{$G_{i t} / Y_{i t}^{\text {pot }}$} & \multicolumn{2}{c}{$D_{i t} / Y_{i t}^{p o t}$} \\
\hline \hline Country & Pooled & USA & Pooled & USA \\
\hline$Y_{i t} / Y_{i t}^{\text {pot }}$ & $-0.0958^{* * *}$ & -0.0828 & $-0.749^{* * *}$ & $-1.131^{* *}$ \\
& $(-3.23)$ & $(-0.84)$ & $(-13.49)$ & $(-3.14)$ \\
$\bar{B}_{i t-1} / Y_{i t}^{\text {pot }}$ & $-0.0150^{* *}$ & -0.0094 & $-0.0288^{* *}$ & -0.0126 \\
Note: Average nominal growth $\left(Y_{i t} / Y_{i t-1}-1\right)$ & $(-3.20)$ & $(-0.66)$ & $(-3.01)$ & $(-0.24)$ \\
Number of observations & & & 0.039 & 0.044 \\
\hline
\end{tabular}

Table B.1: Estimated fiscal rules

multiple periods $t$,

$$
\begin{aligned}
& \frac{G_{i t}}{Y_{i t}^{p o t}}=\gamma_{i}+\alpha_{1} \frac{Y_{i t}}{Y_{i t}^{p o t}}+\alpha_{2} \frac{B_{i t-1}}{Y_{i t}^{p o t}}+\varepsilon_{i t} \\
& \frac{D_{i t}}{Y_{i t}^{p o t}}=\kappa_{i}+\beta_{1} \frac{Y_{i t}}{Y_{i t}^{p o t}}+\beta_{2} \frac{B_{i t-1}}{Y_{i t}^{p o t}}+\eta_{i t}
\end{aligned}
$$

where $\gamma_{i}, \kappa_{i}$ are country fixed effects. These are typical of specifications considered in the fiscal rules literature (e.g. Galí and Perotti 2003). To map estimated coefficients back to our primitive elasticities, note that nominal growth mechanically pushes up countries' deficit-to-GDP ratio-an effect that we would like to correct for in our structural estimates of government fiscal adjustment. Specifically, if countries target a constant $\frac{B_{t-1}}{Y_{t}}=b$, then the deficit-GDP ratio will be $\frac{B_{t}-B_{t-1}}{Y_{t}}=\frac{Y_{t+1}}{Y_{t}} b-b=g \frac{B_{t-1}}{Y_{t}}$, where $g=\frac{Y_{t+1}}{Y_{t}}$ is nominal GDP growth, suggesting an upward-bias of $g$ in our estimate of $\beta_{2}$ in (71). Given average nominal growth of $g$, the estimated coefficients in (70)-(71) therefore relate to our primitive elasticities in (68)-(69) through $\epsilon_{G L}=-\alpha_{1}, \epsilon_{G B}=-\alpha_{2}, \epsilon_{D L}=-\beta_{1}$ and $\epsilon_{D B}=-\beta_{2}+g$.

To run these regressions, we use data for 16 OECD countries over the period 1995 - 2015 from the June 2017 OECD economic outlook. ${ }^{52}$ Our source variable for $D_{t}$ is (the opposite of) government net lending. For $\bar{B}_{t}$ we use general government gross financial liabilities, for $G_{t}$ we use nominal government final consumption expenditure, for $Y_{t}$ we usenominal GDP, and finally for $Y_{t}^{\text {pot }}$ we use nominal potential output in year $t$.

Table B.1 presents the results. Our estimated coefficients on the output gap are negative everyhwere, and much more negative for deficits $D_{i t}$ than for spending $G_{i t}$. This is consistent with governments running countercyclical policy, with deficits being the main adjustment tool. Our esimated coefficients on lagged debt are also negative, consistent with government actively stabilizing debt. The estimates for $\beta_{1}$ are close to zero, however, justifying our setting $\epsilon_{G B}=0$ for our main fiscal rule specification. Moreover, after adjustment for average nominal growth, the estimates for $\beta_{2}$ imply $\epsilon_{D B} \simeq 0.07$, implying a half-life of deficits of around 10 years $\left(\frac{-\log 2}{\log (1-0.07)} \simeq 10\right)$. Together, these estimates lead us to our choice of $\epsilon_{G L}=0.1, \epsilon_{B L}=0.75$ and $\epsilon_{D B}=0.07$, as reported in table 1 .

\footnotetext{
${ }^{52}$ Source: http://stats.oecd.org/Index.aspx?DataSetCode=EO. (Economic Outlook No 101). The 16 countries included in our sample are those countries for which data is available continuously over our sample period: Australia (AUS), Austria (AUT). Belgium (BEL), Canada (CAN), Denmark (DNK), Finland (FIN), France (FRA), Germany (DEU), Italy (ITA), the Netherlands (NLD), Norway (NOR), Portugal (PRT), Spain (ESP), Sweden (SWE), United Kingdom (GBR) and the United States (USA).
} 

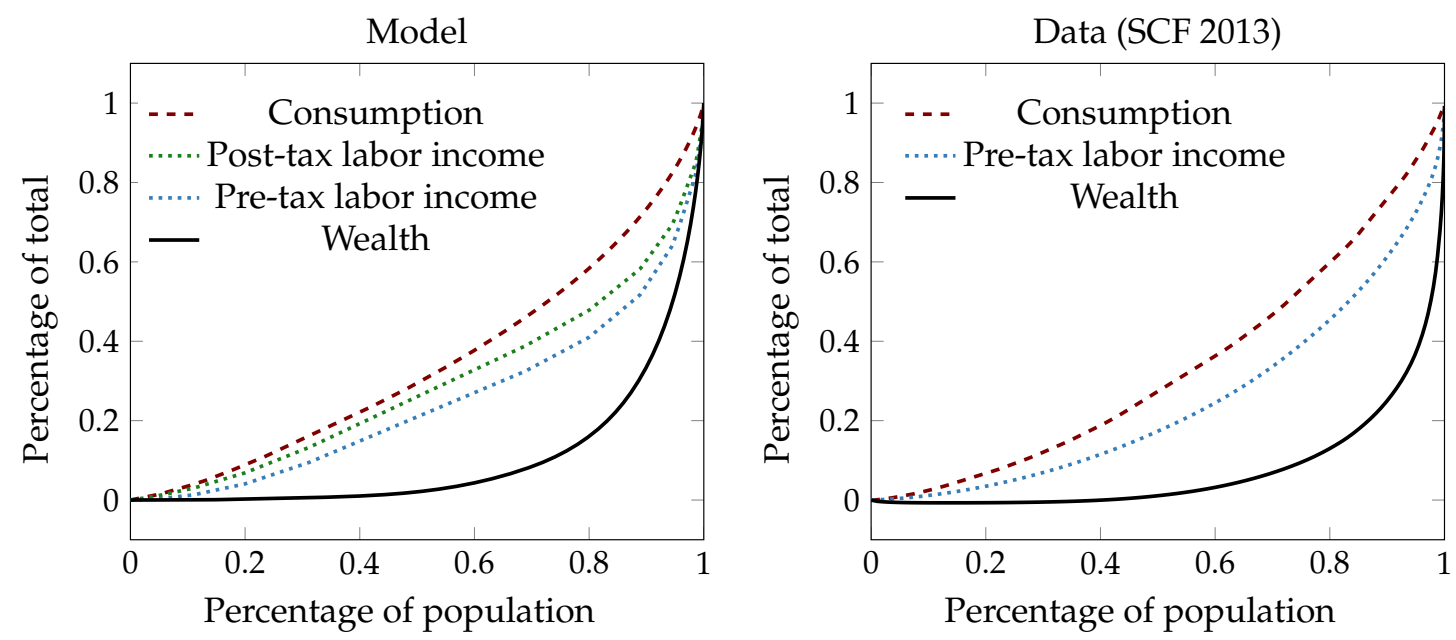

Figure B.3: Lorenz curves for consumption, income and wealth at steady-state

Alternative calibrations. When examining robustness to fiscal rules, we consider a version where $\epsilon_{G L}=0$ and $\epsilon_{D L}$ is maintained at its estimated value of 0.75 . This captures the effect of countercyclical deficits alone, absent government spending. We also consider a version where $\epsilon_{G L}=\epsilon_{D L}=0$, implying that $B=B_{S S}$ and $G=G_{S S}$ at all times. This delivers a procyclical fiscal rule that increases the tax rate when employment falls so as to maintain public spending and debt constant.

\section{B.4 Steady state distributions of consumption, income and wealth}

Figure B.3 displays the Lorenz curves for the steady-state distributions of consumption, pre-tax labor income $e_{i}$, post-tax labor income $y_{i}$, and wealth in our model (on the left panel), and constrasts them with their equivalent in the 2013 SCF (on the right panel). ${ }^{53}$ Our model captures these distributions very well. The income distribution is a good fit by design, but the wealth distribution gets surprisingly close to the data, a result that is typically challenging to obtain for simple calibration of Aiyagari models without entrepreneurial risk or heterogeneity in preferences. This success is mostly due to our earnings dynamics with additional income risk, but our high labor-share calibration plays a role as well, since it effectively amplifies income risk in general equilibrium. The bottom $40 \%$ of the wealth distribution owns exactly $1 \%$ of wealth in the model and the data, and the top $20 \%$ own exactly $84 \%$ in the model and the data. The model does understate, however, the very top of the wealth distribution, since the top $1 \%$ own $17 \%$ of wealth in the model, but own $33 \%$ in the data.

\section{B.5 1980 calibration}

We recalibrate to our model to 1980, by following the same principles as those for our 2013 calibration. Since the U.S. government only started selling Treasury inflation-protected securities in 1997, we instead

\footnotetext{
${ }^{53}$ Specifically, in the 2013 SCF, we define consumption as food at home (foodhome), labor income as wage income (wageinc), and wealth as net worth (networth). In constructing the wage income distribution, we only keep households with annual wage income above $\$ 4000$, since around a quarter of households have zero or extremely low wage income.
} 


\begin{tabular}{cccc} 
Parameters & Description & Main calibration & Target \\
\hline \hline$v$ & EIS & 0.5 & Standard calibration \\
$\beta$ & Discount factor & 0.927 & $r=4 \%$ \\
\hline$\alpha$ & Labor share & $83 \%$ & $\alpha=1-(r+\delta) \frac{K}{Y}$ \\
$\delta$ & Depreciation rate & $2.7 \%$ & NIPA 1980 \\
$\frac{K}{Y}$ & Capital-output ratio & $254 \%$ & FoF hh. net worth 1980 \\
$\frac{I}{Y}$ & Investment rate & $6.8 \%$ & $\delta \frac{K}{Y}$ \\
$\epsilon_{I}$ & Elasticity of $I$ to $q$ & 1 & Macro investment literature \\
\hline$r$ & Eqbm real rate & $4 \%$ & Laubach-Williams $r^{*} 1980$ \\
$L_{S S}$ & Employment gap & 1 & Full employment \\
\hline$\frac{B_{s s}}{Y}$ & Govtt debt & $24.9 \%$ & Domestic holdings 1980 \\
$\frac{G_{s S}}{Y}$ & Govtt spending & $20.6 \%$ & NIPA 1980 \\
\hline
\end{tabular}

Table B.2: Calibration parameters for 1980 steady state

obtain $r$ from the Laubach-Williams estimate of $r^{*}$ for $1980 .^{54}$ The average of the one-sided estimate is $4.02 \%$, hence our choice of $r=4 \%$. We ignore the small 1980 recession and instead assume that the economy is at full employment, $L=1$, and well described by a neoclassical monetary policy rule. (The average unemployment rate was $7.2 \%$ in that year, compared to the CBO estimate of lont-term average rate of $6.2 \%$. In 1979, the economy was at full employment.)

Our calibration for the depreciation rate is now $\delta=\frac{\$ 320 \mathrm{bn}}{\$ 11.9 \operatorname{trn}}=2.7 \%$, which is lower than in 2013 primarily due to a larger relative value of household real estate in that year. Our calibrated government spending to GDP ratio is $\frac{G}{Y}=\frac{\$ 590 \mathrm{bn}}{\$ 2.86 \mathrm{trn}}=20.6 \%$, our calibrated government debt to GDP ratio is $\frac{B}{Y}=$ $\frac{\$ 712 \mathrm{bn}}{\$ 2.86 \mathrm{trn}}=24.9 \%$, and our calibrated asset to GDP ratio is $\frac{A}{Y}=\frac{\$ 7.98 \mathrm{trn}}{\$ 2.86 \mathrm{trn}}=279 \%$, which is slighty smaller than our 2013 calibration. We assume an unchanged degree of progressivity of the tax system, so that $\tau^{r}=17.5 \%$ as in our baseline calibration. We assume the same household portfolios as in section B.1, the same incidence function as in section B.2, and the same fiscal rules as in section B.3. We finally follow our standard procedure of rescaling both the transitory and the persistent component of the income process to achieve the standard deviation of log earnings implied by the Song et al. (2016) for 1980, $\operatorname{sd}(\log e)=0.80$. Given these choices, we recalibrate the household discount factor $\beta$ so that the steadystate real interest rate is equal to our target of $r=4 \%$. Table B.2 summarizes our 1980 parameters.

\section{Proofs}

\section{C.1 Homotheticity and its implications}

We first prove a homogeneity property for the household decision problem from Definition 10.

Lemma 14. Consumption and asset policy functions $c_{t}(a, s)$ and $a_{t}^{\prime}(a, s)$ are homogenous of degree 1 in $\left(a,\left\{y_{t}(s)\right\}\right)$.

\footnotetext{
${ }^{54}$ Source: www.frbsf.org/economic-research/files/Laubach_Williams_updated_estimates.xlsx
} 
Proof. Consider the household problem:

$$
\begin{aligned}
V\left(s, a_{-1} ; y(s)\right) & =\max \mathbb{E}\left[\sum \beta^{t} \frac{c_{t}^{1-\sigma}}{1-\sigma}\right] \\
c_{t}+a_{t} & =y_{t}\left(s_{t}\right)+(1+r) a_{t-1} \\
a_{t} & \geq 0 \\
a_{-1} & \text { given }
\end{aligned}
$$

Suppose that $a_{-1}$ and $\left\{y_{t}(s)\right\}$ are scaled by $\lambda$. If we scale all feasible plans $\left\{a_{t}\right\}$ and $\left\{c_{t}\right\}$, the budget constraint still holds at every time $t$ and utility is scaled by $\lambda^{1-\sigma}$, which leaves relative utility of feasible plans unaffected. Hence the optimum is the same as the original, with consumption and asset policies scaled by $\lambda$.

This implies a homogeneity property for steady state consumption and assets from Definition 12.

Corollary 15. Steady-state consumption $C_{S S}^{P E}$ and assets $A_{s S}^{P E}$ are homogenous of degree 1 in $\{y(s)\}$.

Proof. From homogeneity of the asset policy function in lemma 14, we know that the transition probability from $(s, \lambda a)$ to $\left(s^{\prime}, \lambda a^{\prime}\right)$ under $\{\lambda y(s)\}$ is the same as the transition probability from $(s, a)$ to $\left(s^{\prime}, a^{\prime}\right)$ under $\{y(s)\}$. Hence, the steady-state cumulative distribution function $\Psi(s, \lambda a)$ given $\{y(s)\}$ is equal at every $(s, a)$ to the cumulative distribution function $\Psi(s, a)$ given $\{\lambda y(s)\}$. The population mean of $a$ is therefore $\lambda$ times higher, and since $c(a, s)$ is homogenous of degree 1 in $a$, the population mean of $c$ is also $\lambda$ times higher.

\section{C.2 Steady-state analytics}

In this section we work out some of the analytics of steady state equilibrium, which will be used in appendices C.3 and C.7 through C.8.

Asset demand and supply framework. Steady-state asset market clearing can be written as

$$
A=B+K
$$

where $A$ are aggregate assets owned by households and $B+K$ is the total supply of assets.

We seek to write (72) as an equation with $r$ and $L$ as the only endogenous inputs. To do so, consider the aggregate asset function (55). In the steady state limit, the initial values $p_{-1}, B_{-1}$, and $\widetilde{\Psi}$ can be dropped. Further, we will represent the exogenous income distribution parameters $\left\{e(s), \tau^{r}\right\}$ with a single shifter $\sigma$, resulting in a steady-state asset function $A_{s S}\left(\frac{W}{P}, L, \tau^{g}, r, \sigma\right)$.

As we will characterize below, steady-state real wages and taxes can be written as functions $w(r)$ and $\tau^{g}(r, L)$. Using these functions, we define a consolidated steady-state asset demand function

$$
A^{d}(r, L, \sigma) \equiv A_{s s}\left(w(r), L, \tau^{g}(r, L), r, \sigma\right)
$$

Similarly, steady-state bonds can be written as a function $B(L)$ from the fiscal rule, and steady-state capital can be written as a function $\kappa(r) L$, where the capital-labor ratio $\kappa(r)$ is only a function of $r$. We 
thus define steady-state asset supply as

$$
A^{s}(r, L) \equiv B(L)+\kappa(r) L
$$

Finally, we define normalized asset demand, which divides by aggregate after-tax labor income

$$
\hat{a}^{d}(r, L, \sigma) \equiv \frac{A^{d}(r, L, \sigma)}{\left(1-\tau^{g}(r, L)\right) w(r) L}
$$

In the special case where $\gamma=1$, all after-tax incomes $y(s)$ are proportional to aggregate after-tax income $\left(1-\tau^{g}(r, L)\right) w(r) L$, and it follows from corollary 15 that steady-state asset demand scales with $(1-$ $\left.\tau^{g}(r, L)\right) w(r) L$, implying that $L$ has no additional effect normalized asset demand.

Corollary 16. When $\gamma=1, \hat{a}^{d}(r, L, \sigma)$ is independent of $L$.

With these definitions in hand, steady-state equilibrium is characterized by market clearing

$$
A^{d}(r, L, \sigma)=A^{s}(r, L)
$$

In this section, we will further characterize $A^{d}$ and $A^{s}$. Whether $r$ or $L$ adjusts to maintain equilibrium in (76) depends on the monetary rule, as we will discuss in appendices C.3 and C.7.

Components of asset demand and supply. The components of $A^{d}(r, L, \sigma)$ and $A^{s}(r, L)$ as defined defined above are $B(L), G(L), \tau^{g}(r, L), \kappa(r), w(r)$. We obtain these functions as follows. First, the fiscal rules (13)-(14) imply steady-state spending and bond supply functions

$$
\begin{aligned}
& G(L)=G_{s S}-Y_{s s} \epsilon_{G L}\left(L-L_{s s}\right) \\
& B(L)=B_{S S}-Y_{s s} \frac{\epsilon_{D L}}{\epsilon_{D B}}\left(L-L_{S S}\right)
\end{aligned}
$$

The government budget constraint (57) at steady state is $\tau^{g} \frac{W}{P} L=r B+G$, and it follows that

$$
\tau^{g}(r, L)=\frac{r B(L)+G(L)}{w(r) L}
$$

which we can substitute into (75) to obtain a simplified expression relating normalized and actual asset demand

$$
A^{d}(r, L, \sigma)=(w(r) L-r B(L)-G(L)) \hat{a}^{d}(r, L, \sigma)
$$

Finally, the capital-labor ratio $\kappa(r)$ is given implicitly by equating the marginal product of capital and user cost $r+\delta$ in steady state, and the real wage $w(r)$ is the marginal product of labor at this capital intensity:

$$
\begin{aligned}
& F_{K}(\kappa(r), 1)=r+\delta \\
& F_{L}(\kappa(r), 1)=w(r)
\end{aligned}
$$


Elasticities of asset supply and demand. Using (80), the semielasticity and elasticity of asset demand $A^{d}(r, L, \sigma)$ with respect to $r$ and $L$ are

$$
\begin{aligned}
& \frac{\partial \log A^{d}(r, L, \sigma)}{\partial r}=\frac{1}{1-\tau^{g}} \frac{w^{\prime}(r)}{w(r)}-\frac{1}{1-\tau^{g}} \frac{B(L)}{w(r) L}+\frac{\partial \log \hat{a}^{d}(r, L, \sigma)}{\partial r} \\
& \frac{\partial \log A^{d}(r, L, \sigma)}{\partial \log L}=\frac{1}{1-\tau^{g}}-\frac{1}{1-\tau^{g}} \frac{r B^{\prime}(L)+G^{\prime}(L)}{w(r)}+\frac{\partial \log \hat{a}^{d}(r, L, \sigma)}{\partial L}
\end{aligned}
$$

Using (74), the semielasticity and elasticity of asset supply $A^{s}(r, L)$ with respect to $r$ and $L$ are

$$
\begin{aligned}
& \frac{\partial \log A^{s}(r, L)}{\partial r}=\frac{K}{A} \frac{\kappa^{\prime}(r)}{\kappa(r)} \\
& \frac{\partial \log A^{s}(r, L)}{\partial \log L}=\frac{B}{A} \frac{B^{\prime}(L) L}{B(L)}+\frac{K}{A}
\end{aligned}
$$

To write (83)-(86) more explicitly, we differentiate $B(L)$ and $G(L)$ to obtain

$$
\begin{aligned}
& B^{\prime}(L)=-Y_{S S} \frac{\epsilon_{D L}}{\epsilon_{D B}} \\
& G^{\prime}(L)=-Y_{S S} \epsilon_{G L}
\end{aligned}
$$

The analysis of $w(r)$ and $\kappa(r)$ is slightly more involved. First, use (81)-(82) and Euler's theorem to write $(r+\delta) \kappa(r)+w(r)=F(\kappa(r), 1)$. Differentiating both sides with respect to $r,(r+\delta) \mathcal{K}^{\prime}(r)$ and $F_{K} \mathcal{K}^{\prime}(r)$ cancel out and we are left with simply $w^{\prime}(r)=-\kappa(r)$, implying a wage semielasticity of

$$
\frac{w^{\prime}(r)}{w(r)}=-\frac{\kappa(r)}{w(r)}
$$

Next, observe that if $\varepsilon$ is the elasticity of substitution in the production function $F$ (equal to 1 in our Cobb-Douglas baseline), then $d \log (\kappa(r))=-\varepsilon(\log (r+\delta)-\log w(r))$. Differentiating, we have

$$
\frac{\kappa^{\prime}(r)}{\kappa(r)}=-\varepsilon\left(\frac{1}{r+\delta}+\frac{\kappa(r)}{w(r)}\right)=-\frac{\varepsilon}{\alpha(r)(r+\delta)}
$$

where $\alpha(r)$ is the labor share (constant in our Cobb-Douglas baseline).

Finally, substituting (87)-(90) into (83)-(86), we obtain the following:

$$
\begin{aligned}
& \frac{\partial \log A^{d}(r, L, \sigma)}{\partial r}=-\frac{1}{1-\tau^{g}} \frac{\kappa(r)}{w(r)}-\frac{1}{1-\tau^{g}} \frac{B(L)}{w(r) L}+\frac{\partial \log \hat{a}^{d}(r, L, \sigma)}{\partial r}=-\hat{a}^{d}(r, L, \sigma)+\frac{\partial \log \hat{a}^{d}(r, L, \sigma)}{\partial r} \\
& \frac{\partial \log A^{d}(r, L, \sigma)}{\partial \log L}=\frac{1}{1-\tau^{g}}\left(1+\frac{Y_{S S}}{w(r)}\left(r \frac{\epsilon_{D L}}{\epsilon_{D B}}+\epsilon_{G L}\right)\right)+\underbrace{\frac{\partial \log \hat{a}^{d}(r, L, \sigma)}{\partial \log L}}_{\equiv \eta_{I}}
\end{aligned}
$$


and

$$
\begin{aligned}
& \frac{\partial \log A^{s}(r, L)}{\partial r}=-\frac{K}{A} \frac{\varepsilon}{\alpha(r+\delta)} \\
& \frac{\partial \log A^{s}(r, L)}{\partial \log L}=\frac{K}{A}-\frac{Y_{s s}}{A} \frac{\epsilon_{D L} L}{\epsilon_{D B}}
\end{aligned}
$$

Note the remarkable simplification in (91), where the semielasticity of asset demand breaks into two simple terms: minus normalized asset demand, plus the semielasticity of normalized asset demand. The former term captures the influence of $r$ on after-tax income: at the margin, the cost of higher $r$ is paid entirely by workers, either through lower pretax wages (as the cost of capital in the production function) or through higher taxes. Relative to current after-tax income, the drop in after-tax income resulting from a rise in $r$ is exactly the ratio of assets to after-tax income, i.e. normalized asset demand.

In (92), the elasticity $\eta_{I}$ of normalized asset demand to $L$ is zero by corollary 16 in the case where $\gamma=1$, drastically simplifying the elasticity.

\section{C.3 Equilibrium uniqueness}

Our model's state space includes the distribution of agents over assets and is thus infinite-dimensional. We therefore cannot directly resort to standard tools such as Blanchard and Kahn (1980) to study either a) the uniqueness of steady states, or b) the local uniqueness of rational expectations equilibrium paths around such steady states.

Numerical verification. It is, however, straightforward to numerically verify a) for our calibration, by calculating asset demand and supply and showing that they only intersect once in the relevant space (either $r$ or $L)^{55}$

- For neoclassical monetary policy, $L=1$ is fixed, and in the left panel of figure 9 we plot asset demand $A^{d}(r, 1, \sigma)$ and supply $A^{s}(r, 1)$ with respect to $r$, showing a unique intersection $r^{*}$.

- For constant-r monetary policy with $r^{*}$ at our calibrated value of 0 , the right panel of figure 10 plots asset demand $A^{d}(0, L, \sigma)$ and supply $A^{s}(0, L)$ with respect to $L$, showing a single intersection L. (Figure D.4 provides the same plot under alternative assumptions about $\gamma$, showing that for sufficiently countercyclical income risk there are multiple equilibria.)

- For our benchmark monetary policy, a Taylor rule with ZLB, it is in principle possible for steadystate equilibrium to have full employment $L=1$ (in which case equilibrium is the same as under neoclassical monetary policy), or to have $L<1$ and $\pi=\kappa-1=0$, implying $i=r=0$, as in our calibrated steady state. Evaluating condition (100) later in this section, we rule out the former case. We show quantitatively in figure 12 that uniqueness extends to different assumptions about the wage lower bound $\kappa$ and interest rate lower bound $i$, although the unique equilibrium is $L=1$ for sufficiently low values of the latter. By contrast, for higher values of the inflation target $\pi^{*}$, there do exist multiple equilibria.

Verifying b), local uniqueness of equilibrium paths around the steady state, is more complex. When there is multiplicity, the invertibility condition needed for the derivation of the GE matrix in appendix

\footnotetext{
${ }^{55}$ All other steady-state quantities and prices are unique conditional on $r$ and $L$, as the discussion in appendix C.2 and the derivation of firm and household behavior in appendices A.1 and A.2 shows.
} 
C.5 will not be satisfied. We can test for multiplicity, therefore, by checking whether there are problems with invertibility (i.e. very small singular values) when we numerically calculate the truncated GE matrix. ${ }^{56}$ When we do this for our calibration, we find no evidence of multiplicity. (See the Computational Appendix for more details.)

General case. In the rest of this section, we complement our numerical verification of uniqueness by providing a more general analysis of steady-state uniqueness a) in our model. Along the way, we contribute to the literature by providing a simple condition for uniqueness in the Aiyagari model.

For local uniqueness of paths $b$ ), a general analysis is more complex and beyond the scope of the paper. We are currently developing tools for this, which infer uniqueness directly from partial equilibrium impulse responses, in Auclert et al. (2017).

General case: neoclassical monetary policy. A sufficient condition for a unique neoclassical equilibrium is that the semielasticity (91) of asset demand with respect to $r$ is strictly greater than the semielasticity (93) of asset supply, so that there is only a single intersection of asset demand and asset supply.

The second term in (91) is $\frac{\partial \log \hat{a}^{d}(r, L, \sigma)}{\partial r}$, the semielasticity of normalized asset demand. It depends entirely on the household's partial equilibrium decision problem, and it is positive if, holding the longterm after-tax income level fixed, higher real interest rates lead households to demand a higher aggregate quantity of assets in steady state. In an important contribution, Achdou, Han, Lasry, Lions and Moll (2017) prove that it is positive,

$$
\frac{\partial \log \hat{a}^{d}(r, L, \sigma)}{\partial r}>0
$$

when the elasticity of intertemporal substitution $v$ is at least 1 , in which case it can be unambiguously shown that substitution effects dominate income effects in response to a change in steady-state $r$. When $v<1$, as in the benchmark calibration $v=1 / 2$ in this paper, it is possible in principle for income effects to dominate and cause $\hat{a}$ to slope downward in $r$. In practice, however, this seems to be true only in extreme cases, and we have found only upward-sloping $\hat{a}$ for all variants of the household-side calibrations in this paper.

Conditioning on (95), we have the following proposition.

Proposition 17. There is a unique real steady-state equilibrium under neoclassical monetary policy within the region where households' normalized asset demand $\hat{a}^{d}(r, 1, \sigma)$ is upward-sloping in $r$ and the inequality

$$
\frac{K}{A} \frac{\varepsilon}{r+\delta} \geq \frac{A}{Y} \frac{1}{1-\tau^{g}}
$$

Proof. Real equilibrium is uniquely determined by $r$, and the semielasticity (91) of asset demand is strictly greater than the semielasticity (93) of asset supply-implying a unique intersection $r$-whenever the term $\frac{\partial \log \hat{a}(r, L, \sigma)}{\partial r}$ is strictly positive and $\hat{a}(r, 1, \sigma) \leq \frac{K}{A} \frac{\varepsilon}{\alpha(r+\delta)}$. Writing out $\hat{a}^{d}(r, 1, \sigma)=\frac{A}{\left(1-\tau^{g}\right) w L}=$ $\frac{A}{\left(1-\tau^{g}\right) \alpha Y}$ and multiplying both sides by $\alpha$, we have (96).

\footnotetext{
${ }^{56}$ An alternative approach to numerically verifying uniqueness is to set up the problem recursively using a discretized state space, as in Reiter (2009), and then apply some version of Blanchard and Kahn (1980). We take this approach because it demonstrates uniqueness as a side consequence of a calculation-obtaining the GE matrix-that we are already performing.
} 
Corollary 18. Consider an Aiyagari economy where $\bar{B}=G=0$. Then there is a unique real steady-state equilibrium under neoclassical monetary policy within the region where households' normalized asset demand $\hat{a}^{d}(r, 1, \sigma)$ is upward-sloping in $r$ and the inequality

$$
\varepsilon \geq 1-\alpha
$$

is satisfied-i.e. the elasticity of substitution in the production function is greater than the capital share.

Proof. In this case, $K / A=1, \tau^{g}=0$, and $(r+\delta) K / Y=1-\alpha$, so (96) reduces to (97).

The dramatic simplification in the case without steady-state government debt and spending in corollary 18 may be useful for the literature going forward.

The simpler result also admits a more direct derivation. In the absence of taxes or government debt, normalized asset supply is just the capital-wage ratio $\kappa(r) / w(r)$. This ratio is increasing in $r$ iff the elasticity of wages $w=F_{L}$ with respect to the capital-labor ratio is less than 1 . This elasticity is

$$
\frac{F_{L K} K}{F_{L}}=\frac{F_{L K} F}{F_{L} F_{K}} \frac{F_{K} K}{F}=\varepsilon^{-1}(1-\alpha)
$$

and it is less than 1 when (97) holds.

It is also clear that (97) is nearly always satisfied: the vast majority of calibrations put the elasticity of substitution in the production function above the capital share. Indeed, (97) is trivially satisfied under Cobb-Douglas, in which case corollary 18 establishes global uniqueness as long as $\hat{a}$ is everywhere upward-sloping.

The more general condition (96) does not hold quite as universally: for instance, in the limit where government debt is the only asset, $K / A$ on the left is zero, and the condition cannot hold. In our benchmark calibration, the left side of $(96)$ is $.85 \times \frac{1}{0+0.04} \approx 21.3$, while the right is $\frac{3.76}{0.79}=4.8$, and we are well within the region where the condition holds; in a modified calibration with more government spending and debt, this would be less clear.

General case: constant- $r$ monetary policy. A sufficient condition for unique equilibrium under constant- $r$ monetary policy is that the elasticity (92) of asset demand exceeds the elasticity (94) of asset supply with respect to $L$. The next proposition immediately follows.

Proposition 19. There is a unique equilibrium under constant-r monetary policy within the region where the inequality

$$
\frac{1}{1-\tau^{g}}\left(1+\frac{Y_{S S}}{w}\left(r \frac{\epsilon_{D L}}{\epsilon_{D B}}+\epsilon_{G L}\right)\right)-\frac{K}{A}+\frac{Y_{S S}}{A} \frac{\epsilon_{D L} L}{\epsilon_{D B}}+\frac{\partial \log \hat{a}(r, L, \sigma)}{\partial \log L}>0
$$

holds.

Corollary 20. Equilibrium under constant-r monetary policy is globally unique if $\epsilon_{D L}, \epsilon_{G L}>0, r \geq 0$, and $\gamma=1$.

Proof. If $\gamma=1$, then $\frac{\partial \log \hat{a}(r, L, \sigma)}{\partial \log L}=0$, and inequality (98) follows from $\frac{1}{1-\tau^{8}} \geq 1$ and $\frac{K}{A} \leq 1$.

The condition in proposition 98 is somewhat complex, but assuming that fiscal policy is countercyclical $\left(\epsilon_{D L}, \epsilon_{G L} \geq 0\right)$ and that $r \geq 0$, the first two terms on the left of (98) are unambiguously positive. ${ }^{57}$

\footnotetext{
${ }^{57}$ We always require $\epsilon_{D B}>0$ for stability reasons.
} 
The only danger is that $\frac{\partial \log \hat{a}(r, L, \sigma)}{\partial \log L}$ is very negative; this can happen if income incidence $\gamma$ is such that income risk is highly countercyclical, which makes precautionary savings increase strongly as $L$ falls. Appendix D.6 exhibits cases where this does indeed happen, as highly countercyclical income risk leads to multiplicity. If the income distribution is acyclical, i.e. $\gamma=1$, then this effect is shut off and we are guaranteed global uniqueness by corollary 20 .

The following proposition is a partial inverse of proposition 19, showing that there is multiplicity if (98) does not hold at any equilibrium.

Proposition 21. If $\epsilon_{D L}, \epsilon_{G L} \geq 0$ and $r \geq 0$, a necessary condition for unique steady-state equilibrium is that (98) holds (weakly) at any equilibrium.

Proof. Assuming countercyclical fiscal policy, steady-state taxation $G+r B$ increases as $L$ falls, implying that after-tax income $w L-(G+r B)$ hits 0 at some $\underline{L}>0$, and therefore asset demand hits 0 as well. Meanwhile, with countercyclical fiscal policy, asset supply is bounded from below by $B_{S S}$ as $L$ falls. Therefore, for sufficiently low $L$, the asset demand curve is below the asset supply curve. If, however, the left side of (98) is negative at an equilibrium, then for $L$ immediately below the equilibrium, asset demand is above asset supply. This implies another intersection at some lower $L$.

Proposition 21 provides a simple condition to test for multiplicity: evaluate (98) at the calibrated steady state. If it fails, then multiplicity is certain. Although the inverse is not necessarily true, the quantitative examples in appendix D.6 suggest that it is true in practice: in every case where we find multiplicity, the slope of asset demand is below asset supply at the calibrated steady state, i.e. (98) fails.

General case: benchmark monetary policy. Finally, we study equilibria under the benchmark monetary policy given by (18), a Taylor rule subject to a lower bound $\underline{i}$.

The complementary slackness condition (62) gives two possibilities: either we are in the neoclassical equilibrium with $L=1$, or the nominal wage growth constraint is binding with $W_{t}=\kappa W_{t-1}$.

The real interest rate achieved in steady state, dividing (18) by $1+\pi$, is

$$
1+r=\max \left(\frac{1+\underline{i}}{1+\pi},\left(1+r^{*}\right)\left(\frac{1+\pi}{1+\pi^{*}}\right)^{\phi-1}\right)
$$

This reaches a global minimum at the point where the two arguments of (99) are equal, i.e. where the lower bound $i$ is exactly binding, which is $1+\pi=\left(\frac{1+i}{1+r^{*}}\right)^{\frac{1}{\phi}}\left(1+\pi^{*}\right)^{1-\frac{1}{\phi}}$ and results in a minimum of $1+r=\left(\frac{1+i}{1+\pi^{*}}\right)^{1-\frac{1}{\phi}}\left(1+r^{*}\right)^{\frac{1}{\phi}}$. If this $\pi$ is strictly less than the minimum $\kappa-1$, then the nominal wage growth constraint is such that the ZLB is never binding, and the achievable minimum real interest rate is $1+r=\left(1+r^{*}\right)\left(\frac{\kappa}{1+\pi^{*}}\right)^{\phi-1}$.

Now, let $\tilde{r}^{*}$ denote the natural rate. ${ }^{58}$ There will be a neoclassical equilibrium iff this natural rate is higher than the minimum of $r$, since then there will exist some $\pi \geq \kappa-1$ such that the real interest rate from (99) equals the natural rate. We summarize this reasoning in the following proposition.

\footnotetext{
${ }^{58}$ We use $r^{*}$ to denote the natural rate in the benchmark, and this is what appears in the Taylor rule (18), but we let $\tilde{r}^{*}$ more generally denote the natural rate following a shock.
} 
Proposition 22. Under the benchmark monetary policy given by (18), there exists a "neoclassical" steady state equilibrium with $L=1$ iff the natural rate $\tilde{r}^{*}$ satisfies

$$
\tilde{r}^{*} \geq \max \left(\left(\frac{1+\underline{i}}{1+\pi^{*}}\right)^{1-\frac{1}{\phi}}\left(1+r^{*}\right)^{\frac{1}{\phi}},\left(1+r^{*}\right)\left(\frac{\kappa}{1+\pi^{*}}\right)^{\phi-1}\right)-1
$$

Evaluating (100) for our steady-state calibration, where $\underline{i}=\pi^{*}=\kappa-1=0$ and $\phi>1$, it reduces to $r^{*} \geq\left(1+r^{*}\right)^{\frac{1}{\phi}}-1$, which is impossible since $r^{*}<0$. This allows us to rule out a $L=1$ equilibrium. ${ }^{59}$

The alternative possibility is an equilibrium with $L<1$, where $W_{t}=\kappa W_{t-1}$. In this case, $\pi=\kappa-1$, and the real interest rate achieved in equilibrium is above the natural rate $\tilde{r}^{*}$. Using (99), this gives the following proposition.

Proposition 23. Under the benchmark monetary policy given by (18), there exists a steady state equilibrium with $L<1$ and $\pi=\kappa-1$ iff the natural rate $\tilde{r}^{*}$ satisfies

$$
\tilde{r}^{*}<\max \left(\frac{1+\underline{i}}{\kappa},\left(1+r^{*}\right)\left(\frac{\kappa}{1+\pi^{*}}\right)^{\phi-1}\right)-1
$$

The real interest rate in this equilibrium equals the right side of (101).

Combining propositions 22 and 23 fully characterizes equilibria under the benchmark monetary policy. Uniqueness of equilibrium for proposition 22 is given by our earlier results on uniqueness of neoclassical equilibrium, and uniqueness of equilibrium for proposition 23 is given by our results on uniqueness of constant-r equilibrium, substituting the right side of (101) as the $r$ target.

\section{C.4 Proof of proposition 3}

Consider a one-time redistributive labor income shock. From lemma 13, this affects the path of consumption according to

$$
\partial C_{t}=\sum_{s} \frac{\partial C_{t}^{P E}}{\partial y_{0}(s)} d y_{0}(s)
$$

with income in each state $s$ affected by

$$
d y_{0}(s)=(1-\tau) \frac{W}{P} L \gamma(s, L) d e_{0}(s)+\frac{1}{1-\tau^{r}}\left(\mathbb{E}_{s}[y]-y(s)\right) d \tau_{0}^{r}
$$

We rewrite (102) using individual level responses. Define household i's marginal propensity to consume at time $t$ out of date- 0 income to be

$$
M P C_{i t} \equiv \frac{\partial\left(\mathbb{E}_{0}\left[c_{i t}\right]\right)}{\partial y_{i 0}}
$$

i.e. the change in $i$ 's expected spending at time $t$ conditional on household $i$ 's date- 0 state, as we vary his date- 0 after-tax income.

\footnotetext{
${ }^{59}$ The right panel of figure 12 shows a neoclassical equilibrium does exist for sufficiently higher inflation targets.
} 
Since (51) can be rewritten as $C_{t}=\mathbb{E}_{I}\left[c_{i t}\right]$, we have

$$
\begin{aligned}
\partial C_{t} & =\partial\left(\mathbb{E}_{I}\left[c_{i t}\right]\right)=\partial\left(\mathbb{E}_{I}\left[\mathbb{E}_{0}\left[c_{i t}\right]\right]\right) \\
& =\mathbb{E}_{I}\left[\partial\left(\mathbb{E}_{0}\left[c_{i t}\right]\right)\right]=\mathbb{E}_{I}\left[\frac{\partial\left(\mathbb{E}_{0}\left[c_{i t}\right]\right)}{\partial y_{i 0}} d y_{i 0}\right] \\
& =\mathbb{E}_{I}\left[M P C_{i t} d y_{i 0}\right]=\operatorname{Cov}_{I}\left(M P C_{i t}, d y_{i 0}\right)
\end{aligned}
$$

where the second equality follows from the law of iterated expectations and the third equality follows from interchanging the expectations and differential operators. The final step follows from (103) and (6): since his is a redistributionary shock, $\mathbb{E}_{I}\left[d y_{i 0}\right]=0$.

To prove that $N P V(\partial \mathbf{C})=0$, note that for any realized sequence of shocks, combining the household budget constraints implies

$$
(1+r) a_{i,-1}+\left(\sum_{t=0}^{T} \frac{y_{i t}}{(1+r)^{t}}\right)=\left(\sum_{t=0}^{T} \frac{c_{i t}}{(1+r)^{t}}\right)+\frac{a_{i T}}{(1+r)^{T}}
$$

Taking expectations at date 0 , we have

$$
(1+r) a_{i,-1}+y_{i 0}+\left(\sum_{t=1}^{T} \frac{\mathbb{E}_{0}\left[y_{i t}\right]}{(1+r)^{t}}\right)=\left(\sum_{t=0}^{T} \frac{\mathbb{E}_{0}\left[c_{i t}\right]}{(1+r)^{t}}\right)+\frac{\mathbb{E}_{0}\left[a_{i T}\right]}{(1+r)^{T}}
$$

Totally differentiating with respect to a one-time change in $d y_{i 0}$, we see that the first and third terms are unaffected, and that this becomes

$$
d y_{i 0}=\left(\sum_{t=0}^{T} \frac{\mathbb{E}_{0}\left[\partial c_{i t}\right]}{(1+r)^{t}}\right)+\frac{\mathbb{E}_{0}\left[\partial a_{i T}\right]}{(1+r)^{T}}
$$

Taking the limit as $T \rightarrow \infty$, for $r$ that is not too negative the ergodicity of the model implies that $\frac{\mathbb{E}_{0}\left[\partial a_{i T}\right]}{(1+r)^{T}} \rightarrow 0$, and this simplifies to

$$
d y_{i 0}=\sum_{t=0}^{\infty} \frac{\mathbb{E}_{0}\left[\partial c_{i t}\right]}{(1+r)^{t}}
$$

Taking the population mean $\mathbb{E}_{I}$ of both sides gives, using iterated expectations $\mathbb{E}_{I}\left[\mathbb{E}_{0}[\cdot]\right]=\mathbb{E}_{I}[\cdot]$ and redistributivity $\mathbb{E}_{I}\left[d y_{i 0}\right]=0$,

$$
0=\sum_{t=0}^{\infty} \frac{\mathbb{E}_{I}\left[\partial c_{i t}\right]}{(1+r)^{t}}=\sum_{t=0}^{\infty} \frac{\partial C_{t}}{(1+r)^{t}}=N P V(\partial \mathbf{C})
$$

as desired.

Alternatively, we can see this via MPCs by rewriting (105) as

$$
d y_{i 0}=d y_{i 0} \sum_{t=0}^{\infty} \frac{\mathbb{E}_{0}\left[M P C_{i t}\right]}{(1+r)^{t}}=d y_{i 0} \cdot N P V\left(\mathbf{M P C}_{i}\right)
$$


and then dividing both sides by $d y_{i 0}$ to obtain

$$
N P V\left(\mathbf{M P C}_{i}\right)=1
$$

Then we can apply the covariance result in (104) to conclude that

$$
N P V(\partial \mathbf{C})=\operatorname{Cov}_{I}\left(N P V\left(\mathbf{M P C}_{i}\right), d y_{i 0}\right)=0
$$

as desired.

\section{C.5 Proof of theorem 4}

Case 1: ZLB and constant-r monetary policy. Let

$$
\mathbf{x}_{t} \equiv\left(K_{t}, q_{t}, r_{t}, L_{t}, W_{t}, P_{t}, Y_{t}, p_{t}, d_{t}, \tau_{t}^{g}, B_{t}, G_{t}, \pi_{t}, i_{t}, A_{t}\right)
$$

and let $\mathbf{x}=\left[\mathbf{x}_{t}\right] \in \ell^{\infty}$ be the stacked vector with each of these 15 endogenous series. Also let $\varphi_{t} \equiv$ $\left(\left\{e_{t}(s)\right\}, \tau_{t}^{r}\right)$, and let $\varphi=\left[\varphi_{t}\right] \in \ell^{\infty}$ be the corresponding stacked vector of exogenous series.

For each $t$, define $\mathbf{H}_{t}(\mathbf{x}, \varphi)$ to consist of 15 stacked equations: all 11 equations in appendix A.3 under "firms and production", "fiscal policy", and "inflation and the Fisher equation", plus the relevant monetary policy equation (either ZLB or constant- $r$ ), the binding nominal wage rigidity equation $W_{t}=\kappa W_{t-1}$, the asset demand equation (64), and the asset market clearing condition (66). Let $\mathbf{H}(\mathbf{x}, \varphi)=\left[\mathbf{H}_{t}(\mathbf{x}, \varphi)\right]$ be the stacked set of equations for all $t$.

In the neighborhood of the steady state, general equilibrium is characterized ${ }^{60}$ by

$$
\mathbf{H}_{t}(\mathbf{x}, \varphi)=0
$$

Applying the implicit function theorem for Banach spaces, (for example Teschl 2018), assuming that $\mathbf{H}_{\mathbf{x}}\left(\mathbf{x}_{s s}, \varphi_{s s}\right)$ is invertible, ${ }^{61}$ locally around $\left(\mathbf{x}_{s s}, \varphi_{s s}\right)$ there exists a function $\mathbf{x}(\varphi)$ mapping exogenous $\varphi$ to endogenous outcomes $\mathbf{x}$. This function satisfies

$$
d \mathbf{x}=\mathbf{H}_{\mathbf{x}}^{-1}\left(\mathbf{x}_{s s}, \varphi_{s s}\right) \mathbf{H}_{\varphi}\left(\mathbf{x}_{s s}, \varphi_{s s}\right) d \varphi
$$

Let $I_{A}$ be the mapping that embeds $\mathbf{A}$ in the space of $\mathbf{x}$. Since the components of $\varphi,\left\{e_{t}(s)\right\}$ and $\tau_{t}^{r}$, only enter into the asset demand equation (63), it follows from lemma 13 that

$$
\mathbf{H}_{\varphi}\left(\mathbf{x}_{s S}, \varphi_{s S}\right) d \varphi=\mathbf{I}_{A} \partial \mathbf{A}
$$

where $\partial \mathbf{A}$ is the vector of partial equilibrium asset responses. This links to the consumption responses $\partial \mathbf{C}$ characterized in the same lemma via the relation $\partial \mathbf{C}=-\Delta \partial \mathbf{A}$, where the operator $\Delta$ takes quasi-first differences: $(\Delta \partial \mathbf{A})_{t}=\partial A_{t}-(1+r) \partial A_{t-1}$.

\footnotetext{
${ }^{60}$ In the calibrated steady state with ZLB or constant- $r$ monetary policy, the economy is at $L<1$. In the neighborhood of this, the nominal wage rigidity equation $W_{t}=\kappa W_{t-1}$ is strictly binding and labor market clearing is not binding.

${ }^{61}$ In computing the GE matrix, we numerically verify this invertibility for a truncated version of $\mathbf{H}_{\mathbf{x}}$. See the online Computational Appendix for more details.
} 
Let $S_{Y}$ be a matrix that selects rows associated with endogenous variable $Y_{t}$. Then

$$
\begin{aligned}
d \mathbf{Y} & =S_{Y} d \mathbf{x}=S_{Y} \mathbf{H}_{\mathbf{x}}^{-1}\left(\mathbf{x}_{s s}, \varphi_{s S}\right) I_{A} \partial \mathbf{A} \\
& =\underbrace{-S_{Y} \mathbf{H}_{\mathbf{x}}^{-1}\left(\mathbf{x}_{s s}, \varphi_{s S}\right) I_{A} \Delta^{-1}}_{G_{Y}} \partial \mathbf{C}
\end{aligned}
$$

where $G_{Y}$ is the desired GE matrix. The $\Delta^{-1}$ operator maps bounded $\partial \mathrm{C}$ with net present value zero into bounded perturbations $\partial \mathbf{A}$ to assets. Using the same argument as that in the proof of proposition 3 , all transitory redistributive labor income shocks produce partial equilibrium $\partial \mathbf{C}$ that satisfy $N P V(\partial \mathbf{C})=0$. In particular, $G_{Y} \partial \mathrm{C}$ is defined for all the shocks we consider.

Note, crucially, that $G_{Y}$ is independent of the shock $\varphi$. We can analogously obtain a $G$ matrix for any of the aggregates $\left(K_{t}, q_{t}, r_{t}, L_{t}, W_{t}, P_{t}, Y_{t}, p_{t}, d_{t}, \tau_{t}^{g}, B_{t}, G_{t}, \pi_{t}, i_{t}, A_{t}\right)$ in $\mathbf{x}$.

Case 2: neoclassical monetary policy. This is similar, but there is now potentially nominal indeterminacy, so we will work with only real values. Let now

$$
\mathbf{x}_{t} \equiv\left(K_{t}, q_{t}, r_{t}, L_{t}, W_{t} / P_{t}, Y_{t}, p_{t}, d_{t}, \tau_{t}^{g}, B_{t}, G_{t}, A_{t}\right)
$$

and define $\mathbf{H}_{t}(\mathbf{x}, \varphi)$ to consist of 12 stacked equations: all 9 equations in appendix A.3 under "firms and production" and "fiscal policy", the monetary policy equation $L_{t}=1$, asset demand equation (64), and the asset market clearing condition (66). The rest of the proof now proceeds as in case 1.

\section{C.6 Proof of proposition 5}

If $\tau^{r}=0$, agents' after-tax incomes are proportional to their endowments, which in turn are proportional in all periods to $e^{\omega_{i}}$, where $\omega_{i}$ are the fixed effects. It follows from the homogeneity result in corollary 15 that the average steady-state assets and consumption for agents with a particular fixed effect $\omega_{i}$ are proportional to $e^{\omega_{i}}$.

Redistributive changes in the distribution of fixed effects $\widetilde{\omega}_{i}$ relative to the baseline $\omega_{i}$ must leave the average endowment unchanged, implying that $\mathbb{E}_{I}\left[e^{\widetilde{\omega}_{i}}-e^{\omega_{i}}\right]=0$. But since average steady-state assets and consumption are proportional to $e^{\omega_{i}}$, it follows that these are also unchanged, as desired.

\section{C.7 Proofs of proposition 6, corollary 7 and proposition 8}

Proposition 6 follows from (76), substituting in the special case assumptions $B(L)=B$ and $G(L)=G$ and using homotheticity to write $\hat{a}(r, L, \sigma)=\hat{a}(r, \sigma)$.

For corollary 7 and proposition 8 , start from equation (76) equating asset demand and supply $A(r, L, \sigma)=A^{S}(r, L)$ and apply the implicit function theorem to obtain

$$
\begin{aligned}
d r^{*} & =-\left(\frac{\partial \log A}{\partial r}-\frac{\partial \log A^{s}}{\partial r}\right)^{-1} \frac{\partial \log A}{\partial \sigma} d \sigma \\
\frac{d L}{L} & =-\left(\frac{\partial \log A}{\partial \log L}-\frac{\partial \log A^{s}}{\partial \log L}\right)^{-1} \frac{\partial \log A}{\partial \sigma} d \sigma
\end{aligned}
$$


Substituting the expressions (91) and (93) into (107), we obtain

$$
d r^{*}=-(\underbrace{-\hat{a}+\frac{\partial \log \hat{a}}{\partial r}}_{\epsilon_{D}}+\underbrace{\frac{K}{A} \frac{\varepsilon}{\alpha(r+\delta)}}_{-\epsilon_{S}})^{-1} \frac{\partial \log A}{\partial \sigma} d \sigma
$$

Substituting (92) and (94) into (108), we start with the special case of corollary 7 where $\epsilon_{B L}=\epsilon_{G L}=0$ and $\frac{\partial \hat{a}}{\partial L}=0$, which gives

$$
\begin{aligned}
\frac{d L}{L} & =-\left(\frac{1}{1-\tau^{g}}-\frac{K}{A}\right)^{-1} \frac{\partial \log A}{\partial \sigma} d \sigma \\
& =-\left(\frac{\tau^{g}}{1-\tau^{g}}+\frac{B}{A}\right)^{-1} \frac{\partial \log A}{\partial \sigma} d \sigma
\end{aligned}
$$

Alternatively, away from the special case, we obtain

$$
\begin{aligned}
\frac{d L}{L} & =-\left(\frac{1}{1-\tau^{g}}\left(1+\frac{Y_{S S}}{w(r)}\left(r \frac{\epsilon_{D L}}{\epsilon_{D B}}+\epsilon_{G L}\right)\right)+\frac{\partial \log \hat{a}(r, L, \sigma)}{\partial \log L}-\frac{K}{A}+\frac{Y_{S S}}{A} \frac{\epsilon_{D L} L}{\epsilon_{D B}}\right)^{-1} \frac{\partial \log A}{\partial \sigma} d \sigma \\
& =-(\frac{\tau^{g}}{1-\tau^{g}}+\frac{B}{A}+\underbrace{Y \frac{\epsilon_{D B}}{\epsilon_{D L}}\left(\frac{L}{A}+\frac{r}{\left(1-\tau^{g}\right) w}\right)+Y \frac{\epsilon_{G L}}{\left(1-\tau^{g}\right) w}}_{\equiv \eta_{F}}+\underbrace{\frac{\partial \log \hat{a}(r, L, \sigma)}{\partial \log L}}_{\equiv \eta_{I}})^{-1} \frac{\partial \log A}{\partial \sigma} d \sigma
\end{aligned}
$$

where we have substituted $Y=Y_{s S}$ since we are evaluating at the steady state.

\section{C.8 Proof of proposition 9}

As explained in the main text, the steady-state rules for government spending and debt that we consider in this section replace (13)-(14) with the steady state rules

$$
\begin{aligned}
& \frac{G}{Y}=\frac{G_{s S}}{Y_{s s}}-\epsilon_{G L}\left(L-L_{s s}\right) \equiv b(L) \\
& \bar{B}=\frac{B_{S S}}{Y_{s S}}-\frac{\epsilon_{D L}}{\epsilon_{D B}}\left(L-L_{s s}\right) \equiv g(L)
\end{aligned}
$$

This makes fiscal policy neutral with respect to changes in technology that affect $Y$ directly.

Let $\alpha$ now denote the labor share that is obtained in steady state equilibrium. (It was previously equal to the parameter of the Cobb-Douglas production function, but not in the enriched model.)

We can split the non-labor share into income accruing to capital and monopolistic profits from markups:

$$
1-\alpha=\underbrace{(r+\delta) \frac{X K}{Y}}_{\text {capital share }}+\underbrace{\left(1-\mu^{-1}\right)}_{\text {profit share }}
$$


It follows that

$$
\frac{X K}{Y}=\frac{\mu^{-1}-\alpha}{r+\delta} \quad \frac{\Pi}{Y}=\frac{1-\mu^{-1}}{r}
$$

Total asset supply normalized by output is then

$$
\frac{B+X K+\Pi}{Y}=b(L)+\frac{\mu^{-1}-\alpha}{r+\delta}+\frac{1-\mu^{-1}}{r}
$$

where we summarize the steady-state fiscal rules for debt and government spending by the expressions $b(L)$ and $g(L)$ in (110)-(111). Since after-tax labor income as a share of output is $\alpha-g(L)-r b(L)$, it follows that we can write asset supply normalized by after-tax labor income as

$$
\hat{a}^{S}(r, L ; F, X, \mu)=\frac{b(L)+\frac{\mu^{-1}-\alpha(r ; F, X, \mu)}{r+\delta}+\frac{1-\mu^{-1}}{r}}{(\alpha(r ; F, X, \mu)-g(L)-r b(L))}
$$

where we make the dependence of the labor share $\alpha$ on all inputs except $L$ explicit. ${ }^{62}$

Asset market clearing can then be written as the equality of normalized asset supply and demand

$$
\hat{a}^{d}(r, L)=\hat{a}^{s}(r, L ; F, X, \mu)
$$

and, analogously to appendix C.7, we can get the equilibriating change following a shock by totally differentiating and solving given the appropriate monetary rule. For neoclassical policy, the adjustment in $r$ is

$$
d r=\left(\frac{\partial \log \hat{a}^{d}}{\partial r}-\frac{\partial \log \hat{a}^{s}}{\partial r}\right)^{-1} \underbrace{\left(\frac{\partial \log \hat{a}^{s}}{\partial F} d F+\frac{\partial \log \hat{a}^{s}}{\partial X} d X+\frac{\partial \log \hat{a}^{s}}{\partial \mu} d \mu\right)}_{\equiv d \log \hat{a}^{s, \text { partial }}}
$$

where we define $d \hat{a}^{s, \text { partial }}$ to be the impact on $\hat{a}^{s}$ from changes in $F, X$, and $\mu$, but not including the impact from general equilibrium changes in $r$. Similarly, for constant- $r$ or benchmark monetary policy we start from a depressed steady state, implying that steady-state $r$ is locally constant, we have

$$
\frac{d L}{L}=\left(\frac{\partial \log \hat{a}^{d}}{\partial \log L}-\frac{\partial \log \hat{a}^{s}}{\partial \log L}\right)^{-1} d \log \hat{a}^{s, p a r t i a l}
$$

In (114), the normalization in $\log \hat{a}^{d}$ and $\log \hat{a}^{s}$ cancels out, and the first expression in parentheses equals $\frac{\partial \log A^{d}}{\partial r}-\frac{\partial \log A^{s}}{\partial r}$, which following the discussion in appendix C.3 must be positive to guarantee uniqueness. The analogous claim is true for the first expression in parentheses in (115). As stated in subsection 2.2, we are assuming uniqueness throughout this paper, and therefore we assume that both these expressions are positive for comparative statics. ${ }^{63}$ Given this, any shock resulting in a positive $d \log \hat{a}^{s, \text { partial }}$ will result in positive $d r$ and $d L / L$ in the neoclassical and constant- $r$ /benchmark cases, respectively.

\footnotetext{
${ }^{62}$ The labor share is unaffected by $L$, which simply scales output and incomes conditional on $r$ and the production parameters $F, X$, and $\mu$.

${ }^{63}$ This is just another instance of the ubiquitous point that a condition needed for equilibrium uniqueness or stability is also needed to characterize comparative statics.
} 
All that remains is to characterize $d \log \hat{a}^{s, \text { partial }}$. From (112), we write

$$
d \log \hat{a}^{s, \text { partial }}=\frac{1}{A}\left(\frac{d \mu^{-1}-d \alpha^{\text {partial }}}{r+\delta}-\frac{d \mu^{-1}}{r}\right)-\frac{d \alpha^{\text {partial }}}{\alpha(1-\tau)}
$$

where $d \alpha^{\text {partial }} \equiv \frac{\partial \alpha}{\partial F} d F+\frac{\partial \alpha}{\partial X} d X+\frac{\partial \alpha}{\partial \mu} d \mu$ is defined (analogously to $\left.d \hat{a}^{s, p a r t i a l}\right)$ to be the impact on labor share $\alpha$ from changes in $F, X$, and $\mu$, holding $r$ constant.

Note that the sign on $d \alpha^{\text {partial }}$ in (116) is negative. Therefore, if there is a shock to either the production function $F$ or investment prices $X$ that results in a decline $d \alpha^{\text {partial }}<0$ in the labor share while leaving markups unchanged, we have $d \log \hat{a}^{\text {spartial }}>0$, as desired.

The coefficient on $d \mu^{-1}$ in (116) is negative, since $1 /(r+\delta)<1 / r$. A rise in markups $d \mu>0$, which implies $d \mu^{-1}<0$, therefore contributes positively to (116). If the rise in markups causes a decline in the labor share, therefore, combined with our previous result, we have $d \log \hat{a}^{s, p a r t i a l}>0$ as well. This completes the proof. ${ }^{64}$

\section{Additional results}

\section{D.1 Labor supply in heterogeneous agent models}

Most of the heterogeneous agent models with nominal rigidities in the literature remain as close as possible to the canonical representative agent model by assuming sticky prices, flexible wages, and separable preferences (e.g., McKay et al. 2016, Kaplan et al. 2016, Athreya et al. 2017). Using the simplified asset notation of section A.2, under this alternative assumption, households solve

$$
\begin{array}{cl}
\max _{c_{i t}, n_{i t}} & \mathbb{E}\left[\sum \beta^{t}\left\{u\left(c_{i t}\right)-v\left(n_{i t}\right)\right\}\right] \\
\text { s.t. } & c_{i t}+a_{i t}=T_{t}+\left(1-\tau_{t}\right) \frac{W_{t}}{P_{t}} n_{i t} e_{t}\left(s_{i t}\right)+\left(1+r_{t-1}\right) a_{i t-1} \\
& a_{i t} \geq 0
\end{array}
$$

where the rest of the notation is as in section 2. The first order condition for the choice between hours and consumption is then

$$
v^{\prime}\left(n_{i t}\right)=\left(1-\tau_{t}\right) \frac{W_{t}}{P_{t}} e_{t}\left(s_{i t}\right) u^{\prime}\left(c_{i t}\right)
$$

Equations (118) trace out a labor supply curve for each individual, and the real wage $\frac{W_{t}}{P_{t}}$ is determined in equilibrium such that the labor market clears, ie

$$
\mathbb{E}\left[n_{i t} e_{t}\left(s_{i t}\right)\right]=L_{t}
$$

Equations (118)-(119) replace equations (4)-(6). Moreover, since prices are rigid but wages are flexible, (11) is replaced by an equation determining price inflation $\frac{P_{t}}{P_{t-1}}$.

\footnotetext{
${ }^{64}$ In cases with an extremely high elasticity of substitution $\varepsilon$, it is possible for a rise in markups to result in a rise in the labor share, because the direct negative effect is outweighed by the substitution away from capital. If this rise in the labor share is large enough, then the effect of $d \alpha$ partial $>0$ can dominate and lead to the opposite macro effects. Conditional on a rise in markups resulting in a decline in the labor share (the case commonly understood to be true, and considered in proposition 9), however, the result is unambiguous.
} 
Micro implications of separable preferences. Consider the implications of this alternative formulation for household-level data. As in the main text, let $M P C_{i t} \equiv \frac{\partial c_{i t}}{\partial T_{t}}$ be the marginal propensity to consume in period $t$ out of unearned income in period $t$, and now let $M P E_{i t} \equiv\left(1-\tau_{t}\right) \frac{W_{t}}{P_{t}} e_{t}\left(s_{i t}\right) \frac{\partial n_{i t}}{\partial T_{t}}$ be the after-tax marginal propensity to earn in period $t$ out of unearned income in period $t$. Also let $\psi \equiv \frac{v^{\prime}}{n v^{\prime \prime}}$ be the Frisch elasticity of labor supply and $v \equiv \frac{-u^{\prime}}{c u^{\prime \prime}}$ be the elasticity of intertemporal substitution. Totally differentiating (118), we obtain

$$
M P E_{i t}=-\frac{\left(1-\tau_{t}\right) \frac{W_{t}}{P_{t}} e_{t}\left(s_{i t}\right) n_{i t}}{c_{i t}} \frac{\psi}{v} M P C_{i t}
$$

Equation (120) implies a relationship between marginal propensities to earn $M P E_{i t}$ and marginal propensity to consume $M P C_{i t}$ that is at odds with the data in two dimensions.

First, the implied levels of marginal propensities to earn are much too high relative to the data. Many studies, such as Chetty, Guren, Manoli and Weber (2011), find that the Frisch elasticity of labor supply is close to or above our calibration of 0.5 for the elasticity of intertemporal substitution $(\psi \simeq v=0.5$ ); while budget constraints imply that post-tax income must account for an important part of consumption in the crosssection. For example, in the steady state of our model, given that $r=0$, on average $\frac{\mathbb{E}_{I}\left[\left(1-\tau_{t}\right) \frac{W_{t}}{P_{t}} n_{i t} e_{t}\left(s_{i t}\right)\right]}{\mathbb{E}_{I}\left[c_{i t}\right]}=$ $1-\frac{T_{t}}{\mathbb{E}_{[}\left[c_{i t}\right]} \simeq 1-\tau^{r}\left(1-\tau^{g}\right)=0.85$. Putting these estimates together, we obtain $\mathbb{E}_{I}\left[M P E_{i t}\right] \simeq-0.85 \times$ $\mathbb{E}_{I}\left[M P C_{i t}\right]$. Most studies of the marginal propensity to earn, however, find extremely low levels of $\mathbb{E}_{I}\left[M P E_{i t}\right]$. Using a sample of Swedish lottery winners matched to administrative data on earnings, Cesarini et al. (2017), a paper representative of the studies in the literature, find an average MPE of -0.01 . This is inconsistent with studies of marginal propensities to consume, that find numbers in the range of 0.25 . Even in our model, in which the average marginal propensity to consume is 0.175 , the average marginal propensity to consume implied by (120) remains an order of magnitude too large relative to these studies.

Second, the implied heterogeneity in marginal propensities to earn is at odds with the data. Equation (120) implies that marginal propensities to consume and work should be inversely related in the cross-section: high $M P C$ should come together with high negative $M P E$, except for individuals with no labor earnings. There is no evidence in the data to support this hypothesis. Cesarini et al. (2017) find no significant evidence of heterogeneity in MPE by income. The limited heterogeneity suggested by the data goes in the other direction as that implied by equation (120): the highest tercile of earners respond slightly more to lottery wins, with an $M P E$ of -0.01 relative to an MPE of -0.005 for the bottom two terciles (see their figure 3, panel F).

Alternative preference specifications. An alternative to this preference specification that avoids these implications for wealth effects on labor supply is to shut them down entirely by assuming GHH preferences (eg, Bayer et al. 2017). In Auclert and Rognlie (2017b), we explain why the feedbacks from consumption-labor complementarities implied by this specification are problematic. In a representative agent model, we show that they imply that the fiscal multiplier $\frac{\partial y_{t}}{\partial g_{t}}$ is equal to to the inverse of the steady state labor wedge, which in our model is equal to the marginal tax rate $\tau$. Hence, in our model, such preferences would put the fiscal multiplier above 3, well outside of the range of empirical estimates. More generally, in Auclert and Rognlie (2017b) we make the case that there is no specification of within period utility $U\left(c_{i t}, n_{i t}\right)$ that maintains flexible wages and can both rationalize the microeconomic evidence on marginal propensities to earn and the macroeconomic evidence on fiscal multipliers. We conclude that 
our specification in the main text, which assumes wage rigidities and removes the short-run choice of labor (118), is a better match to micro evidence than any of these leading alternatives from the literature.

\section{D.2 Goods vs asset market clearing}

While our short-run analysis focuses on flows and discussion of goods market equilibrium, our longrun analysis is based on asset market equilibrium instead. Could we conduct the long-run analysis in the goods market instead? The answer is no.

For a simple example of why, consider the special case in section C.7. Start with the long-run goods market clearing equation

$$
C+I+G=F(K, L)
$$

In steady state, $I=\delta K=\delta \kappa(r) L$ and $F(K, L)=w(r) L+(r+\delta) K=w(r) L+(r+\delta) \kappa(r) L$. Further, in our model, steady-state consumption $C$ equals the steady state flow of after-tax income accruing to households. Therefore, $C=(1-\tau) w(r) L\left(1+r \hat{a}^{d}(r, \sigma)\right)$, where after-tax labor earnings are $(1-\tau) w(r) L$ and the flow of income on assets is $r \hat{a}(r, \sigma)$ times this. Since $\tau w(r) L=G+r \bar{B}$ by the government budget constraint, this can be written as $C=(w(r) L-(G+r \bar{B}))(1+r \hat{a}(r, \sigma))$.

Substituting these into steady-state goods market clearing (121) gives

$$
\underbrace{(w(r) L-(G+r \bar{B}))(1+r \hat{a}(r, \sigma))}_{C}+\underbrace{\delta \kappa(r) L}_{I}+G=\underbrace{w(r) L+(r+\delta) \kappa(r) L}_{F(K, L)}
$$

We immediately see that a $w(r) L$ and $\delta \kappa(r) L$ are on both the left and right and cancel, and $G$ and $-G$ cancel on the left. Moving $r \bar{B}$ to the right, (122) then becomes

$$
r(w(r) L-(G+r \bar{B})) \widehat{a}(r, \sigma)=r(\bar{B}+\kappa(r) L)
$$

Notably, this goods market clearing condition is exactly $r$ times the asset market clearing condition (27) derived in appendix C.7. Equation (27) implies (123), but not the other way around. Instead, in our benchmark calibration with $r=0$, (123) reduces to the degenerate $0=0$ and holds regardless of whether the $L$ is consistent with asset market clearing.

Effectively, Walras' law breaks down in the steady state, and goods market clearing can be insufficient for equilibrium. We conclude that long-run macroeconomic adjustment is best understood in terms of stocks, not flows.

\section{D.3 Monetary policy implementation}

We have assumed that monetary policy sets the nominal interest rate $i_{t}$, which is connected to the real interest rate $r_{t}$ along perfect-foresight paths by the Fisher equation (17):

$$
1+r_{t}=\frac{1+i_{t}}{1+\pi_{t+1}}
$$

To clarify how this is possible, let us augment the set of assets that the household trades, introducing a nominal bond $b_{i t}^{n}$ and money $m_{i t}$ (where money is the numeraire, a nominal asset with no other special properties). 
The budget constraint (2), still expressed in real terms, then becomes

$$
\begin{aligned}
c_{i t}+b_{i t}+\frac{b_{i t}^{n}}{P_{t}}+\frac{m_{i t}}{P_{t}}+p_{t} v_{i t}= & y_{t}\left(s_{i t}\right)+\left(1+r_{t-1}\right) b_{i t-1} \\
& +\frac{\left(1+i_{t-1}\right) b_{i t-1}^{n}}{P_{t}}+\frac{\left(1+i_{t-1}^{m}\right) m_{i t-1}^{n}}{P_{t}}+\left(p_{t}+d_{t}\right) v_{i t-1} \\
b_{i t}+\frac{b_{i t}^{n}}{P_{t}}+\frac{m_{i t}}{P_{t}}+p_{t} v_{i t} \geq & 0
\end{aligned}
$$

where $i_{t}^{m}$ is the interest rate paid on money and $i_{t}$ is the interest rate on nominal bonds.

To complete our description of this augmented economy, suppose that asset market clearing holds in nominal bonds and money, so that the population means of $b_{i t}^{n}$ and $m_{i t}$ equal the supplies $B_{t}^{n}$ and $M_{t}$, and that these enter into the government budget constraint as

$$
\tau_{t} \frac{W_{t}}{P_{t}} L_{t}+\bar{B}_{t}+\frac{B_{t}^{n}}{P_{t}}+\frac{M_{t}^{n}}{P_{t}}=G_{t}+\left(1+r_{t-1}\right) \bar{B}_{t-1}+\frac{\left(1+i_{t-1}\right) B_{t-1}^{n}}{P_{t}}+\frac{\left(1+i_{t-1}\right) M_{t-1}}{P_{t}}
$$

Household optimization implies that along a perfect foresight path, the returns on real bonds, nominal bonds, and money must be equalized. Equal return for real and nominal bonds is the Fisher equation (17), while equal return for nominal bonds and money is

$$
i_{t}=i_{t}^{m}
$$

Hence, we can think about monetary policy working as follows. Monetary policy sets the interest rate paid on money $i_{t}^{m}$, which through household optimization is equated with the nominal interest rate $i_{t}$ on bonds and then sets the real interest rate $r_{t}$ via the Fisher equation. ${ }^{65}$

In our model, we assume that nominal bonds and money are in zero net supply, and we calibrate initial individual household positions such that each household has $b_{i,-1}^{n}=m_{i,-1}^{n}=0$. Since there is no distinction between these assets along perfect foresight paths, $b_{t}^{n}$ and $m_{t}^{n}$ can also be rolled for $t \geq 0$ into the consolidated household asset position $a_{t}$ as discussed in appendix A.2. These assumptions mean that nominal bonds and money, aside from facilitating monetary policy, play no role in the model. They are therefore omitted in the description (2) of the household budget constraint in the main text. ${ }^{66}$

For each monetary regime we consider, monetary policy sets $i_{t}$ via $i_{t}^{m}$. This is straightforward for our benchmark Taylor rule with a zero lower bound, which directly specifies the choice of $i_{t}$. For neoclassical

\footnotetext{
${ }^{65}$ This is distinct from the traditional view of monetary policy, where there is a convenience yield on money due to its value in overcoming transactional frictions, and where monetary policy controls the nominal interest rate by changing the supply of money and therefore its marginal convenience yield.

This traditional view is no longer an accurate depiction of monetary policy in many large economies, including the US, where post-2008 there has been an abundance of excess reserves and the prevailing short-term nominal interest rate has been roughly equal to the interest rate on excess reserves. Interpreting $i_{t}^{m}$ as the interest rate on excess reserves, therefore, we believe this model more accurately depicts the mechanics of monetary policy in its current form.

${ }^{66}$ It is worth noting that even if we did not assume zero net supply and zero initial household positions $b_{i,-1}^{n}=m_{i,-1}^{n}=0$, the perfect foresight assumption means that neither nominal bonds or money make any difference to either the household or government budget constraints, except at date 0 following an unanticipated shock. Our treatment of nominal bonds and money can therefore be viewed as a simplifying assumption for the date- 0 calibration of asset positions, one that is relatively innocuous given the limited inflation response to our shocks. See Auclert (2017) for more discussion of how different initial asset positions lead to redistributive effects from changes in the price level and nominal interest rate.
} 
policy, the central bank sets $i_{t}$ such that the $r_{t}$ implied by expected inflation is consistent with $L_{t}=1$ at all $t$. For constant- $r$ policy, the central bank attempts to set $i_{t}$ such that the $r_{t}$ implied by expected inflation is constant at $r_{t}=r^{*}$. This is not always feasible, since sometimes maintaining this target for $r_{t}$ would require $L_{t}>1$; it is feasible as long as constant $r$ is consistent with $L_{t} \leq 1$ in equilibrium, which is the case in all of the experiments in this paper.

\section{D.4 Taylor rules}

Here we examine the robustness of our results to an alternative monetary regime with active Taylor rules. We begin with our benchmark Taylor rule (18) with a zero lower bound $\underline{i}=0$ :

$$
i_{t}=\max \left(i_{,}\left(1+r^{*}\right)\left(1+\pi^{*}\right)\left(\frac{P_{t} / P_{t-1}}{1+\pi^{*}}\right)^{\phi}-1\right)
$$

In the paper thus far, $\phi$ has turned out to be irrelevant, since the lower bound is always binding in our experiments.

In this extension we start by supposing that the monetary authority follows the same monetary rule but that it is not constrained by any lower bound (i.e. $\underline{i}=-\infty$ ). We then additionally consider a slightly broader family of standard Taylor rules, which respond to both inflation and unemployment-where we use $L_{t} / L_{s s}$ as our measure of the deviation of unemployment from steady state:

$$
i_{t}=\left(1+r^{*}\right)\left(1+\pi^{*}\right)\left(\frac{P_{t} / P_{t-1}}{1+\pi^{*}}\right)^{\phi_{\pi}}\left(\frac{L_{t}}{L_{s s}}\right)^{\phi_{L}}-1
$$

To see how these changes in the monetary regime affect the equilibrium response to temporary and permanent inequality shocks in our model, we recompute the general equilibrium impulse responses in figures 4 and 11. We continue to display the impulse responses under the ZLB monetary regime (18) as a benchmark, but now we additionally display impulse responses under a Taylor rule (126) with coefficients $\left(\phi_{\pi}=1.5, \phi_{L}=0\right)$ and $\left(\phi_{\pi}=1.5, \phi_{L}=0.5\right)$. The first specification captures a Taylor rule that responds only to inflation, with a standard slope of 1.5 , and the second specification captures a Taylor rule that additionally responds to unemployment.

It is important to note that when we recalibrate the model to these alternative monetary regimes, we continue to assume the same steady-state calibration targets, including $i^{*}=0$ and $\pi^{*}=0$. This parallels our earlier treatment of different monetary regimes (e.g. neoclassical vs. ZLB), and it facilitates easier interpretation by ensuring that we only see differences in the impulse response to inequality shocks, not in the steady states prior to those shocks.

Inequality in the short run. Figure D.1 displays the results from recomputing the GE impulse responses in figure 4 under our new Taylor rule specifications.

The Taylor rule that only responds to inflation, with $\phi_{\pi}=1.5$, delivers results nearly identical to our benchmark ZLB specification. The differences are minor and vary over the impulse response: with $\phi_{\pi}=1.5$, the initial drop in output is slightly smaller, but the persistent decline in output is slightly larger. The impact here is small because our model features relatively little variability in inflation when the downward nominal wage rigidity constraint is binding. Locally, changes in price inflation come entirely from changes in the marginal product of labor as the capital/labor ratio varies due to the business cycle, rather than from wage inflation. 

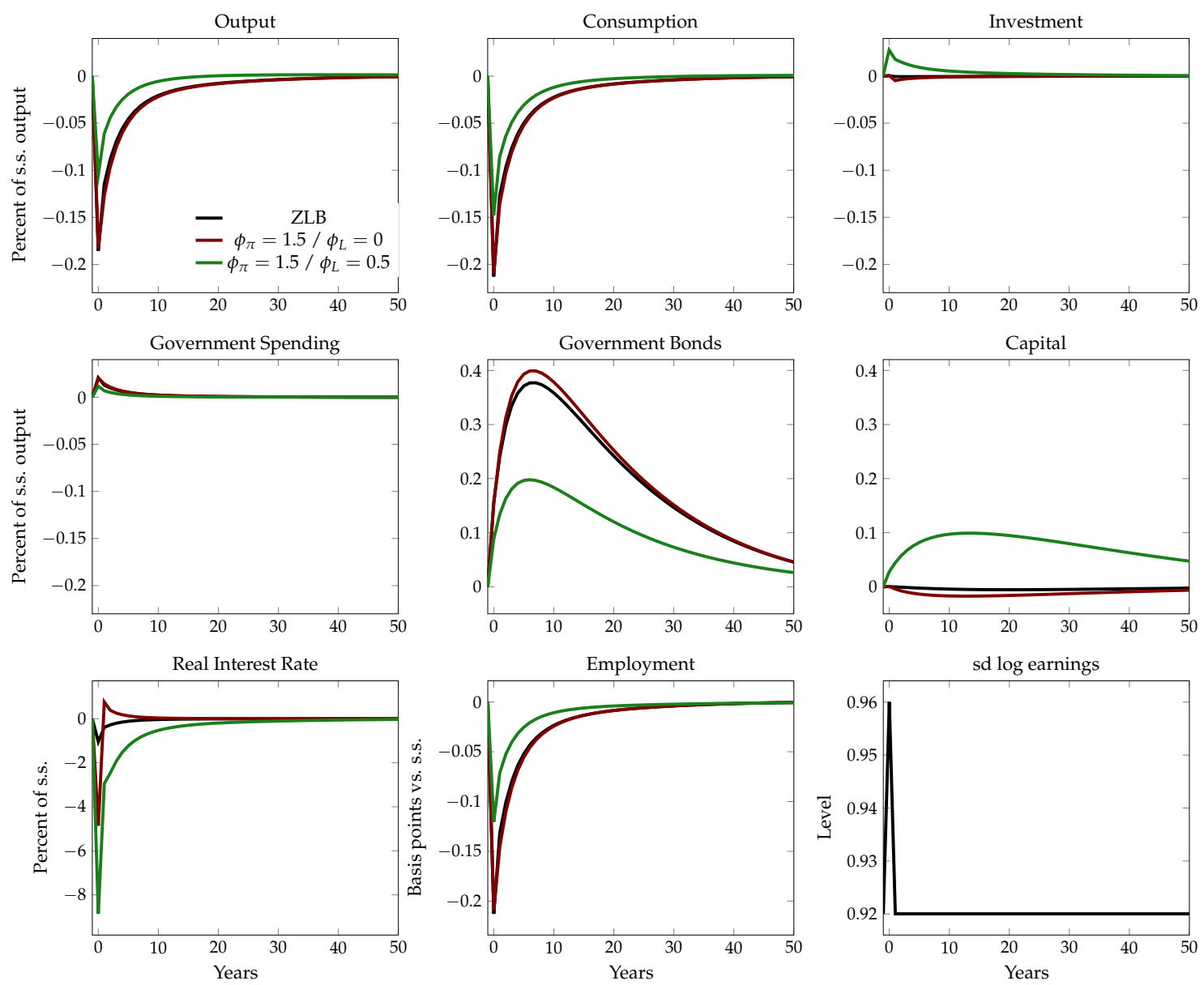

Figure D.1: General equilibrium for temporary shock with Taylor rules

When we add $\phi_{L}=0.5$ to the Taylor rule, the output response to the inequality shock shrinks to roughly half its previous magnitude. Qualitatively, most of the impulse responses look similar, with the key difference being that there is now a positive net investment response to the contraction: the decline in real interest rates from the Taylor rule overwhelms the declining marginal product of capital in (22).

Inequality in the long run. Figure D.2 displays the results from recomputing the GE impulse responses in figure 11 under our new Taylor rule specifications.

Again, the Taylor rule that only responds to inflation, with $\phi_{\pi}=1.5$, delivers results that are nearly identical to our benchmark along the transition path. Furthermore, both monetary regimes converge to exactly the same steady state. The reason is that long-term inflation is locally pinned down by the downward nominal wage rigidity constraint, and without any change in long-term inflation there can be no difference between the long-term Taylor rule and ZLB responses.

By contrast, the Taylor rule that adds $\phi_{L}=0.5$ features an increase in steady-state gross output, thanks to long-term capital accumulation driven by lower interest rates. Employment still declines, but only by about one-tenth the ZLB benchmark response. Net output also declines, with an decrease in 

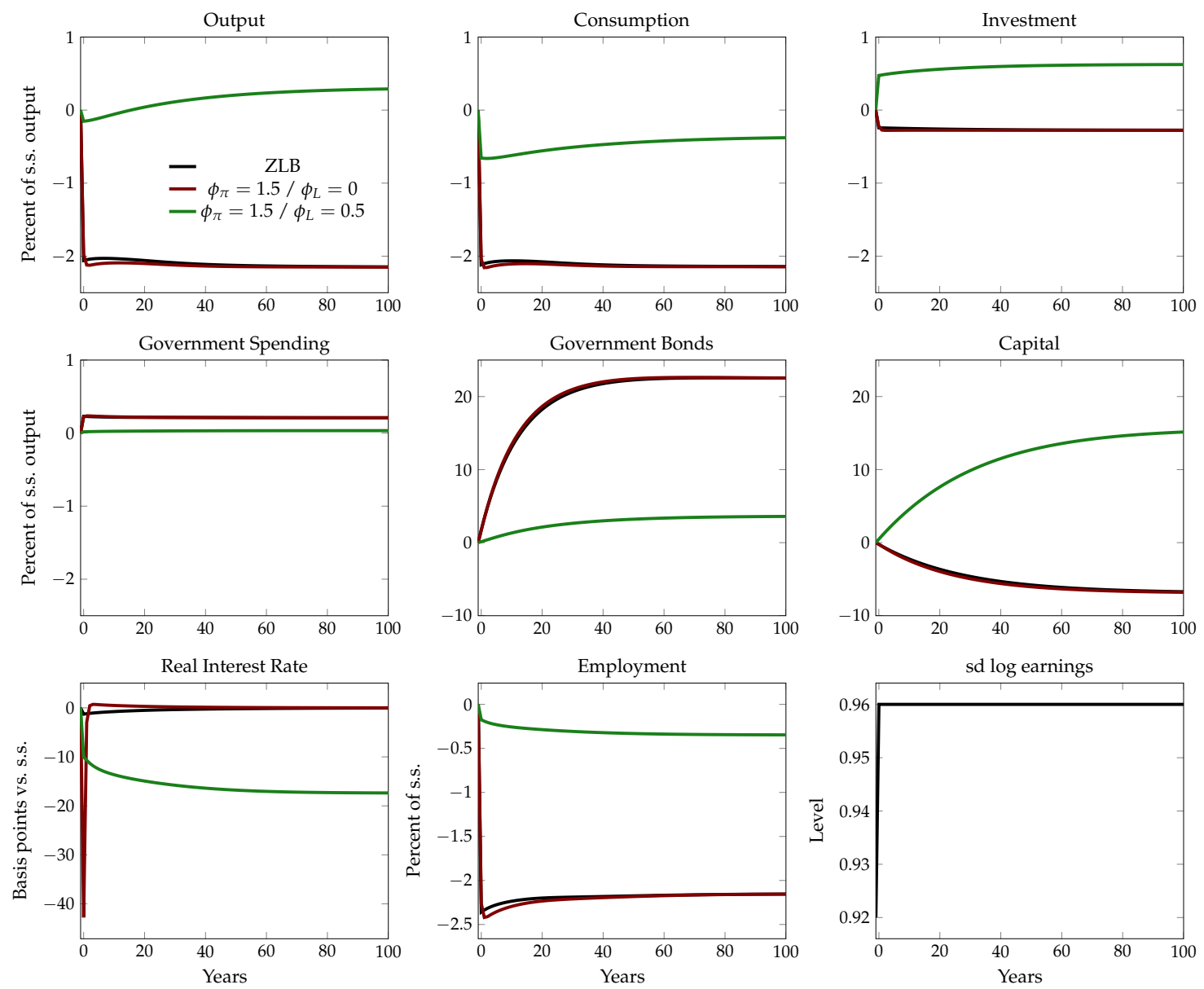

Figure D.2: General equilibrium for permanent shock with Taylor rules

steady-state consumption offsetting a small increase in steady-state government spending. ${ }^{67}$

In short, with this Taylor rule response, the economy settles into a muted long-term malaise. The effect of interest rate flexibility in this long run case is larger than in the short run, because permanent changes in interest rates lead to substantial, permanent changes in labor and capital.

Summary discussion of Taylor rule results. Broadly, the lesson here is consistent with our earlier discussion of the impact of inequality shocks: they are only recessionary when interest rates do not move with sufficient speed and magnitude to offset their aggregate demand impact. More responsive Taylor rules bring the economy closer to the neoclassical case, where the employment effect is zero and the gross output effect is positive. In our calibration, however, the sensitivity of inflation to slack is too weak for Taylor rules responding only to inflation to make much difference; we therefore only see this effect with a Taylor rule that responds directly to employment. (In a alternative calibration with more

${ }^{67}$ Since we start by calibrating to $r=0$, the capital-labor ratio in the initial steady state is at its golden rule level, and locally any change in the capital-labor ratio will have zero effect on steady-state combined private and government consumption (which in this model, without growth, equal net output). The state-state employment and net output effects here are therefore equal in percentage terms. 

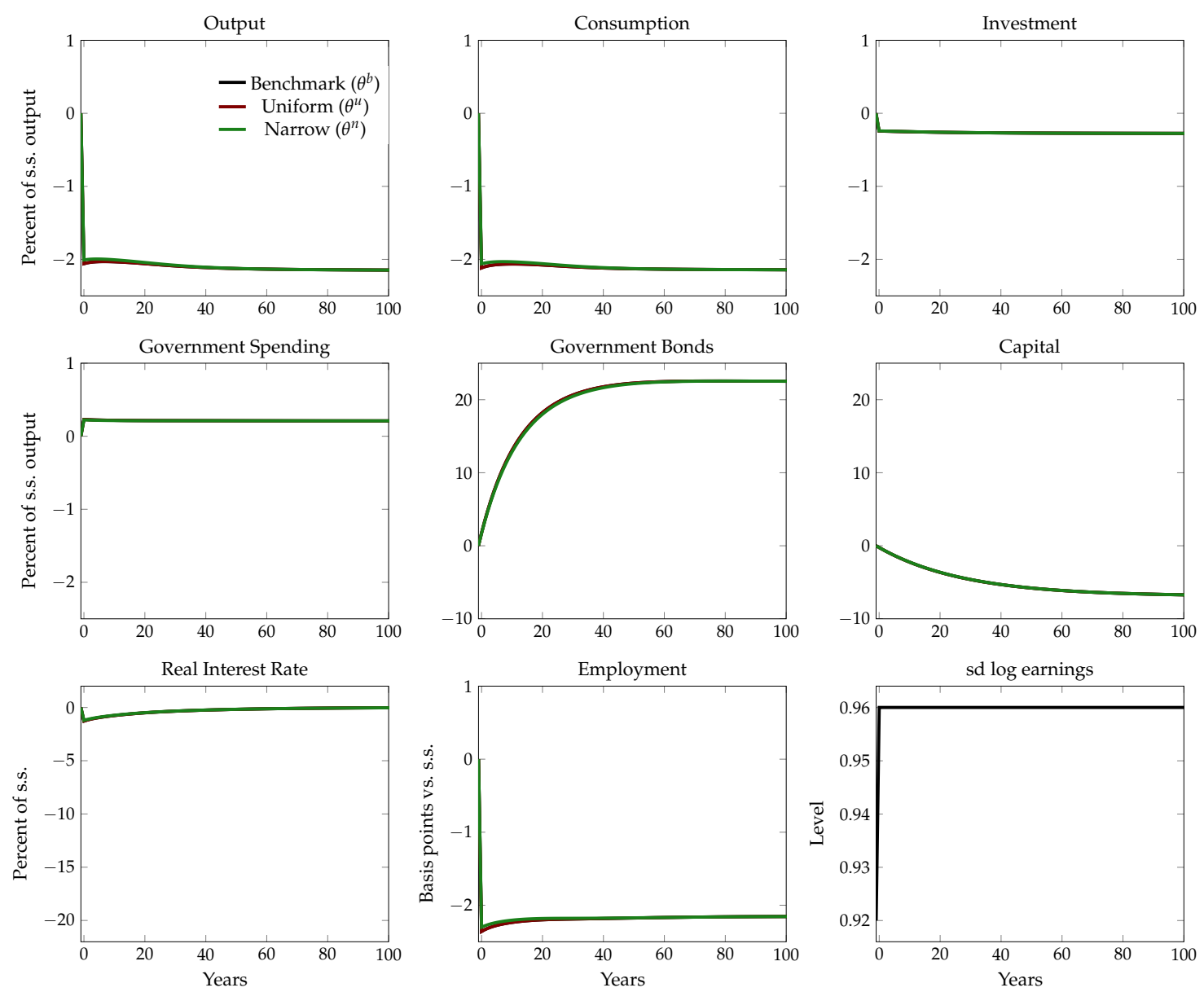

Figure D.3: Permanent shock under alternative initial portfolio allocations

responsive wage inflation, both components in the Taylor rule would most likely matter.)

In sum, although we prefer the ZLB case as a benchmark because we view it as the most transparent and realistic case of interest rate insensitivity, any monetary regime with an insufficiently responsive interest rate will deliver similar results.

\section{D.5 The role of asset revaluations}

Here we show that our results are nearly invariant to asset revaluation effects-that is, to the the particular $\theta(\cdot)$ function we use. As described in section B.1, we consider $\theta^{u}, \theta^{b}$ and $\theta^{e q}$ as three possible distributions of household portfolios. Figure D.3 considers the impact of our permanent shock under ZLB monetary policy, depending on the initial assumption about $\theta$. While it is clear that in the steady state, reallocation should no longer matter, this figure makes clear that quantitatively, even for the initial periods of the transition path these differential revaluation effects are very small. The only apparent effect is that broader distributions of assets imply a slighly more contractionary effect of rising inequality since the wealth effect from falling asset prices is felt more broadly in the population-by contrast, under our narrow definition of equity holdings, the lower-MPC, higher-asset agents tend to bear the cost of the falling asset prices alone, mitigating the downturn. 


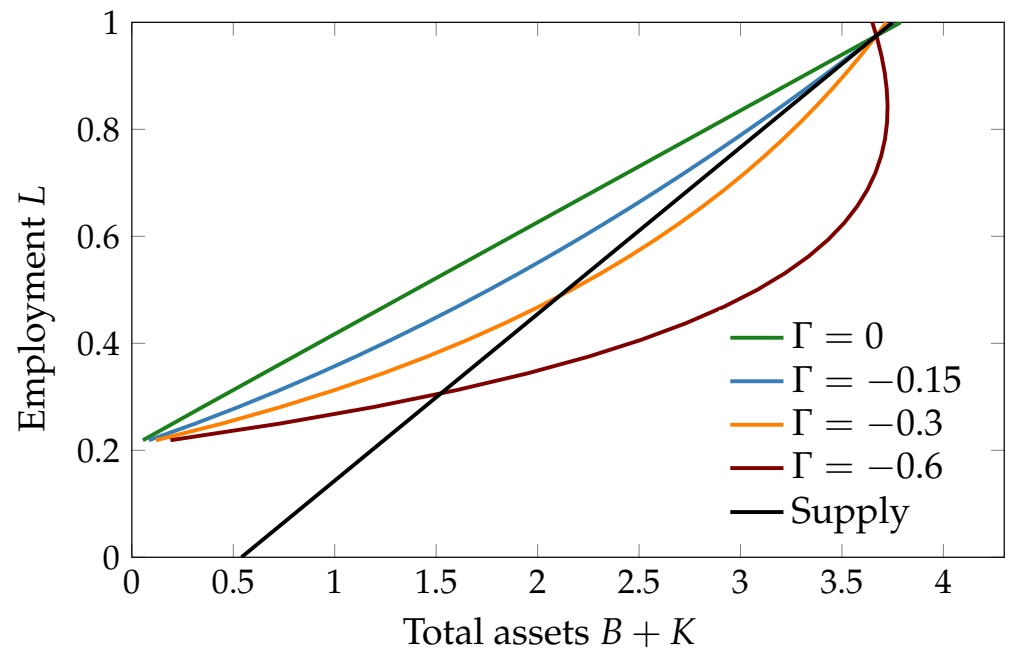

Figure D.4: Possibility of multiple equilibria with countercyclical income risk

While there is a very small difference across impulse responses with different initial asset distributions in this example, the case of a transitory shock at the ZLB has all responses even more closely aligned. The reason is that in that case investment barely moves on impact, so that $q_{0} \simeq 1$. As a result the revaluation effects are extremely muted.

\section{D.6 Multiple equilibria}

Figure D.4 shows that our specification with countercyclical risk built into the income incidence function, i.e. (67) with $\Gamma<0$, can potentially generate multiple equilibria. As employment $L$ falls, income risk increases, pushing up asset demand relative to our benchmark. This makes the asset demand curve in figure D.4 steeper in $A-L$ space, or even backward-bending around our calibrated steady state for sufficiently negative $\Gamma$. And when asset demand is steeper than asset supply at our steady state, there are multiple equilibria globally: this follows from the necessary condition for uniqueness in proposition 21 (which also turns out to be sufficient throughout the cases in figure D.4).

In addition to adding countercyclical risk, figure D.4 modifies our benchmark calibration by assuming that fiscal policy keeps debt and spending constant. This contributes to multiplicity by decreasing the slope of the asset supply curve. Indeed, in our benchmark calibration, countercyclical fiscal policy makes asset supply slope downward (see figure 10), which would rule out multiplicity except for extremely negative $\Gamma<0$. Essentially, by providing assets in slumps where increased income risk places those assets in heavy demand, countercyclical fiscal policy dampens feedback and pushes toward uniqueness.

The steady-state multiplicity under countercyclical risk in figure D.4 is closely related to similar steady-state multiplicity in Kreamer (2016) and Heathcote and Perri (2018). 